\author{
Évelin Aline Zanardo
}

\title{
Avaliação da variação do número de cópias (CNVs) genômicas em pacientes com atraso do desenvolvimento neuropsicomotor e/ou múltiplas malformações congênitas por meio das técnicas de sequenciamento completo do exoma e bead array
}

Tese apresentada à Faculdade de Medicina da Universidade de São Paulo para obtenção do título de Doutora em Ciências.

Programa: Patologia

Orientadora: Prof. ${ }^{a}$ Dr. ${ }^{a}$ Leslie Domenici Kulikowski

São Paulo 


\author{
Évelin Aline Zanardo
}

\title{
Avaliação da variação do número de cópias (CNVs) genômicas em pacientes com atraso do desenvolvimento neuropsicomotor e/ou múltiplas malformações congênitas por meio das técnicas de sequenciamento completo do exoma e bead array
}

Tese apresentada à Faculdade de Medicina da Universidade de São Paulo para obtenção do título de Doutora em Ciências.

Programa: Patologia

Orientadora: Prof. ${ }^{\text {a }}$ Dr. ${ }^{a}$ Leslie Domenici Kulikowski

São Paulo 
Dados Internacionais de Catalogação na Publicação (CIP)

Preparada pela Biblioteca da

Faculdade de Medicina da Universidade de Săo Paulo

Creprodução autorizada pelo autor

\section{Zanardo, Évelin Aline}

Avaliaçăo da variação do número de cópias (CNVs)

genômicas em pacientes com atraso do desenvolvimento

neuropsicomotor e/ou múltiplas malformaçōes

congênitas por meio das técnicas de sequenciamento

completo do exoma e bead array / Évelin Aline

Zanardo. -- São Paulo, 2019.

Tese (doutorado)--Faculdade de Medicina da

Universidade de São Paulo.

Programa de Patologia.

Orientadora: Leslie Domenici Kulikowski.

Descritores: 1.Testes genéticos 2.Variações do número de cópias de DNA 3.Sequenciamento completo do exoma 4 .Análise de sequência com séries de oligonucleotideos

USP/FM/DBD-229/19

Responsável: Erinalva da Conceição Batista, CRB-8 6755 


\section{DEDICATÓRIA}


Dedico este trabalho com muito carinho à minha família. 
AGRADECIMENTOS 
Agradeço...

Aos meus pais, Carlos e Márcia, pelo incentivo, dedicação e amor. Agradeço por todo apoio, preocupações e pelos conselhos, principalmente nos momentos difíceis. Obrigada por sempre estarem do meu lado.

À minha irmã, Rafaela, por toda ajuda e opinião sobre a tese, pelos momentos de apoio e pelo incentivo. Obrigada pelas ligações no fim da tarde e pelas distrações nos momentos de desespero.

Ao meu namorado, Jackson, por toda compreensão e apoio. Obrigada pelas críticas, sugestões e conselhos. Obrigada por me encorajar sempre, pelo companheirismo e carinho.

À minha querida orientadora, Leslie, pela confiança, orientação e contribuições para meu crescimento profissional e pessoal. Obrigada por toda dedicação à pesquisa, pelo otimismo nos momentos mais complicados e por toda amizade.

Ao meu coorientador, Fernando, à Fabíola e a toda equipe da Mendelics pela ajuda com a realização dos experimentos e interpretação dos dados do sequenciamento.

Aos meus queridos amigos da velha guarda, Alexandre, Marília, Gil e Roberta. Obrigada pelos conselhos e por todo auxílio para a realização desta pesquisa, obrigada pelos momentos de descontração, pelos momentos de desabafo e, principalmente, obrigada por toda amizade.

À minha amiga Samar por toda ajuda, pelas sugestões e pelas correções da tese, mesmo durante às férias. Obrigada por todo companheirismo, por aguentar minhas frustrações nos momentos difíceis. Agradeço aos meus amigos Yanca e Gleyson, por todo apoio e tarefinhas realizadas. Muito obrigada por toda dedicação e momentos de distrações. Agradeço também aos meus amigos, Amom, Thaís, Fabrícia, Mayara, Amanda, Lucas e Jullian por toda colaboração, auxílio e opiniões. 
À minha família pelo apoio e compreensão da minha ausência. Aos meus amigos pelo incentivo, apoio emocional e momentos de distrações.

À Coordenação de Aperfeiçoamento de Pessoal de Nível Superior (Capes) pelo auxílio financeiro (bolsa de estudo).

Ao Prof. Raymundo e ao departamento de Patologia da FMUSP pela oportunidade e suporte financeiro.

Aos que me incentivaram e colaboraram para a realização deste trabalho.

Muito obrigada! 
“A tarefa não é tanto ver aquilo que ninguém viu, mas pensar o que ninguém ainda pensou sobre aquilo que todo mundo vê". (Arthur Schopenhauer) 
Esta tese está de acordo com as seguintes normas, em vigor no momento desta publicação:

Referências: adaptado de International Committee of Medical Journals Editors (Vancouver).

Universidade de São Paulo. Faculdade de Medicina. Divisão de Biblioteca e Documentação. Guia de apresentação de dissertações, teses e monografias. Elaborado por Anneliese Carneiro da Cunha, Maria Julia de A. L. Freddi, Maria F. Crestana, Marinalva de Souza Aragão, Suely Campos Cardoso, Valéria Vilhena. $3^{\text {a }}$ ed. São Paulo: Divisão de Biblioteca e Documentação; 2011.

Abreviaturas dos títulos dos periódicos de acordo com List of Journals Indexed in Index Medicus. 


\section{SUMÁRIO}

\section{LISTAS}

Lista de Figuras

Lista de Tabelas

Lista de Gráficos

Lista de Quadros

Lista de Abreviaturas

Lista de Símbolos

Lista de Siglas

RESUMO

ABSTRACT

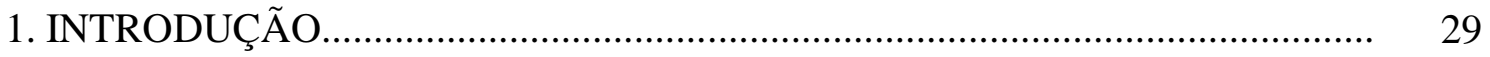

1.1. Variantes genômicas................................................................................ 29

1.1.1. Interpretação e classificação das CNVs............................................ 30

1.2. Técnicas citogenômicas para a detecção de variantes.................................... 32

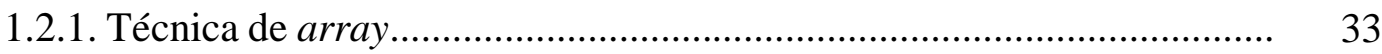

1.2.2. Técnica de sequenciamento completo do exoma................................. 34

1.2.2.1. Análise de CNVs pelo sequenciamento completo do exoma.......... 35

1.3. Aspectos da deteç̧ão de CNVs.................................................................... 38

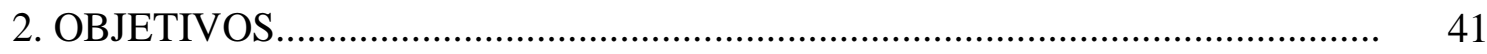

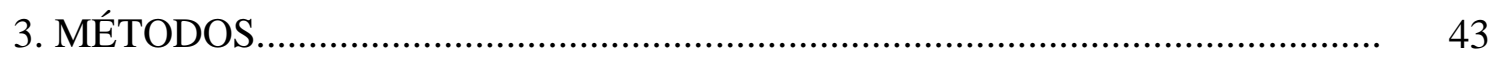

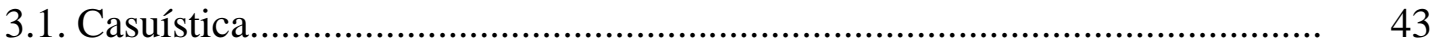

3.2. Técnicas citogenômicas................................................................................ 43

3.2.1. Isolamento e quantificação de DNA........................................................ 43

3.2.2. Técnica de sequenciamento completo do exoma..................................... 44

3.2.3. Técnica de array ................................................................................ 51

3.2.4. Análise bioinformática.................................................................... 52

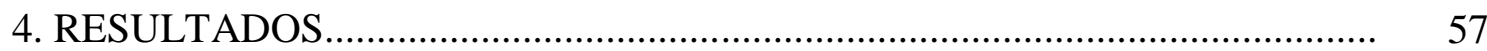

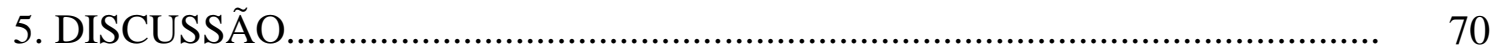

5.1. Considerações finais.............................................................................. 76

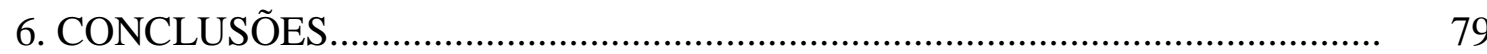




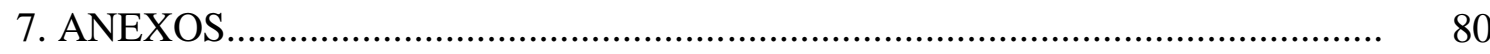

Anexo A: Termo de consentimento livre e esclarecido......................................... 81

Anexo B: Aprovação do Comitê de Ética e Pesquisa da Faculdade de Medicina da Universidade de São Paulo............................................................................ $\quad 85$

Anexo C: Tabela 2 ............................................................................... 86

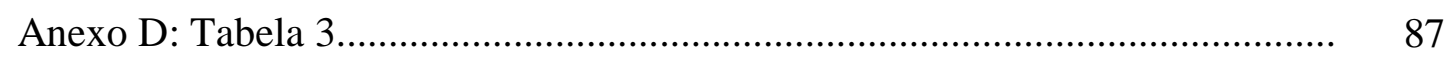

Anexo E: Quadro 2 2.................................................................................. 88

Anexo F: Descrição, por amostra, das CNVs patogênicas detectadas pelo sequenciamento completo do exoma e pelo array.............................................. 92

Anexo G: Descrição, por amostra, das ROHs detectadas apenas pelo array...... 104

8. REFERÊNCIAS ............................................................................... 107 APÊNDICES

Apêndice A - Artigo submetido para publicação

Apêndice B - Abstracts de artigos publicados durante o desenvolvimento deste doutorado, porém sem relação direta com a temática do presente estudo 
LISTAS 


\section{LISTA DE FIGURAS}

Figura 1 - Estratégias para detecção de CNVs por meio do sequenciamento de nova geração.

Figura 2 - Estratégia baseada em profundidade de leitura de regiões de interesse para a identificação de CNVs por meio do sequenciamento completo do exoma.

Figura 3 - $\quad$ Passos do processo de preparação da biblioteca e enriquecimento referentes à técnica de sequenciamento completo do exoma da plataforma Illumina ${ }^{\circledR}$.

Figura 4 - Passos do processo de clusterização referente à técnica de sequenciamento completo do exoma da plataforma Illumina ${ }^{\circledR}$.

Figura 5 - Passos do processo de sequenciamento por síntese referente à técnica de sequenciamento completo do exoma da plataforma Illumina ${ }^{\circledR}$.....

Figura 6 - Passos referentes à técnica de array da plataforma Illumina ${ }^{\circledR}$

Figura 7 - $\quad$ Representação gráfica dos resultados obtidos por meio da técnica de array.....

Figura 8 - $\quad$ Parâmetros utilizados no software BlueFuse ${ }^{\circledR}$ para análise das CNVs e das ROHs por meio da técnica de array..............................

Figura 9 - Avaliação da integridade do DNA das 38 amostras por meio da eletroforese em gel de agarose a 1,5\%.

Figura 10 - Fluxograma da avaliação dos resultados encontrados pelos métodos de sequenciamento completo do exoma e de array separados por grupos conforme a elucidação do diagnóstico citogenômico. 


\section{LISTA DE TABELAS}

Tabela 1 - Avaliação da concentração do DNA nas 38 amostras por meio do fluorímetro Qubit ${ }^{\circledR}$.

Tabela 2 - Controles de qualidade do teste de sequenciamento completo do

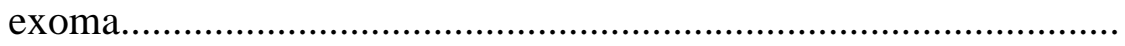

Tabela 3 - Controles de qualidade do teste de array pelo software BlueFuse ${ }^{\circledR}$

Tabela 4 - Tamanho das variantes detectadas pelas técnicas de sequenciamento completo do exoma e array

Tabela 5 - Quantidade de variantes equivalentes/totais (> $18 \mathrm{~kb}$ ) identificadas no sequenciamento completo do exoma e no array em cada amostra.

Tabela 6 - CNVs patogênicas detectadas no sequenciamento completo do exoma em concordância com o array por amostra.............................. 66

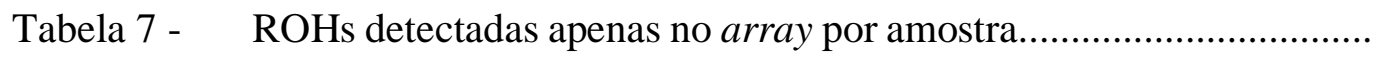

Tabela 8 - Amostras sem CNV patogênica e com SNV detectada após reclassificação dos resultados do sequenciamento completo do exoma 


\section{LISTA DE GRÁFICOS}

Gráfico 1 - Quantidade de variantes detectadas por meio das técnicas de sequenciamento completo do exoma e array.

Gráfico 2 - Proporção de detecção de variantes.....................................................

Gráfico 3 - Quantidade de variantes detectadas por meio das técnicas de sequenciamento completo do exoma e de array em relação ao seu tamanho $(\mathrm{kb})$

Gráfico 4 - Quantidade de variantes menores que 50 kb detectadas em relação ao seu tamanho $(\mathrm{kb})$

Gráfico 5 - Proporção dentre as porcentagens de detecção total de variantes da técnica de sequenciamento completo do exoma e de array

Gráfico 6 - Proporção da taxa de detecção de variantes equivalentes e não equivalentes entre as técnicas de sequenciamento completo do exoma e array 


\section{LISTA DE QUADROS}

Quadro 1 - Banco de dados disponíveis na internet para a análise de dados de CNVs......

Quadro 2 - Variantes (> $18 \mathrm{~kb}$ ) detectadas no sequenciamento completo do exoma, que apresentaram equivalência no array..... 


\section{LISTA DE ABREVIATURAS}

$\begin{array}{ll}\text { del } & \text { Deleção } \\ \text { Dr. } & \text { Doutor } \\ \text { Dr. }^{\text {a }} & \text { Doutora } \\ \text { dup } & \text { Duplicação } \\ \text { ed. } & \text { Edição } \\ \text { et al. } & \text { E outros (as) } \\ \text { n. }^{\text {o }} & \text { Número } \\ \text { Prof. }^{\text {a }} & \text { Professora } \\ \text { v } & \text { Versão }\end{array}$




\section{LISTA DE SÍMBOLOS}

$\begin{array}{ll}\sim & \text { Aproximadamente } \\ / & \text { Barra } \\ \mathrm{p} & \text { Braço curto dos cromossomos } \\ \mathrm{q} & \text { Braço longo dos cromossomos } \\ { }^{\circ} \mathrm{C} & \text { Grau Celsius } \\ \mathrm{kb} & \text { Kilobase } \\ > & \text { Maior que } \\ { }^{\circledR} & \text { Marca registrada } \\ \mathrm{Mb} & \text { Megabase } \\ < & \text { Menor que } \\ - & \text { Menos } \\ \mu \mathrm{L} & \text { Microlitro } \\ \mathrm{mL} & \text { Mililitro } \\ \mathrm{ng} & \text { Nanograma } \\ \mathrm{pb} & \text { Par de base } \\ \% & \text { Porcentagem } \\ \mathrm{mers} & \text { Sequência de nucleotídeos } \\ \mathrm{x} & \text { Vezes }\end{array}$




\section{LISTA DE SIGLAS}

A Adenina

ADNPM Atraso do Desenvolvimento Neuropsicomotor

AS Assembly

BAF B Allele Frequency

C Citosina

CN Copy Number

CNV Copy Number Variation

DECIPHER Database of Chromosomal Imbalance and Phenotype in Humans Using Ensembl Resources

DGV Database of Genomic Variants

DNA Deoxyribonucleic acid

EUCARUCA European Cytogeneticists Association Register of Umbalanced Chromosome Aberrations

G Guanina

GC Guanina-Citosina

GRCh37 Genome Reference Consortium Human Build 37

HMM Hidden Markov-Model

InDels Insertions-Deletions

ISCA The International Standards for Cytogenomic Arrays

LIM Laboratórios de Investigação Médica

LRR Log R Ratio

MMC Múltiplas Malformações Congênitas

NCBI National Center for Biotechnology Information

OMIM Online Mendelian Inheritance in Man

PCR Polymerase Chain Reaction

PEM Paired-End Mapping

PQ Ponto de Quebra

PubMed National Library of Medicine

RD Read Depth

$\mathrm{ROH} \quad$ Region of Homozygosity 


$\begin{array}{ll}\text { rpm } & \text { Rotação por Minuto } \\ \text { SNV } & \text { Single Nucleotide Variant } \\ \text { SR } & \text { Split Read } \\ \text { T } & \text { Timina } \\ \text { UCSC } & \text { University of California Santa Cruz } \\ \text { UPD } & \text { Uniparental Disomy } \\ \text { UTR } & \text { Untranslated Region } \\ \text { VUS } & \text { Variants of Uncertain Significance }\end{array}$


RESUMO E ABSTRACT 


\section{RESUMO}

Zanardo, EA. Avaliação da variação do número de cópias (CNVs) genômicas em pacientes com atraso do desenvolvimento neuropsicomotor elou múltiplas malformações congênitas por meio das técnicas de sequenciamento completo do exoma e bead array [tese]. São Paulo: Faculdade de Medicina, Universidade de São Paulo; 2019.

O papel das variações do número de cópias ( $\mathrm{CNVs})$, das variantes de nucleotídeo único (SNVs), das inserções e deleções de um ou alguns nucleotídeos (InDels), e das regiões de homozigosidade (ROHs) em pacientes com atraso do desenvolvimento neuropsicomotor e/ou malformações congênitas está cada vez mais sólido na literatura. Em paralelo ocorre o contínuo aperfeiçoamento e desenvolvimento de métodos de análise de variantes clínicas relevantes. Entre as metodologias para a identificação e caracterização dessas variantes estão a técnica de array genômico, considerado padrão ouro para a identificação de CNVs e ROHs em regiões exônicas e intrônicas, e o sequenciamento completo do exoma, que detecta predominantemente SNVs e InDels nas regiões codificantes do genoma (éxons). Assim esse estudo teve como objetivo avaliar a capacidade de detecção de CNVs relevantes clinicamente nos resultados do sequenciamento do exoma com o kit Nextera Rapid Capture Exomes ${ }^{\circledR}$ (Illumina $^{\circledR}$ ) utilizando o software ExomeDepth ${ }^{\circledR}$. Para esta pesquisa foram avaliadas 38 amostras de DNA de pacientes com atraso do desenvolvimento neuropsicomotor e/ou múltiplas malformações congênitas e sem SNVs ou InDels patogênicas detectadas previamente pelo sequenciamento do exoma. Concomitantemente as amostras foram avaliadas pela técnica de array com o Infinium CytoSNP-850K BeadChip ${ }^{\circledR}$ (Illumina $^{\circledR}$ ) utilizando o software BlueFuse ${ }^{\circledR}$ para a confirmação dos achados e/ou exclusão de outras deleções e duplicações. Dentre as 38 amostras avaliadas, um total de 745 CNVs (534 deleções e 211 duplicações) foram detectadas nos resultados do sequenciamento completo do exoma e 332 CNVs (224 deleções e 108 duplicações) e 37 ROHs foram identificadas por meio do array. Na análise final, o software ExomeDepth ${ }^{\circledR}$ detectou 18 CNVs patogênicas das 19 identificadas pelo array utilizando o software BlueFuse ${ }^{\circledR}$ e ao mesmo tempo revelou grande quantidade de CNVs, que não puderam ser confirmadas como verdadeiras por limitações técnicas (671 variantes falso-positivas e 313 variantes falso-negativas). O BlueFuse ${ }^{\circledR}$ também revelou três amostras com ROHs importantes por sugerir associação com dissomia uniparental, 
imprinting genômico, ou ocorrência de doenças recessivas relacionadas com uma variante de ponto, enquanto que o ExomeDepth ${ }^{\circledR}$ não detecta essas regiões. Vencer os desafios para a identificação inequívoca de CNVs é essencial para ampliar o entendimento do papel das variantes genômicas no fenótipo clínico. Nesse sentido, com o aprimoramento dos softwares e banco de dados, o sequenciamento completo do exoma pode se tornar uma excelente estratégia na rotina do diagnóstico clínico de pacientes.

Descritores: Testes genéticos; Variações do número de cópias de DNA; Sequenciamento completo do exoma; Análise de sequência com séries de oligonucleotídeos. 


\section{ABSTRACT}

Zanardo, EA. Evaluation of genomic copy number variation $(C N V s)$ in patients with developmental delay and/or multiple congenital malformations using whole exome sequencing and bead array techniques [thesis]. São Paulo: "Faculdade de Medicina, Universidade de São Paulo"; 2019.

The role of copy number variations (CNVs), single nucleotide variants (SNVs), insertions and deletions of one or few nucleotides (InDels), and regions of homozygosity (ROHs) in patients with developmental delay and/or congenital malformations is becoming more solid in the literature. In parallel, there is the continuous improvement and development of analysis methods for relevant clinical variants. Among the methodologies for identification and characterization of these variants are the genomic array, considered gold standard for detection of CNVs and ROHs in exonic and intronic regions, and the whole exome sequencing, which predominantly detects SNVs and InDels in the coding regions of the genome (exons). Therefore, this study evaluated the ability to detect clinically relevant CNVs in the exome sequencing results with Nextera Rapid Capture Exomes $^{\circledR}$ (Illumina ${ }^{\circledR}$ ) kit using ExomeDepth ${ }^{\circledR}$ software. In this research, 38 DNA samples from patients with developmental delay and/or multiple congenital malformations and without pathogenic SNVs or InDels previously detected by exome sequencing were assessed. Concomitantly the samples were evaluated by array technique with the Infinium CytoSNP-850K BeadChip ${ }^{\circledR}$ (Illumina ${ }^{\circledR}$ ) using BlueFuse ${ }^{\circledR}$ software for confirmation of the findings and/or exclusion of other deletions and duplications. Of the 38 samples evaluated, a total of $745 \mathrm{CNVs}$ (534 deletions and 211 duplications) were detected in the whole exome sequencing results and $332 \mathrm{CNVs}$ (224 deletions and 108 duplications) and $37 \mathrm{ROHs}$ were identified through the array. In the final analysis, ExomeDepth ${ }^{\circledR}$ software showed 18 pathogenic CNVs of the 19 identified by the array using the BlueFuse ${ }^{\circledR}$ software, and at the same time revealed a large number of CNVs that could not be confirmed as true due technical limitations (671 false-positive and 313 false-negative variants). BlueFuse ${ }^{\circledR}$ also revealed three samples with important $\mathrm{ROH}$ suggesting an association with uniparental disomy, genomic imprinting, or occurrence of recessive diseases related with a SNV, whereas ExomeDepth ${ }^{\circledR}$ do not detect these regions. Overcoming the challenges for the unequivocal identification of CNVs is essential to 
expand the understanding of genomic variants role in the clinical phenotype. In this sense, with the enhancement of softwares and databases, whole exome sequencing can become an excellent strategy in the diagnostic routine of the patients.

Descriptors: Genetic testing; DNA copy number variations; Whole exome sequencing; Oligonucleotide array sequence analysis. 


\section{INTRODUÇÃO}

\subsection{Variantes genômicas}

O genoma humano é composto por diversos tipos de variantes e características estruturais, que contribuem para a diversidade genética e susceptibilidade à doença, podendo, então, estar associadas ou não a alterações clínicas específicas, como deficiência intelectual, atraso do desenvolvimento neuropsicomotor, déficit no crescimento, dismorfismos faciais e malformações congênitas (Galasso et al., 2010; Vissers et al., 2010; Marenne et al., 2011; Tan et al., 2014; Hwang et al., 2015).

Dentre as variantes genômicas conhecidas estão as SNVs (do inglês, Single Nucleotide Variants - variantes de nucleotídeo único), que compreendem a substituição de um único nucleotídeo da sequência de DNA por outro; as InDels (do inglês, INsertionsDELetions), que são inserções e deleções de um ou alguns nucleotídeos na fita do DNA de um indivíduo; e as CNVs (do inglês, Copy Number Variations - variações no número de cópias), caracterizadas por deleções e duplicações genômicas, as quais variam de aproximadamente $1 \mathrm{~kb}$ a muitos megabases $(\mathrm{Mb})$ de tamanho (Emanuel e Saitta, 2007; LaFramboise, 2009; Connolly et al., 2014; Hwang et al., 2015).

As CNVs são geralmente herdadas e sua frequência varia dependendo do tamanho considerado na alteração, mas estimativas sugerem que mais de $12 \%$ do genoma de qualquer indivíduo podem conter variações em número de cópias, ou seja, indivíduos normais e saudáveis também apresentam CNVs em seu genoma (Redon et al., 2006; Edelmann e Hirschhorn, 2009; Conrad et al., 2010; Connolly et al., 2014; Harel e Lupski, 2018). Até o presente momento já foram descritas mais de 100000 CNVs únicas, sendo que a maioria delas é classificada como variantes benignas (Conrad et al., 2010; Connolly et al., 2014).

Essas anormalidades na arquitetura genômica também podem causar grande variedade de manifestações clínicas, sendo diagnosticadas em 8,1 \% das gestações reconhecidas clinicamente. Elas representam uma das principais causas de mortalidade em estágios precoces do desenvolvimento fetal, com uma frequência de aproximadamente $50 \%$ dos abortos espontâneos, $6 \%$ entre os natimortos e $0,8 \%$ nos 
nascidos vivos (Vasconcelos et al., 2007; Kulikowski et al., 2013), no entanto o diagnóstico inequívoco dessas anormalidades nem sempre é possível.

Além das variantes, o genoma humano também pode apresentar características específicas como as ROHs (do inglês, Regions of Homozygosity - regiões de homozigosidade), que são trechos longos de homozigosidade genômica, apresentando relevância para as doenças recessivas (Bruno et al., 2009; Gijsbers et al., 2009; LaFramboise, 2009; Alkuraya, 2010; Kearney et al., 2011; Lu et al., 2018).

\subsubsection{Interpretação e classificação das CNVs}

Inúmeros estudos na literatura avaliam o genoma dos pacientes com fenótipo clínico relevante, possibilitando a relação genótipo-fenótipo e relatando a presença de CNVs com efeitos significativos ou sem efeitos completamente conhecidos (Bruno et al., 2009; Edelmann e Hirschhorn, 2009; Gijsbers et al., 2009; Koolen et al., 2009; Galasso et al., 2010; Miller et al., 2010; Zanardo et al., 2017).

Dessa forma as CNVs são classificadas a partir das características fenotípicas do paciente e informações reunidas em diversos bancos de dados, como por exemplo, o Database of Genomic Variants (DGV), no qual relata variantes estruturais descritas em indivíduos saudáveis, e o Database of Chromosomal Imbalance and Phenotype in Humans Using Ensembl Resources (DECIPHER), que lista variantes genômicas associadas a um fenótipo clínico específico, dentre outros bancos de dados (Quadro 1) (Edelmann e Hirschhorn, 2009; Hanemaaijer et al., 2012; Connolly et al., 2014). 
Quadro 1 - Bancos de dados disponíveis na internet para a análise de dados de CNVs

\begin{tabular}{|c|c|c|}
\hline Banco de Dados & Endereço eletrônico & Propósito \\
\hline Database of Genomic Variants (DGV) & http://dgv.tcag.ca/dgv/app/home & $\begin{array}{l}\text { Banco de dados de } \\
\text { variantes benignas }\end{array}$ \\
\hline $\begin{array}{c}\text { Database of Chromosomal Imbalance } \\
\text { and Phenotype in Humans Using } \\
\text { Ensembl Resources (DECIPHER) }\end{array}$ & http://decipher.sanger.ac.uk/ & \multirow{3}{*}{$\begin{array}{c}\text { Banco de dados de } \\
\text { variantes em afetados. } \\
\text { Inclui fenótipo } \\
\text { associado a cada } \\
\text { variante }\end{array}$} \\
\hline $\begin{array}{c}\text { European Cytogeneticists Association } \\
\text { Register of Unbalanced Chromosome } \\
\text { Aberrations (EUCARUCA) }\end{array}$ & $\begin{array}{l}\text { http://umcecaruca01.extern.umcn.nl } \\
\text { :8080/ecaruca/ecaruca.jsp }\end{array}$ & \\
\hline $\begin{array}{l}\text { The International Standards for } \\
\text { Cytogenomic Arrays (ISCA) }\end{array}$ & https://www.iscaconsortium.org/ & \\
\hline $\begin{array}{c}\text { National Center for Biotechnology } \\
\text { Information (NCBI), que inclui o } \\
\text { PubMed }\end{array}$ & $\begin{array}{l}\text { http://www.ncbi.nlm.nih.gov/ } \\
\text { pubmed/ }\end{array}$ & \multirow{4}{*}{$\begin{array}{l}\text { Banco de dados } \\
\text { citogenômicos geral. } \\
\text { Contém localização de } \\
\text { genes, descrição clínica } \\
\text { sondas, SNVs, } \\
\text { variantes, etc. }\end{array}$} \\
\hline $\begin{array}{l}\text { Online Mendelian Inheritance in Man } \\
\text { (OMIM) }\end{array}$ & https://www.omim.org & \\
\hline $\begin{array}{l}\text { University of California Santa Cruz } \\
\text { (UCSC) Genome Browser }\end{array}$ & http://genome.ucsc.edu/ & \\
\hline Ensembl Genome Browser & http://www.ensembl.org/index.html & \\
\hline
\end{tabular}

FONTE: Kulikowski et al., 2013.

Até o momento são atribuídas, de uma maneira em geral, três interpretações e classificações para as CNVs: as possivelmente benignas ou polimórficas, as patogênicas ou clinicamente relevantes, e as VUS (do inglês, Variants of Uncertain Significance variantes de significado clínico incerto).

Estas denominações são atribuídas de acordo com as características das CNVs, assim os critérios para a classificação das variantes incluem a avaliação e descrição da variante nos bancos de dados relacionados com o fenótipo específico, a caracterização do conteúdo genômico da região alterada, se a variante ocorre em genes causadores de doenças, tipo e tamanho da variante, a segregação da doença em uma família, se a variante apresenta frequência rara, além da descrição em bancos de dados populacionais sem relação com a alteração fenotípica, dentre outras características (Miller et al., 2010; Hanemaaijer et al., 2012; Vermeesch et al., 2012).

Assim as CNVs consideradas benignas são variantes que podem ocorrer em regiões com nenhum ou com poucos genes, porém elas devem ser do mesmo tipo (ganho ou perda) e observadas em mais de $1 \%$ dos indivíduos considerados normais ou relatadas no banco de dados de variantes benignas pelo menos três vezes em distintas referências. 
Além disso, também podem ser variantes herdadas de um dos pais quando este não apresenta alterações clínicas.

Já as CNVs classificadas como patogênicas são variantes que foram previamente descritas associadas a uma síndrome de microdeleção/microduplicação específica. Elas estão relacionadas às grandes variantes e regiões ricas em genes, e já foram relatadas em pacientes fenotipicamente alterados ou são herdadas de um dos pais que apresentam fenótipo clínico relevante.

E a última categoria para interpretação das CNVs são as VUS, as quais envolvem variantes em genes que não apresentam uma função bem estabelecida. Estas CNVs são variantes já descritas em pacientes considerados normais e em pacientes fenotipicamente alterados, ou são variantes que não foram descritas previamente (Koolen et al., 2009; Miller et al., 2010; Hanemaaijer et al., 2012; Vermeesch et al., 2012), ou seja, mesmo com os avanços citogenômicos, muitas variantes detectadas permanecem inexplicáveis quando relacionadas ao fenótipo (Redon et al., 2006; Alkan et al., 2011; Zanardo et al., 2017; Harel e Lupski, 2018).

Assim, para estabelecer um diagnóstico citogenômico inequívoco, é importante que as variantes já descritas sejam caracterizadas corretamente e que novas variantes possam ser classificadas como patogênicas ou benignas, sendo que a identificação dessas variantes no genoma é possível a partir das técnicas citogenômicas (Redon et al., 2006; Bruno et al., 2009; Alkan et al., 2011; Connolly et al., 2014; Zanardo et al., 2017).

\subsection{Técnicas citogenômicas para a detecção de variantes}

Dada a importância das variantes e características estruturais genômicas, diferentes ferramentas podem ser utilizadas para analisar o DNA, avaliando e determinando o número de cópias presentes por indivíduo, os pontos de quebra das variantes e perfis atribuídos a determinadas regiões (Marenne et al., 2011; Zanardo et al., 2017). 


\subsubsection{Técnica de array}

Uma técnica citogenômica muito utilizada para o estudo de microvariações no genoma é o array. Esta metodologia permite a quantificação (identificação de deleções e duplicações) do genoma de um paciente com um alto nível de resolução (resolução média de $~ 10-100 \mathrm{~kb}$ ) dependendo da plataforma, tipos de sondas e como elas são distribuídas no genoma (Manning e Hudgins, 2010; Vissers et al., 2010; Siggberg et al., 2012; HehirKwa et al., 2015; Nam et al., 2016; Harel e Lupski, 2018).

A técnica de array consiste na hibridação por complementariedade do DNA proveniente de diversas amostras biológicas às sondas (segmentos de sequência genômica) contidas nas lâminas ou chips de arrays e posterior análise da emissão de fluorescência das sequências pesquisadas por meio de softwares específicos (Salman et al., 2004; Emanuel e Saitta, 2007).

Comercialmente existem diversas empresas que disponibilizam esta tecnologia em diferentes plataformas e lâminas/chips. Todas estas lâminas/chips apresentam uma alta densidade ou cobertura do genoma, mas variam entre si em relação à quantidade de sondas utilizadas, sendo que algumas delas podem interrogar milhões de regiões em uma única amostra (Emanuel e Saitta, 2007; Edelmann e Hirschhoern, 2009; Vissers et al., 2010; Alkan et al., 2011; Siggberg et al., 2012).

A principal vantagem do array é sua capacidade de investigar simultaneamente o genoma completo (regiões exônicas e intrônicas) em um mesmo experimento com um maior poder de resolução e acurácia em relação à citogenética tradicional e molecular, já que ele permite a investigação de rearranjos muito sutis, mas que podem ter impacto no fenótipo de pacientes sem diagnóstico definido. Assim o array tem sido empregado no diagnóstico de pacientes com múltiplas malformações congênitas e/ou deficiência intelectual (Salman et al., 2004; Bruno et al., 2009; Edelmann e Hirschhoern, 2009; Manning e Hudgins, 2010; Zanardo et al., 2017).

Além da sua capacidade de detectar ganhos e perdas submicroscópicas em todo o genoma, por meio desta técnica também é possível identificar mosaicismo (> $30 \%$ ), aneuploidias, ROHs e UPD (do inglês, Uniparental Disomy - dissomia uniparental). Sendo que essas variantes afetam o quadro fenotípico uma vez que podem alterar os níveis de transcrição, a sequência, a estrutura e a função de diferentes genes (Edelmann e Hirschhorn, 2009; Gijsbers et al., 2009; Fan et al., 2013; Lu et al., 2018). 
Portanto esta técnica aumenta a taxa de detecção de desequilíbrios sutis nos cromossomos e diagnostica pacientes com fenótipo clínico sem etiologia conhecida (Gijsbers et al., 2009; Zanardo et al., 2017; Harel e Lupski, 2018).

\subsubsection{Técnica de sequenciamento completo do exoma}

Desenvolvida mais recentemente, o sequenciamento de nova geração tem facilitado significativamente o diagnóstico e a descrição de novos genes, especialmente com a propagação do sequenciamento do exoma (Bergant et al., 2018).

O sequenciamento completo de regiões codificantes do genoma, também conhecido como exoma, tem se tornado o principal método de escolha para identificar variantes genéticas e doenças complexas (Zhao et al., 2013; Hehir-Kwa et al., 2015; Kadalayil et al., 2015).

Esta técnica de sequenciamento completo do exoma consiste primeiramente na seleção ou captura das regiões correspondentes aos éxons de todos os genes e posterior leitura e identificação (sequenciamento) de todos os nucleotídeos presentes nestas regiões (Bamshad et al., 2011; Guo et al., 2012).

Da mesma forma que os arrays, comercialmente diversas empresas oferecem kits para a captura e sequenciamento das regiões alvo. Embora haja diferenças técnicas entre elas, no geral, o desempenho e rendimento dos kits são equivalentes (Bamshad et al., 2011; Guo et al., 2012).

Apesar das regiões codificantes do genoma (éxons) constituírem apenas cerca de 1 a $3 \%$ de todo o genoma humano, com aproximadamente 30 a 50 milhões de pares de bases, variantes nestas regiões desempenham um papel importante nas doenças genômicas (Guo et al., 2012; Kadalayil et al., 2015).

A grande maioria das variantes é causada por SNVs em genes que modificam a função das proteínas geradas, assim cerca de $85 \%$ das variantes descritas como causadoras de doenças estão localizadas nessas regiões codificantes do genoma. Por esta razão o sequenciamento completo do exoma apresenta uma abordagem vantajosa para a detecção de pequenas variantes patogênicas (SNVs e InDels) (Guo et al., 2012; Samarakoon et al., 2014; Kadalayil et al., 2015).

Assim o sequenciamento do exoma é utilizado principalmente para a detecção de 
variantes do tipo SNVs e InDels em doenças genômicas, mas dependendo do tipo de análise também pode identificar CNVs por meio de softwares específicos (De Ligt et al., 2013; Guo et al., 2013; Kadalayil et al., 2015; Hong et al., 2016), sendo, dessa forma, uma abordagem atraente e prática, porém ainda pouco utilizada (Guo et al., 2012; Guo et al., 2013; Tan et al., 2014, Nam et al, 2016).

\subsubsection{Análise de CNVs pelo sequenciamento completo do exoma}

Segundo dados da literatura a integração da análise genômica de variantes no nível de pares de bases e CNVs aumentaram em $58 \%$ o diagnóstico de pacientes com deficiência intelectual e diminuíram os custos técnicos (De Ligt et al., 2013; Gambin et al., 2017).

Até o momento, a detecção de CNVs baseada no sequenciamento de nova geração pode ser realizada por meio de cinco estratégias: (1) paired-end mapping (PEM), que identifica CNVs através de leituras mapeadas de forma discordantes, sendo detectadas se a distância entre as duas extremidades de um par de leituras for significativamente diferente do seu tamanho médio; (2) split read (SR), a qual utiliza as leituras mapeadas de maneira incompleta de cada par para identificar pequenas CNVs; (3) read depth (RD), abordagem que detecta CNVs pela contagem do número de leituras em cada região genômica; (4) assembly (AS), alinhamento do genoma que identifica as CNVs a partir do mapeamento e sobreposição de contigs (fragmentos de uma região) para um genoma de referência; (5) combinação de abordagens diferentes - PEM e RD (Zhao et al., 2013; Tam et al., 2014).

Todas essas estratégias têm suas vantagens e desvantagens e foram desenvolvidas para detecção de CNVs de uma maneira específica e utilizando técnicas de sequenciamento diferentes, como por exemplo, sequenciamento completo do genoma ou do exoma. Além disso, elas avaliam tamanhos distintos de variantes e influenciam na precisão do ponto de quebra (Figura 1) (Zhao et al., 2013; Hehir-Kwa et al., 2015). 


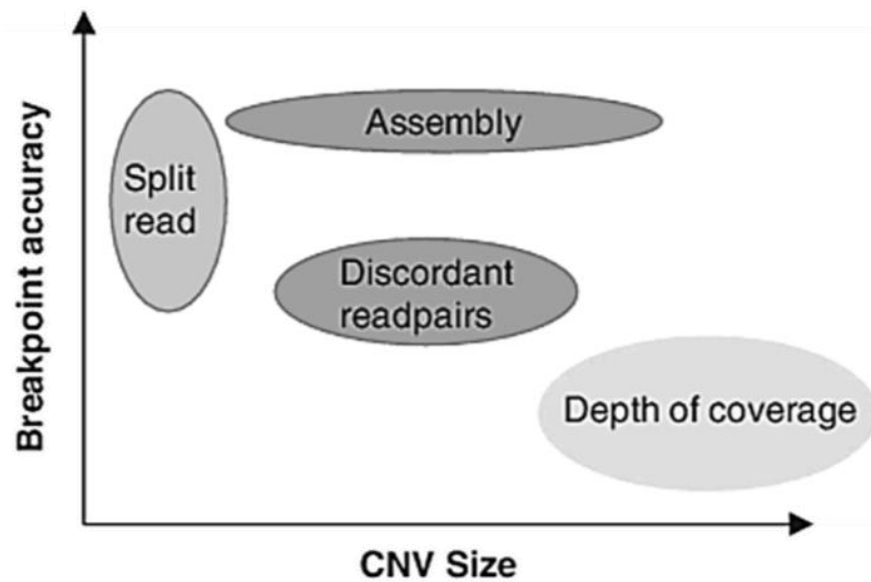

Figura 1 - Estratégias para detecção de CNVs por meio de sequenciamento de nova geração. Para a detecção de deleções ou duplicações em dados de sequenciamento quatro abordagens foram desenvolvidas, sendo que elas diferem no tamanho de identificação das CNVs (CNV size) e na precisão do ponto de quebra dessas variantes (breakpoint accuracy) (Hehir-Kwa et al., 2015)

Dentre essas estratégias, a análise de profundidade de leitura das regiões de interesse (abordagem RD ou depth of coverage) (Figura 2) é a principal delas para avaliação de dados de sequenciamento do exoma, pois não requer uma informação contínua ou o exato ponto de quebra para identificar uma CNV (Tan et al., 2014; Hehir-Kwa et al., 2015).

Além disso, o sequenciamento do exoma apresenta uma quantidade elevada de cobertura das regiões de interesse, ideal para esta estratégia (Plagnol et al., 2012; Zhao et al., 2013; Hehir-Kwa et al., 2015; Hwang et al., 2015).

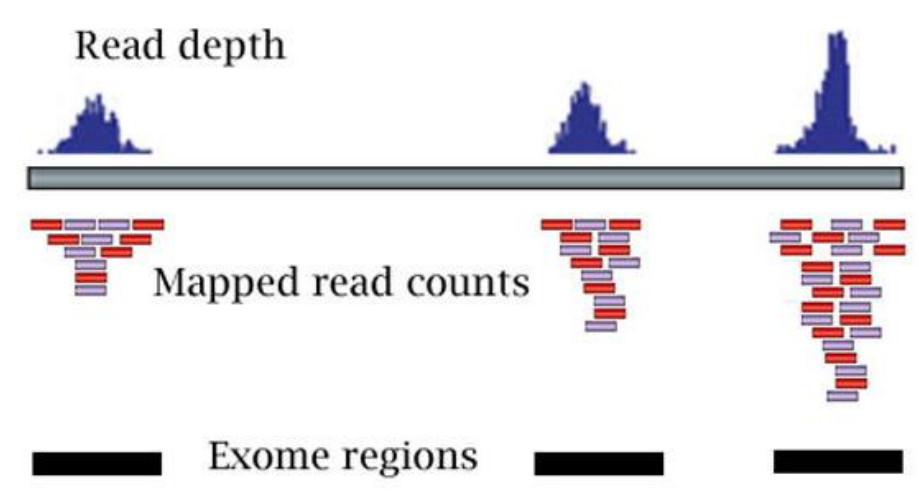

Figura 2 - Estratégia baseada em profundidade de leitura de regiões de interesse para a identificação de CNVs por meio do sequenciamento completo do exoma. Os retângulos pretos representam os éxons, os retângulos vermelhos e rosas representam a quantidade de leitura mapeada em cada região, e os picos azuis representam o número de cópia da região (Zhao et al., 2013)

As estratégias baseadas em profundidade de leitura seguem quatro passos até a 
identificação das CNVs: mapeamento e alinhamento das leituras curtas ao genoma de interesse, normalização dos dados, estimativa do número de cópias e segmentação (Zhao et al., 2013).

Para determinar o número de cópias, esse método avalia a quantidade de fragmentos mapeados em uma região genômica da amostra teste, normalizando as amostras para a correção de vieses causados principalmente por conteúdo GC (porcentagem de bases guanina e citosina em uma região genômica) e regiões repetitivas. Posteriormente, ele compara o dado obtido com a mesma região de um grupo de amostras referência ou com regiões com número de cópias semelhantes entre si (assumindo que apresentam duas cópias), que são mescladas para detectar número de cópias discordantes, estimando a quantidade de DNA presente. Assim, em uma deleção ou duplicação, a região deve apresentar uma quantidade menor ou maior de leituras (Plagnol et al., 2012; De Ligt et al., 2013; Zhao et al., 2013; Tan et al., 2014; Hehir-Kwa et al., 2015).

Dessa forma, por ser considerada a estratégia mais adequada para a identificação de deleções e duplicações a partir do sequenciamento do exoma, a maioria dos softwares existentes atualmente, como por exemplo, o ExomeDepth ${ }^{\circledR}$, foi desenvolvida baseada nessa abordagem (Plagnol et al., 2012; De Ligt et al., 2013; Zhao et al., 2013; Hehir-Kwa et al., 2015).

Porém as taxas relatadas na literatura em relação à comparação da eficiência na detecção de variantes entre diferentes ferramentas baseadas na profundidade de leitura variaram muito entre os estudos, tornando a interpretação e a avaliação do desempenho dessas ferramentas muito difíceis (Plagnol et al., 2012; Tan et al., 2014; Kadalayil et al., 2015).

Então, até o momento, ainda não há um consenso sobre qual é a ferramenta a mais eficaz para a avaliação de CNVs a partir dos dados do exoma, sendo que cada algoritmo tem suas vantagens e desvantagens (Zhao et al., 2013; Tan et al., 2014).

O ExomeDepth ${ }^{\circledR}$ é uma das ferramentas que utiliza a abordagem de leitura de profundidade e é considerada adequada para a identificação de CNVs raras, já que para determinar uma deleção ou duplicação a amostra teste é comparada a um grupo de amostras referência, o qual é assumido que não apresenta CNVs patogênicas (Miller et al., 2011; Plagnol et al., 2012; Zhao et al., 2013; Samarakoon et al., 2014; Hwang et al., 2015).

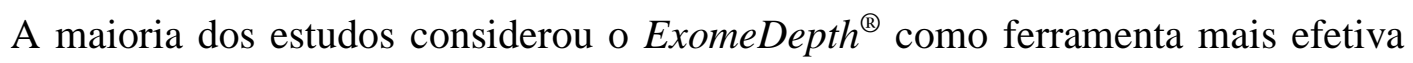


quando a média da profundidade de leitura do sequenciamento era elevada e as amostras não apresentavam variabilidade técnica, principalmente nas etapas de captura e sequenciamento (Plagnol et al., 2012; Kadalayil et al., 2015), sendo capaz de detectar tanto CNVs pequenas $(<1 \mathrm{~kb})$ como CNVs grandes $(>100 \mathrm{~kb})$, ao contrário de outros softwares (Tan et al., 2014).

Além disso, a característica principal do ExomeDepth ${ }^{\circledR}$ é o modelo estatístico aprimorado (modelo beta-binomial) que é aplicado para ajustar vários tipos de vieses presentes, incluindo o conteúdo GC e diferenças no mapeamento das regiões (Miller et al., 2011; Zhao et al., 2013).

\subsection{Aspectos da detecção de CNVs}

Alcançar um diagnóstico inequívoco é fundamental para entender a etiologia da doença, e assim fornecer respostas sobre o prognóstico, riscos de recorrência e direcionar o paciente à terapia específica, o que pode minimizar o custo financeiro dessas doenças e até mesmo possibilitar a inclusão desses indivíduos na sociedade (Galasso et al., 2010).

Atualmente a técnica de array é utilizada como primeiro teste diagnóstico para a detecção de CNVs em pacientes com atraso do desenvolvimento neuropsicomotor (ADNPM) e múltiplas malformações congênitas (MMC) (Hehir-Kwa et al., 2015; Harel e Lupski, 2018).

Embora esta técnica tenha uma alta resolução e apresente sondas distribuídas por todo genoma, inclusive para as regiões intrônicas, ainda existe espaçamento entre elas, o qual é dependente da quantidade e distribuição dessas sondas em cada densidade de array. Dessa forma a identificação de variantes de ponto, de InDels, bem como a acurácia na determinação dos pontos de quebra das CNVs acabam sendo limitadas (De Ligt et al., 2013; Hwang et al., 2015).

Já a técnica de sequenciamento do exoma avalia de forma completa as sequências exônicas de todos os genes, identificando variantes relacionadas a doenças raras e geneticamente heterogêneas. Portanto a padronização da identificação de CNVs por meio desta técnica utilizando softwares específicos aumentaria sua versatilidade como método de detecção de variantes, já que é atribuído que o exoma apresenta uma melhor resolução e acurácia que a técnica de array (De Ligt et al., 2013; Guo et al., 2013; Nam et al., 2016). 
Dessa forma uma menor quantidade de ensaios genômicos seria requerida para se chegar ao diagnóstico final, melhorando o custo-benefício e ao mesmo tempo permitindo alcançar uma compreensão mais profunda dos mecanismos da doença, aperfeiçoando as estratégias de prevenção e terapêutica (Bamshad et al., 2011; De Ligt et al., 2013; Hwang et al., 2015).

Portanto este projeto avaliou a eficácia da detecção de CNVs no genoma de pacientes com atraso do desenvolvimento neuropsicomotor e/ou múltiplas malformações congênitas por meio da técnica de sequenciamento completo do exoma com o software ExomeDepth $^{\circledR}$, e para a confirmação dos achados e/ou exclusão de outras deleções e duplicações foi utilizada a técnica de array. 


\section{OBJETIVOS}

O presente estudo teve como objetivos:

- Investigar o genoma de pacientes com ADNPM e/ou MMC por meio das técnicas de sequenciamento completo do exoma e array;

- Avaliar a capacidade do sequenciamento completo do exoma para a identificação de deleções e duplicações por meio do software de análise ExomeDepth ${ }^{\circledR}$;

- Comparar os métodos do sequenciamento completo do exoma e do array para a detecção das CNVs patogênicas. 
MÉTODOS 


\section{MÉTODOS}

\subsection{Casuística}

A casuística deste estudo foi composta por 38 pacientes com ADNPM e/ou MMC, e resultado prévio negativo por meio sequenciamento completo do exoma para a identificação de SNVs patogênicas, ou seja, sem variantes de ponto relacionadas com as características fenotípicas de cada paciente.

Este estudo foi realizado no Laboratório de Citogenômica - LIM 03 do Hospital das Clínicas da Faculdade de Medicina da Universidade de São Paulo com a colaboração do Laboratório Mendelics Análise Genômica.

Os pacientes e pais ou responsáveis foram informados da realização da pesquisa, sendo que todos assinaram o termo de consentimento livre e esclarecido (Anexo A) aprovado pelo Comitê de Ética e Pesquisa da Faculdade de Medicina da Universidade de São Paulo (n. ${ }^{\circ}$ 235/15) (Anexo B).

\subsection{Técnicas citogenômicas}

Para a realização deste estudo, os resultados do sequenciamento exoma de cada uma das amostras foram analisados por meio de um software específico para a pesquisa de CNVs e os achados foram comparados com a avaliação genômica por meio da técnica de array para a confirmação dessas CNVs encontradas e exclusão de outras deleções ou duplicações.

\subsubsection{Isolamento e quantificação de DNA}

O material genético dos indivíduos foi extraído a partir dos leucócitos do sangue periférico dos pacientes por meio do QIAamp ${ }^{\circledR}$ DNA Blood Mini Kit (250) (Qiagen ${ }^{\circledR}$ ) 
segundo protocolo do fabricante com algumas modificações.

Em um tubo de 1,5 mL devidamente identificado foram misturados $20 \mu \mathrm{L}$ de Protease com $200 \mu \mathrm{L}$ de sangue periférico total. Posteriormente, a mistura foi homogeneizada e foram adicionados $200 \mu \mathrm{L}$ do Buffer AL.

O tubo foi vortexado por 15 segundos, incubado a $56{ }^{\circ} \mathrm{C}$ durante 10 minutos e centrifugado brevemente, após foram adicionados $200 \mu \mathrm{L}$ de etanol absoluto e novamente homogeneizado no vórtex e centrifugado.

A mistura foi, então, aplicada na coluna de extração e centrifugada a 8000 rpm por 1 minuto. Terminada a centrifugação, o tubo contendo o filtrado foi descartado e a coluna transferida para um novo tubo de $2 \mathrm{~mL}$.

No novo tubo contendo a coluna foram adicionados $500 \mu \mathrm{L}$ do Buffer AW1 e este foi centrifugado a $800 \mathrm{rpm}$ durante 1 minuto. Logo após a centrifugação, a coluna foi transferida novamente para um novo tubo de $2 \mathrm{~mL}$, foram adicionados $500 \mu \mathrm{L}$ do Buffer AW2 e o tubo foi centrifugado a $14000 \mathrm{rpm}$ durante 3 minutos. A coluna foi transferida novamente para um novo tubo de 1,5 mL e foram adicionados $100 \mu \mathrm{L}$ de Buffer AE. O tubo foi incubado durante 5 minutos, centrifugado a $8000 \mathrm{rpm}$ durante 1 minuto e a coluna foi descartada.

A concentração das amostras de DNA foi avaliada pelo fluorímetro Qubit ${ }^{\circledR}$ $\left(\right.$ Invitrogen ${ }^{\circledR}$ ), que quantifica um corante fluorescente alvo-específico incorporado à dupla fita de DNA, conferindo a esta metodologia uma alta seletividade e sensibilidade. Além da quantificação, o DNA também foi avaliado quanto à sua integridade por meio da eletroforese em gel de agarose a $1,5 \%$.

Dessa forma foram incluídas nos experimentos apenas as amostras que apresentaram uma quantificação superior a $50 \mathrm{ng} / \mu \mathrm{L}$ e não exibiram um padrão de fragmentação do DNA.

As alíquotas de DNA elegíveis foram armazenadas em freezer a $-20{ }^{\circ} \mathrm{C}$ até a realização dos experimentos e posteriormente em freezer a $-80^{\circ} \mathrm{C}$.

\subsubsection{Técnica de sequenciamento completo do exoma}

A técnica do sequenciamento do exoma foi realizada por meio do kit Nextera Rapid Capture Exomes $^{\circledR}$, da Illumina ${ }^{\circledR}$, utilizado para a preparação da biblioteca e 
enriquecimento. Este kit possui um conjunto de cerca de 340000 sondas de 95-mers, que oferece ampla cobertura avaliando cerca de 200 mil éxons de 20500 genes.

Os experimentos foram realizados de acordo com as instruções do fabricante, utilizando 50 ng de DNA para a preparação das bibliotecas (Figura 3).

O processo se iniciou com a "etiquetagem", na qual o DNA foi fragmentado por meio de transposons, sem a necessidade de fragmentação mecânica, seguindo para a etapa de PCR (do inglês, Polymerase Chain Reaction - reação em cadeia da polimerase) para a ligação de adaptadores e índices às extremidades dos fragmentos gerados.

Posteriormente, a biblioteca foi denaturada e sondas marcadas com biotina foram adicionadas para hibridarem nas regiões alvo-específicas. A hibridação das sondas nos éxons permitiu enriquecer de forma seletiva os fragmentos de DNA a partir da adição de beads marcadas com estreptavidina que se ligaram às sondas biotiniladas.

Assim os fragmentos de DNA biotinilados ligados às beads com estreptavidina puderam ser magneticamente separados da solução. Os fragmentos de DNA enriquecidos foram, então, eluídos das beads e hibridados para uma segunda etapa de captura, seguindo para o passo de clusterização e sequenciamento. 

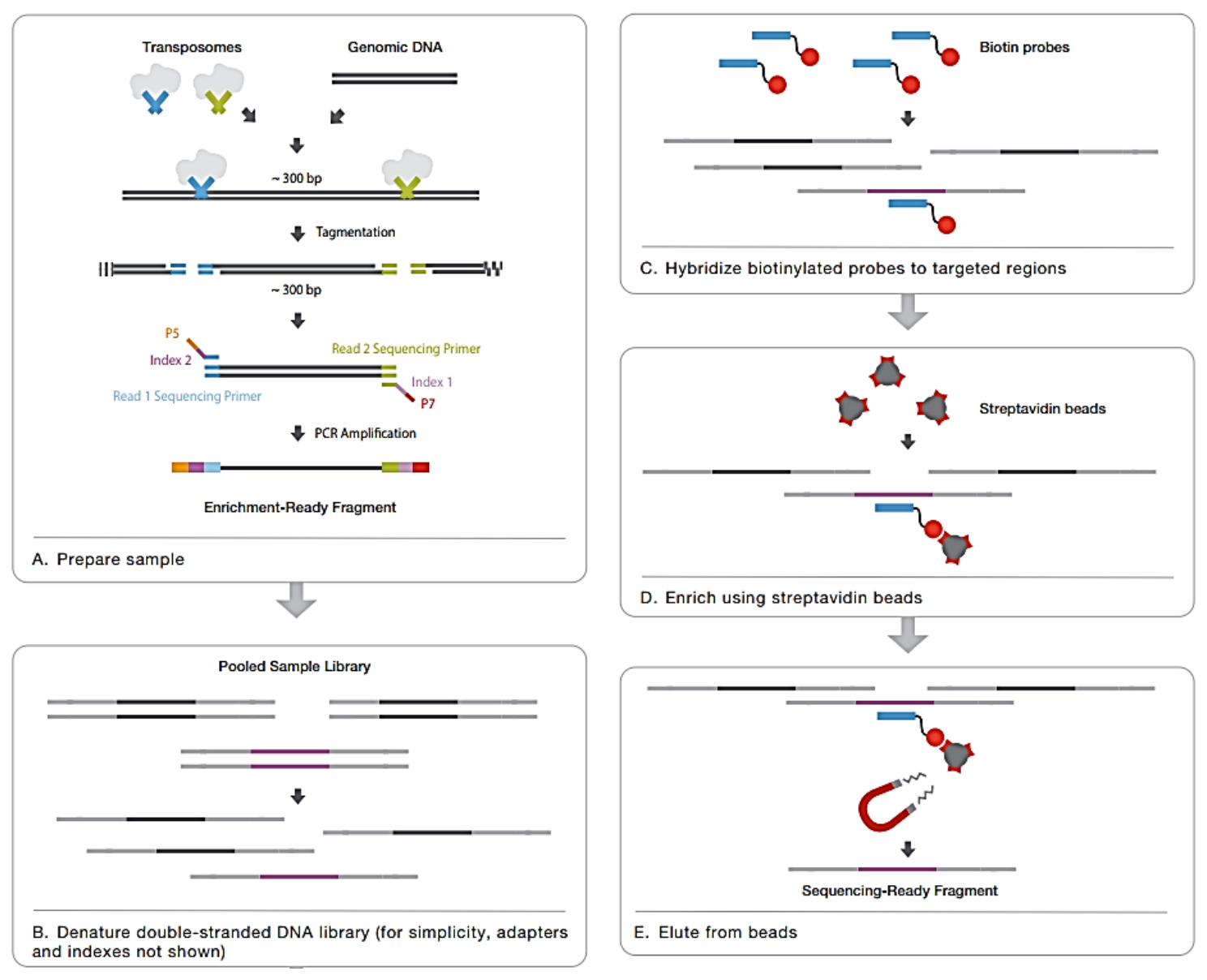

Figura 3 - Passos do processo de preparação da biblioteca e enriquecimento referentes à técnica de sequenciamento completo do exoma da plataforma Illumina ${ }^{\circledR}$ : Primeiramente o DNA é fragmentado e adaptadores específicos são ligados em ambas as extremidades (passo A preparação da biblioteca). A biblioteca, então, é denaturada (passo B) e sondas (retângulo azul) marcadas com biotina (esfera vermelha) são adicionadas, hibridando nas regiões alvo-específicas (região roxa) (passo C). Assim é possível enriquecer a solução selecionando apenas os fragmentos de interesse a partir da ligação de beads magnéticas marcadas com estreptavidina (esfera cinza) às sondas com biotina (passos $\mathrm{D} e \mathrm{E}$ )

FONTE: https://www.illumina.com/documents/products/datasheets/datasheet_nextera_rapid_ capture_exome.pdf.

O processo de clusterização teve como objetivo principal a obtenção de DNA suficiente para ser lido durante o sequenciamento. Este passo foi realizado no equipamento cBot System ${ }^{\circledR}$ da Illumina ${ }^{\circledR}$ de acordo com as instruções do fabricante (Figura 4).

Nessa etapa, adaptadores A e B foram incorporados às extremidades dos fragmentos de DNA, possibilitando a ligação randômica das moléculas de fita simples de DNA à superfície da flowcell. Esta ligação ocorreu devido aos adaptadores A e B serem complementar às sequências de oligonucleotídeos aderidos à flowcell. 
A seguir se iniciou o processo de anelamento, na qual o adaptador da extremidade livre da molécula aderida à flowcell se ligou à sua sequência de oligonucleotídeos complementar, formando uma estrutura em ponte. A partir dessa estrutura e com a adição de reagentes necessários foi possível realizar a amplificação do material genômico, conhecida como PCR em fase sólida.

As pontes de dupla fita formadas foram, então, denaturadas por elevação da temperatura e as etapas de anelamento, amplificação e denaturação foram repetidas diversas vezes, dando origem aos clusters. 


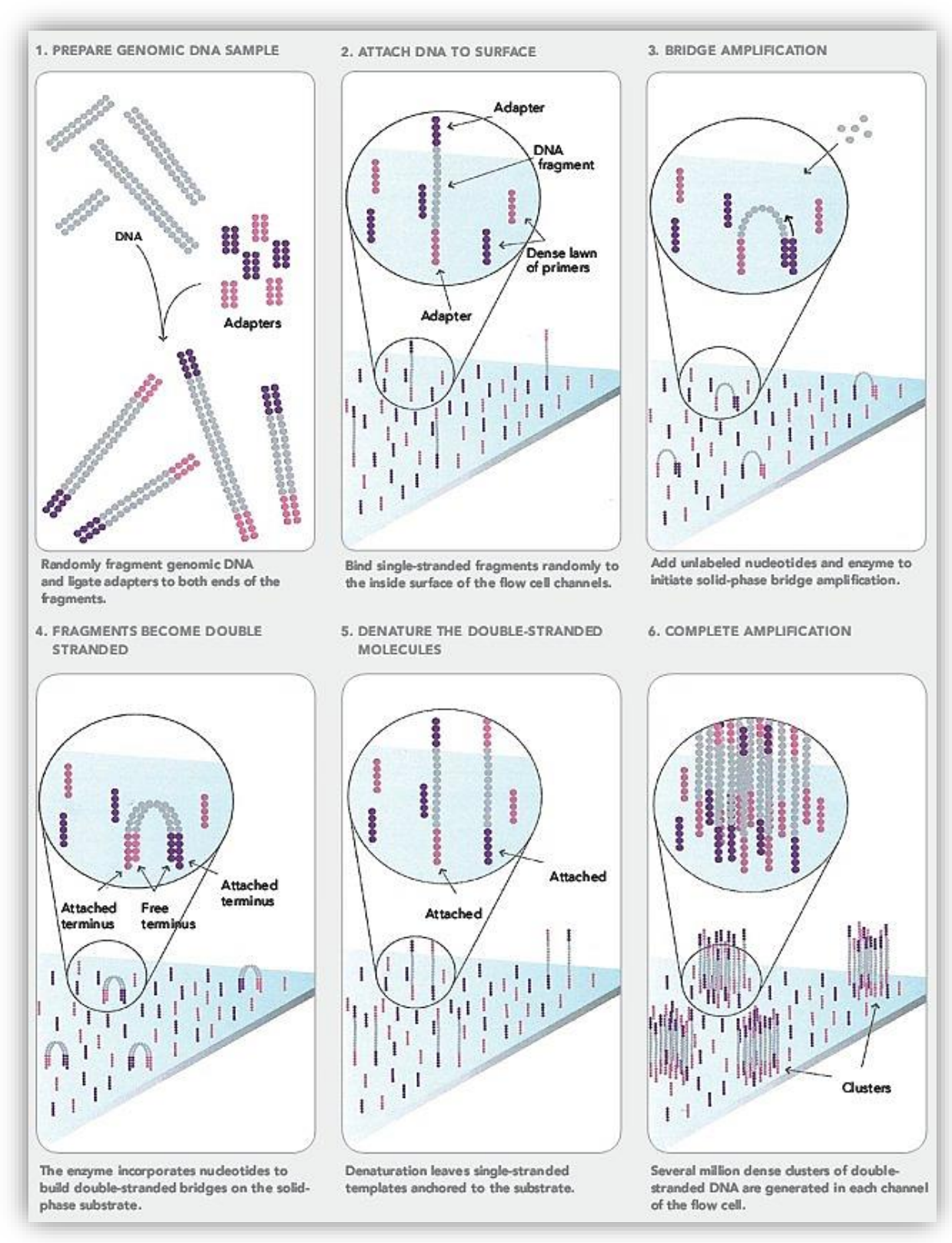

Figura 4 - Passos do processo de clusterização referente à técnica de sequenciamento completo do exoma da plataforma Illumina ${ }^{\circledR}$ : Primeiramente adaptadores A e B (roxo e rosa) são inseridos às extremidades dos fragmentos de DNA (passo 1), nos quais permitem a ligação desses fragmentos na superfície na flowcell (passo 2). Posteriormente, o adaptador da extremidade livre se liga à sua sequência complementar na flowcell (etapa de anelamento) e se inicia a amplificação por ponte em fase-sólida (passo 3), dando origem a fragmentos de dupla fita (passo 4), e posteriormente ocorre a denaturação dos fragmentos (passo 5). As etapas de anelamento, amplificação e denaturação são repetidas várias vezes dando origem aos clusters (passo 6)

FONTE: https://www.illumina.com/documents/products/techspotlights/techspotlight_sequencin g. pdf.

Posteriormente ocorreu a etapa de sequenciamento por síntese (Figura 5), na qual nucleotídeos marcados diferentemente foram adicionados e a partir da excitação pelo 
laser foi gerado um sinal fluorescente em cada fragmento, o qual foi capturado pelo dispositivo de leitura e interpretado como um dos quatro possíveis nucleotídeos componentes da molécula de DNA (A, T, C ou G).

Os processos de incorporação de nucleotídeos marcados, excitação e leitura foram repetidos até que todas as bases fossem lidas, e assim foi determinada a sequência completa de cada cluster, tendo como referência a versão GRCh37 do genoma humano.

A etapa de sequenciamento foi realizada na plataforma HiSeq 2500 System $^{\circledR}$ da Illumina ${ }^{\circledR}$ de acordo com as instruções do fabricante. 


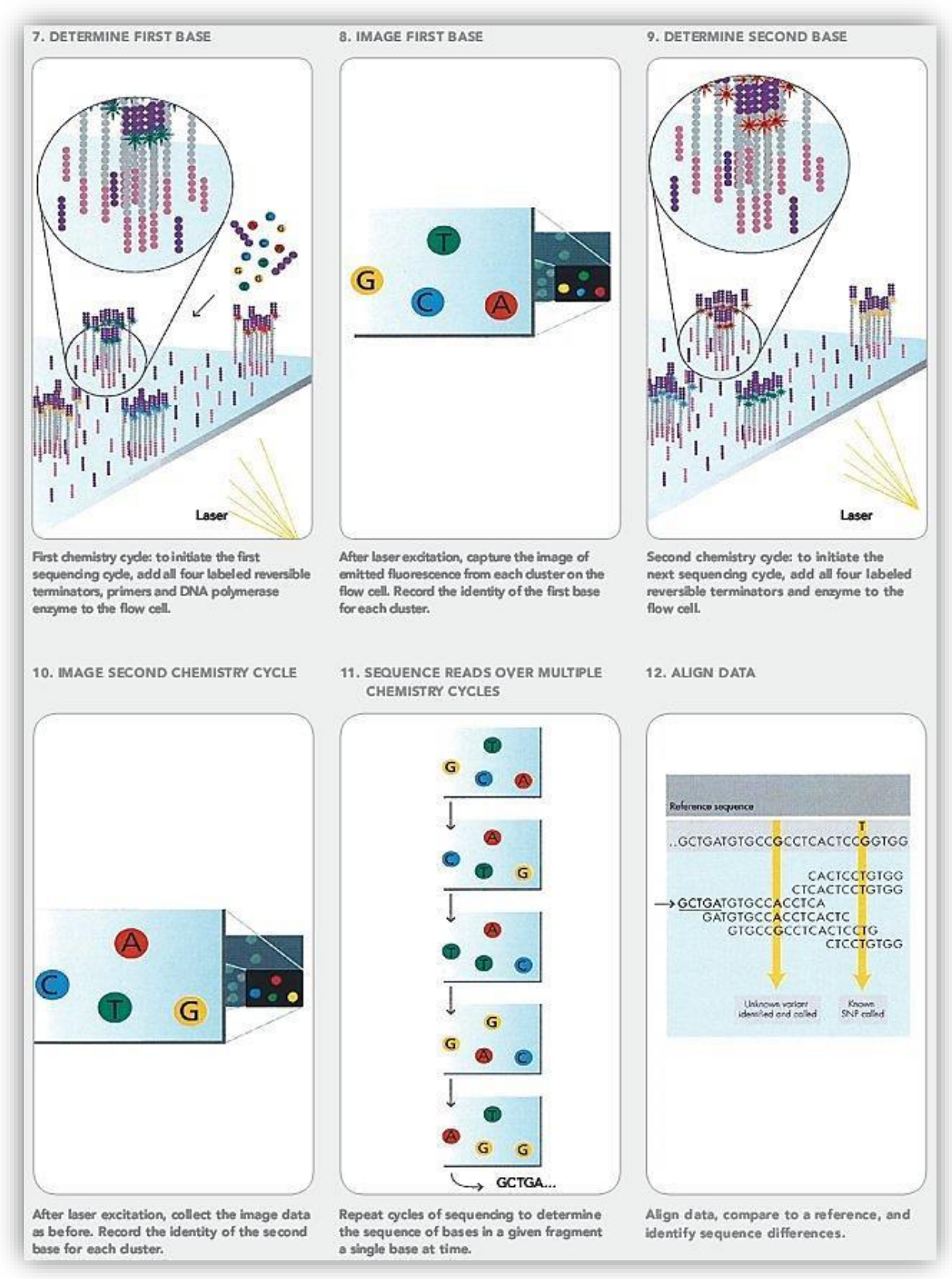

Figura 5 - Passos do processo de sequenciamento por síntese referente à técnica de sequenciamento completo do exoma da plataforma Illumina ${ }^{\circledR}$ : Primeiramente os nucleotídeos marcados diferentemente são adicionados junto com os primers e a enzima DNA polimerase (passo 7). Posteriormente ocorre a excitação por meio de um laser e a imagem do sinal fluorescente emitido da primeira base anelada é capturada em cada cluster (passo 8). As etapas de incorporação de nucleotídeos marcados, excitação e leitura (passos 9 e 10) são repetidas até que a leitura de todas as bases termine (passo 11), determinando a sequência completa de cada fragmento. O passo final é o alinhamento desses fragmentos ao genoma de referência para identificar as variantes (passo 12)

FONTE: https://www.illumina.com/documents/products/techspotlights/techspotlight_sequencin g.pdf.

O sequenciamento gerou um arquivo .BAM, que foi utilizado para alimentar uma 
ferramenta específica de análise de CNVs, o ExomeDepth ${ }^{\circledR}$ v1.0.7 (disponível em: https://www.rdocumentation.org/packages/ExomeDepth/versions/1.0.7), desenvolvida e executada utilizando a linguagem de programação R v3.1.2.

\subsubsection{Técnica de array}

A técnica de bead array foi realizada utilizando o Infinium CytoSNP-850K BeadChip ${ }^{\circledR}$ da plataforma Illumina ${ }^{\circledR}$. Este BeadChip compreende um painel de triagem do genoma contendo aproximadamente 850000 sondas de oligonucleotídeos de 50-mers, com um espaçamento médio de $1,8 \mathrm{~kb}$ entre elas.

Estas sondas abrangem todo o genoma e são consideradas sondas alvo para todas as regiões de importância citogenética conhecidas, incluindo regiões subteloméricas, pericentroméricas e dos cromossomos sexuais.

Os experimentos foram realizados de acordo com instruções do fabricante (Figura 6), utilizando $4 \mu \mathrm{L}$ de DNA a uma concentração final de $200 \mathrm{ng}$.

As amostras extraídas foram transferidas para uma placa MSA3 específica para que o DNA pudesse ser denaturado quimicamente e em seguida neutralizado por reagentes específicos fornecidos no kit. Posteriormente foi realizada a etapa de amplificação genômica, na qual as amostras foram incubadas a $37{ }^{\circ} \mathrm{C}$ por $20-24$ horas.

$\mathrm{Na}$ próxima etapa, pós-PCR, o DNA primeiramente foi fragmentado por ação de uma enzima (reagente FMS) e, após, precipitado usando os reagentes 2-propanol e PM1.

A placa com as amostras foi mantida invertida por pelo menos 1 hora à temperatura ambiente para que o pellet pudesse secar. Em seguida, o DNA precipitado foi ressuspendido com um reagente denominado RA1 e aplicado no BeadChip. Este foi incubado a $48{ }^{\circ} \mathrm{C}$ por aproximadamente 16 horas para que ocorresse a hibridação das amostras nas sondas específicas.

Terminada a etapa da hibridação, o BeadChip foi lavado e preparado para o processo de coloração. Nesta etapa o DNA não hibridado foi removido e os nucleotídeos (A, T, C e $\mathrm{G})$ foram adicionados, seguindo para a etapa de coloração dos nucleotídeos hibridados com fluorocromos específicos (A e T - marcação em vermelho; C e G - marcação em verde).

Logo após a lavagem, a intensidade dos sinais foi medida por um laser scanner por 
meio do equipamento iScan System ${ }^{\circledR}$ (Illumina ${ }^{\circledR}$ ), e os arquivos .GTC gerados foram analisados com o auxílio do software específico disponibilizado, BlueFuse Multi $4.3^{\circledR}$ (BlueGnome ${ }^{\circledR}$ ).

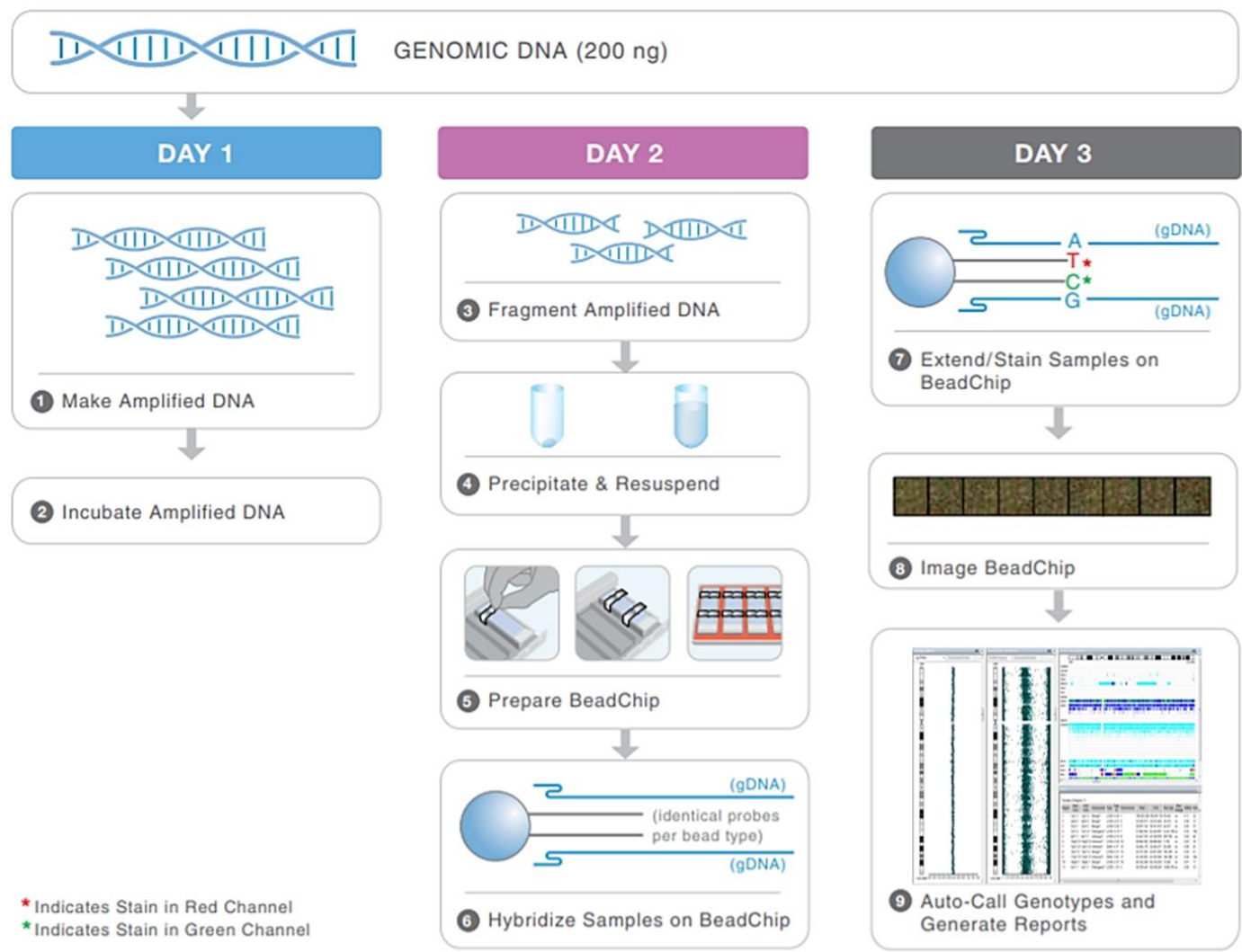

Figura 6 - Passos referentes à técnica de array da plataforma Illumina ${ }^{\circledR}$ : A amostra de DNA é isotermicamente amplificada overnight (passos 1 e 2). O produto amplificado é, então, fragmentado por um processo enzimático controlado (passo 3), seguindo para os passos de precipitação alcoólica e ressuspensão do DNA (passo 4). Posteriormente, o BeadChip é preparado para a hibridação (passo 5), as amostras são aplicadas e incubadas overnight. Estas, durante o passo de hibridação, se anelam às sondas específicas de 50-mers presentes na superfície das beads de sílica (passo 6). Cada bead apresenta em sua superfície várias sondas iguais correspondentes a uma região genômica específica. Logo após a hibridação, o alelo específico é determinado por extensão de base com subsequente coloração fluorescente (passo 7). As intensidades da fluorescência das beads são detectadas pelo scanner (passo 8) e os dados são analisados por softwares específicos (passo 9)

FONTE: https://support.illumina.com/content/dam/illumina-marketing/documents/products/ workflows/workflow_infinium.pdf.

\subsubsection{Análise bioinformática}

Para a avaliação dos dados brutos do sequenciamento do exoma foi utilizada uma 
ferramenta específica para análise de CNVs, o ExomeDepth ${ }^{\circledR}$ v1.0.7, o qual é um pacote do $\mathrm{R}$, que usa um modelo binomial robusto para gerar, de maneira iterativa, um grupo otimizado de dados de referência a partir do grupo de amostras. Posteriormente é estabelecido um valor de probabilidade para a identificação do número de cópias (normal, deleção ou duplicação) para cada éxon, e finalmente é aplicado o HMM (do inglês, Hidden Markov Model - modelo oculto de Markov) para combinar a probabilidade através de múltiplos éxons (Tan et al., 2014; Hwang et al., 2015; Kadalayil et al., 2015).

Assim esta ferramenta gerou uma lista de "scores" para todas as regiões que apresentaram CNVs, posteriormente foi aplicado um valor corte de confiabilidade e foram selecionados apenas os scores acima de 50 definidos pelo software ExomeDepth ${ }^{\circledR}$.

As ROHs não foram identificadas no sequenciamento do exoma por limitação do software de análise.

Já a análise dos dados brutos do array foi realizada por meio do software BlueFuse Multi $^{\circledR} 4.3$ (BlueGnome $^{\circledR}$ ), assim as amostras foram normalizadas e parâmetros foram selecionados para que as variantes pudessem ser identificadas.

As CNVs e ROHs foram identificadas a partir dos gráficos $B$ Allele Frequency (BAF) e Log R Ratio (LRR). Deste modo os gráficos de BAF representaram a frequência alélica e possuíam valores que variavam de 0 a 1 , sendo que regiões diploides normais apresentavam sondas distribuídas em 0, 0,5 e 1, regiões de homozigosidade exibiam sondas com valores de BAF em 0 e 1, e áreas de alteração alélica apresentavam valores intermediários (deleção - valores das sondas em 0 e 1; e duplicação - valores das sondas em 0, 0,25, 0,75 e 1). Já os gráficos de LRR representaram o número de cópias genômicas, sendo que valores em 0 referiram-se a duas cópias, valores menores a deleções e valores maiores a duplicações (Figura 7) (LaFramboise, 2009). 


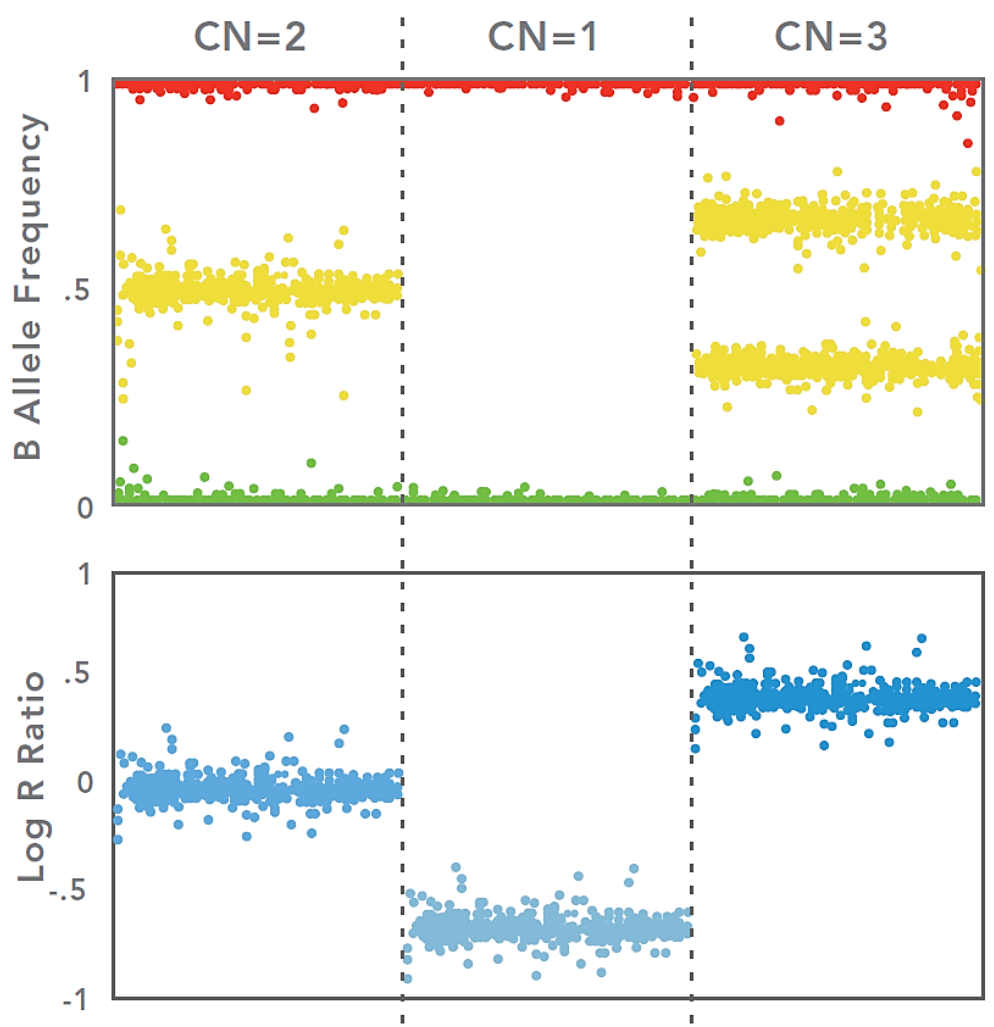

Figura 7 - Representação gráfica dos resultados obtidos por meio da técnica de array. $\mathrm{CN}=2$ refere-se ao resultado normal (duas cópias genômicas), $\mathrm{CN}=1$ representa a deleção (uma cópia genômica), e $\mathrm{CN}=3$ equivale à duplicação ( 3 cópias genômicas)

FONTE: https://www.illumina.com/documents/products/datasheets/datasheet_cytogenetics.pdf.

Assim foram consideradas as deleções e as duplicações que envolviam pelo menos 10 sondas consecutivas, e as ROHs que envolviam pelo menos 500 sondas consecutivas e $3 \mathrm{Mb}$ de tamanho (Figura 8). Além disso, todas as variantes foram checadas para que fossem obtidas apenas as CNVs e as ROHs verdadeiras. 


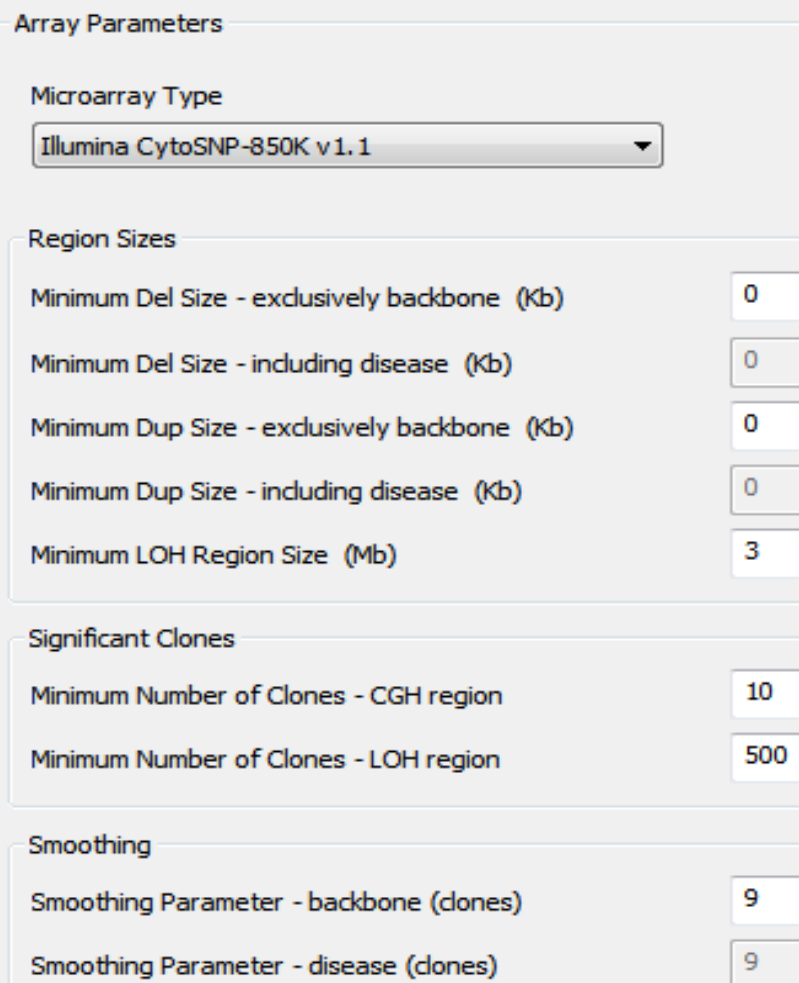

Figura 8 - Parâmetros utilizados no software BlueFuse ${ }^{\circledR}$ para análise das CNVs e das ROHs por meio da técnica de array

Segundo informações do fabricante Illumina ${ }^{\circledR}$, para este array, utilizando o BeadChip CytoSNP-850K ${ }^{\circledR}$, a média da resolução mínima de detecção de CNVs é de cerca de $18 \mathrm{~kb}$. 


\section{RESULTADOS}

Neste estudo, foram avaliadas as CNVs presentes no genoma de 38 pacientes por meio de dois métodos diferentes: sequenciamento completo do exoma e array.

Antes de iniciar os experimentos citogenômicos, as amostras foram analisadas em relação à quantidade e qualidade do DNA extraído e todas elas estavam elegíveis para a realização de ambas as técnicas (Tabela 1 e Figura 9).

Tabela 1 - Avaliação da concentração do DNA nas 38 amostras por meio do fluorímetro Qubit ${ }^{\circledR}$

\begin{tabular}{cc}
\hline Amostra & Concentração ng/uL \\
\hline 01 & 175 \\
02 & 367 \\
03 & 73,4 \\
04 & 580 \\
05 & 439 \\
06 & 307 \\
07 & 216 \\
\hline 08 & 770 \\
\hline 09 & 87,6 \\
\hline 10 & 471 \\
11 & 58 \\
\hline 12 & 98,3 \\
\hline 13 & 79,2 \\
\hline 14 & 376 \\
\hline 15 & 119 \\
\hline 16 & 120 \\
\hline 17 & 68,1 \\
\hline 18 & 45,8 \\
\hline 19 & 69,5 \\
\hline
\end{tabular}

\begin{tabular}{cc}
\hline Amostra & Concentração ng/uL \\
\hline 20 & 73,3 \\
\hline 21 & 116 \\
22 & 142 \\
\hline 23 & 64,7 \\
\hline 24 & 65,3 \\
\hline 25 & 153 \\
\hline 26 & 104 \\
\hline 27 & 70,4 \\
\hline 28 & 85,8 \\
\hline 29 & 45,9 \\
\hline 30 & 76,8 \\
\hline 31 & 51,9 \\
\hline 32 & 61,4 \\
\hline 33 & 116 \\
\hline 34 & 56,9 \\
\hline 35 & 48,1 \\
\hline 36 & 52,3 \\
\hline 37 & 49,3 \\
\hline 38 & 94,4 \\
\hline & \\
\hline
\end{tabular}



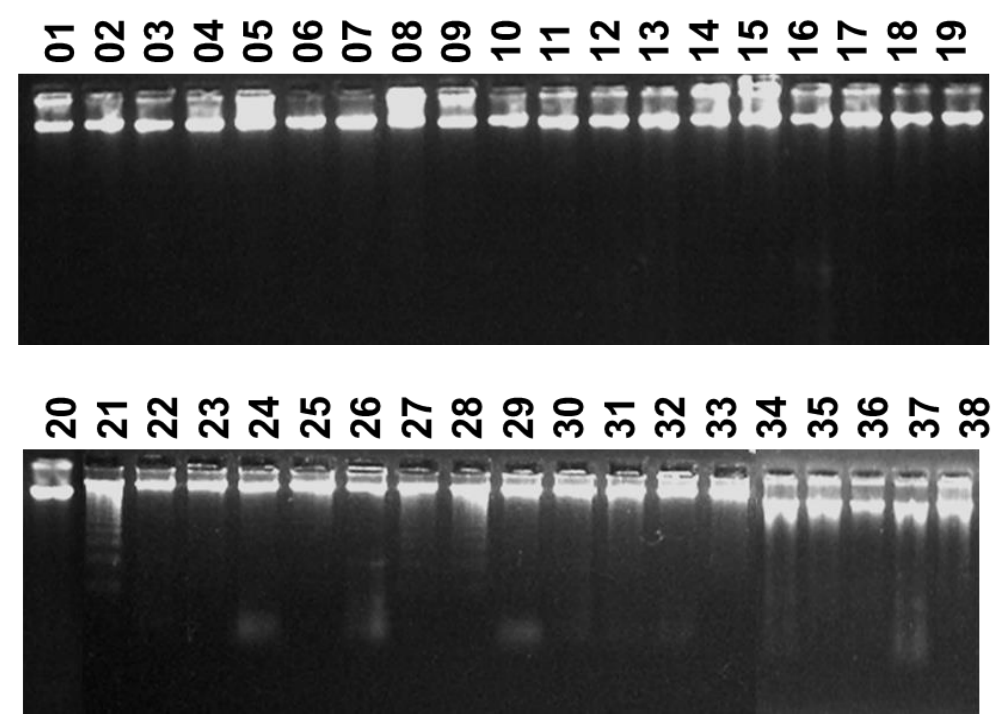

Figura 9 - Avaliação da integridade do DNA das 38 amostras por meio da eletroforese em gel de agarose a $1,5 \%$

Os resultados obtidos por meio das metodologias de sequenciamento do exoma e array foram avaliados pelos softwares ExomeDepth ${ }^{\circledR}$ e BlueFuse ${ }^{\circledR}$, respectivamente, e todas as variantes foram checadas e interpretadas a fim de eliminar os ruídos e resultados falso-positivos. Além disso, os controles de qualidade dos testes também foram avaliados para cada amostra (Anexo C, Tabela 2 e Anexo D, Tabela 3).

Dessa forma foram selecionados para esse estudo apenas as variantes que caracterizaram um resultado verdadeiro, ou seja, os resultados com scores abaixo de 50 (valor de corte de confiabilidade) gerados pelo software ExomeDepth ${ }^{\circledR}$ foram excluídos da análise do sequenciamento do exoma e os resultados característicos de ruídos ou vieses gerados BlueFuse ${ }^{\circledR}$ pelo foram excluídos da análise do array.

Dentre as 38 amostras já filtradas, um total de $745 \mathrm{CNVs}$ foram identificadas por meio da técnica de sequenciamento do exoma, sendo 534 deleções e 211 duplicações, paralelamente, $37 \mathrm{ROHs}$ e $332 \mathrm{CNV}$ s foram identificadas por meio da técnica de array nas mesmas amostras, dentre elas 224 eram deleções e 108 duplicações (Gráfico 1). 
Gráfico 1 - Quantidade de variantes detectadas por meio das técnicas de sequenciamento completo do exoma e array

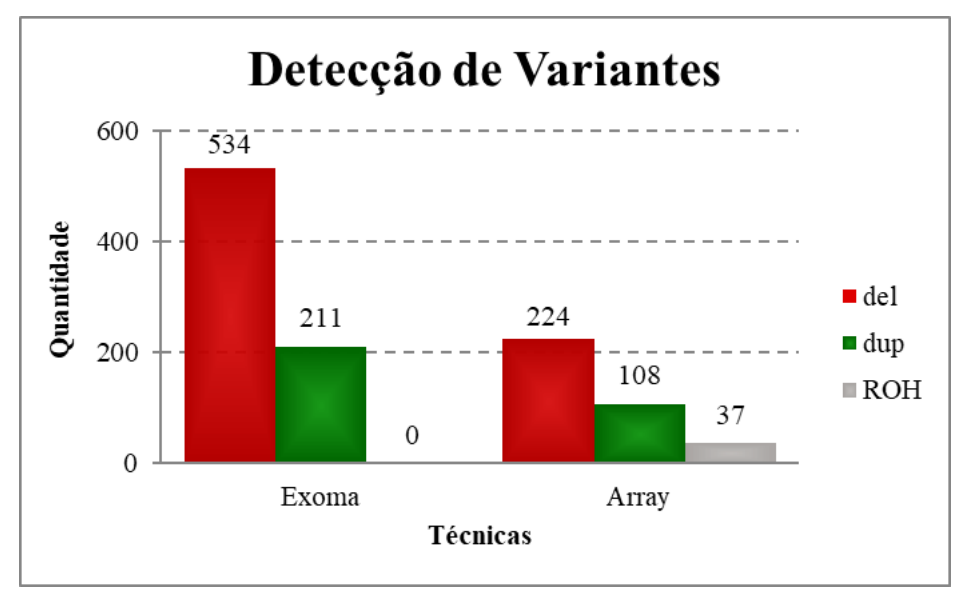

NOTA: As barras vermelhas representam as deleções, as barras verdes as duplicações e a barra cinza as regiões de homozigosidade.

Assim as taxas de detecção de deleções e duplicações corresponderam a aproximadamente $70,4 \%$ e $66,1 \%$ para o sequenciamento do exoma e $29,6 \%$ e $33,9 \%$ para o array, respectivamente. Portanto houve uma disparidade entre as técnicas na identificação das CNVs, sendo que o sequenciamento do exoma identificou uma quantidade muito superior de deleções e de duplicações em relação ao array (Gráfico 2 A).

Porém a capacidade de identificação das variantes foi proporcionalmente semelhante em ambas as técnicas, ou seja, foi verificado que nas duas técnicas cerca de $70 \%$ de variantes foram do tipo deleções (Gráfico 2 - B). 
Gráfico 2 - Proporção de detecção de variantes
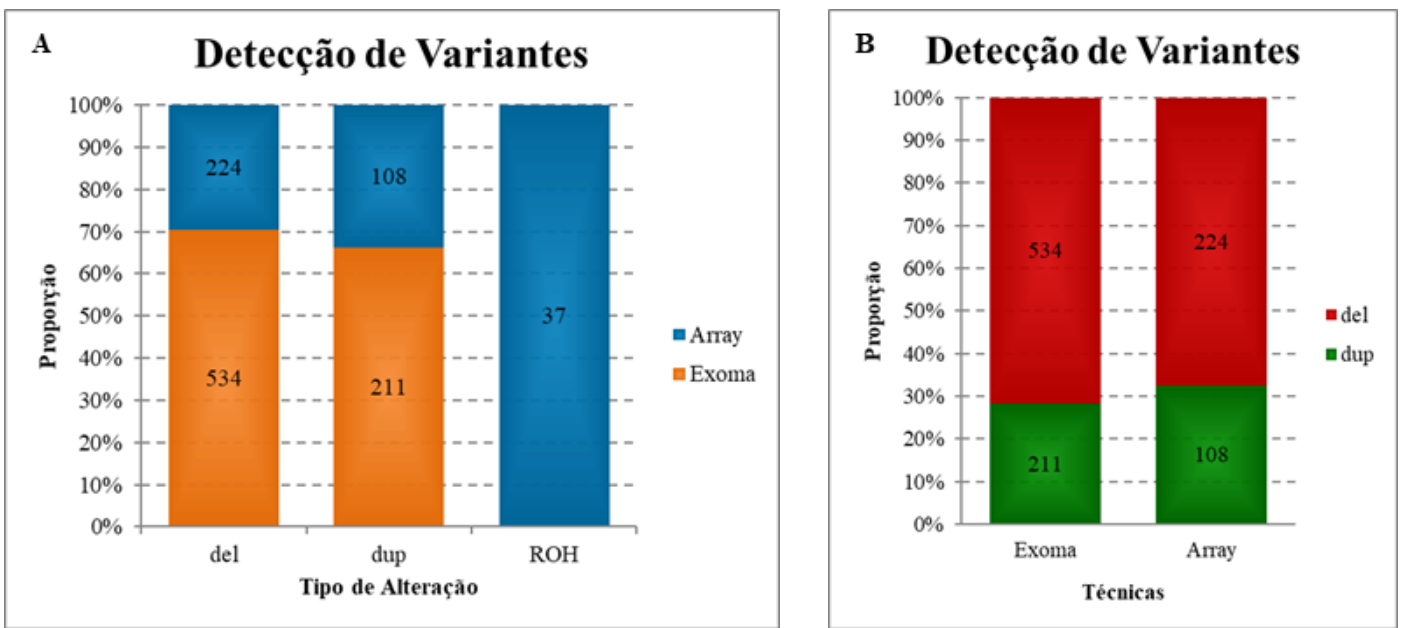

NOTA: No gráfico A, as variantes detectadas na técnica de sequenciamento completo do exoma estão representadas em laranja e no array em azul. No gráfico B, as barras vermelhas correspondem às deleções e as verdes às duplicações.

O tamanho das CNVs também foi avaliado. Dessa maneira a menor variante detectada foi de $70 \mathrm{pb}$ pelo sequenciamento do exoma e de 1.702 pb pelo array e a maior variante foi de 10.994 .555 pb pelo exoma e 26.560 .780 pb pelo array (Tabela 4).

Tabela 4 - Tamanho das variantes detectadas pelas técnicas de sequenciamento completo do exoma e array

\begin{tabular}{ccccc}
\hline Variantes (pb) & Técnica & Deleção & Duplicação & ROH \\
\hline \multirow{2}{*}{ Menor } & Exoma & 70 & 1.688 & - \\
& Array & 1.702 & 3.917 & 3.036 .260 \\
\multirow{2}{*}{ Maior } & Exoma & 10.994 .556 & 7.984 .948 & - \\
& Array & 12.446 .474 & 26.560 .780 & 243.034 .523 \\
\hline
\end{tabular}

Observando o conjunto dos resultados, foi verificado que aproximadamente $50 \%$ $(556 / 1114)$ das variantes apresentaram tamanho inferior a $50 \mathrm{~kb}$, sendo que destas cerca de $74 \%$ (411/556) foram detectadas no sequenciamento completo do exoma (Gráfico 3). 
Gráfico 3 - Quantidade de variantes detectadas por meio das técnicas de sequenciamento completo do exoma e de array em relação ao seu tamanho $(\mathrm{kb})$

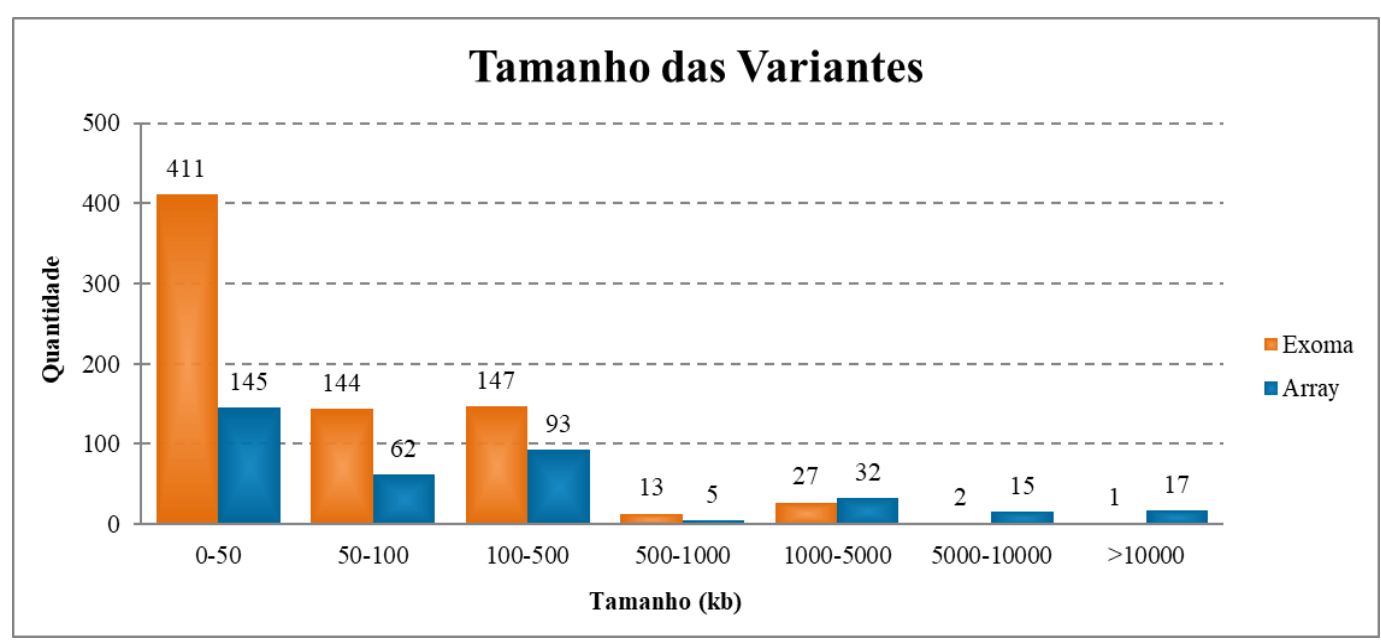

NOTA: As variantes detectadas na técnica de sequenciamento completo do exoma estão representadas em laranja e no array em azul.

Segundo informações da Illumina ${ }^{\circledR}$, a média da resolução mínima de detecção de CNVs para o array, utilizando o BeadChip CytoSNP-850K ${ }^{\circledR}$, é de cerca de $18 \mathrm{~kb}$, dessa forma foram identificadas abaixo desse tamanho apenas 59 CNVs (48 deleções e 11 duplicações) na técnica de array, sendo que essa quantidade chegou a 232 CNVs (189 deleções e 43 duplicações) no sequenciamento do exoma (Gráfico 4), ou seja, cerca de $31 \%$ de todas as variantes detectadas no exoma eram CNVs menores que $18 \mathrm{~kb}$.

Gráfico 4 - Quantidade de variantes menores que $50 \mathrm{~kb}$ detectadas em relação ao seu tamanho $(\mathrm{kb})$

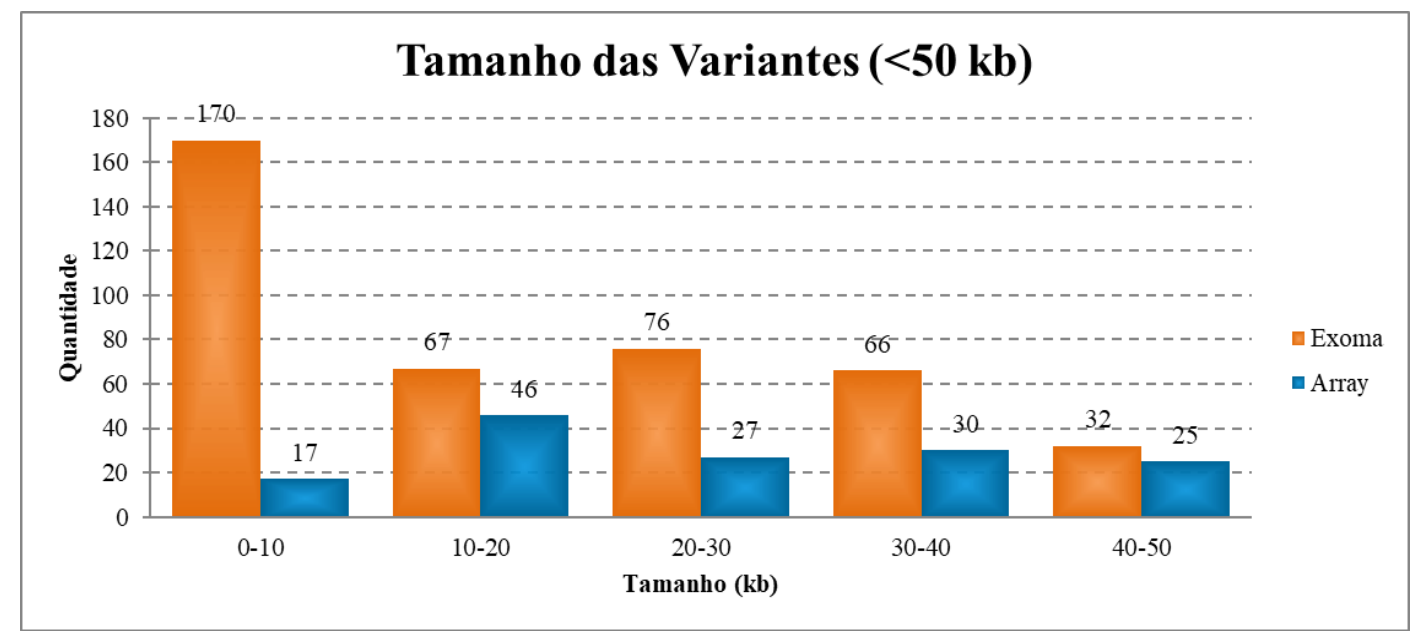

NOTA: As variantes detectadas na técnica de sequenciamento completo do exoma estão representadas em laranja e no array em azul. 
Além disso, a porcentagem de detecção de variantes do array, em um determinado grupo de tamanho em relação ao total de detecção da técnica, apresentou resultados superiores ou semelhantes em todos os intervalos de tamanho quando comparada à taxa de detecção do sequenciamento completo do exoma, com exceção do grupo das variantes pequenas $(<18 \mathrm{~kb})$ e do grupo das variantes grandes $(>1 \mathrm{Mb})$, que apresentaram resultados muito discrepantes para menos e mais variantes respectivamente (Gráfico 5).

Gráfico 5 - Proporção dentre as porcentagens de detecção total de variantes da técnica de sequenciamento completo do exoma e de array

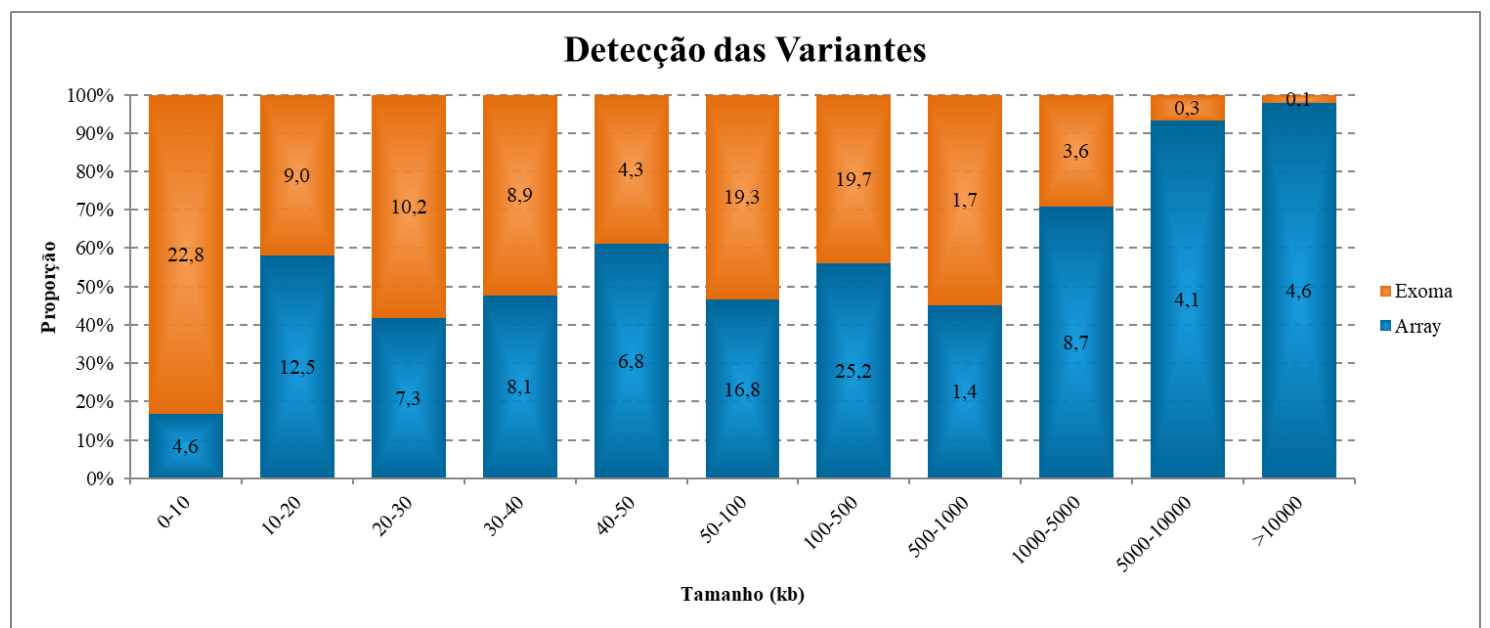

NOTA: As variantes detectadas na técnica de sequenciamento do exoma estão representadas em laranja e no array em azul.

Assim, em uma segunda fase de análise, foram contempladas as variantes maiores que $18 \mathrm{~kb}$ para que apenas os resultados plausíveis de comparação fossem avaliados, determinando a relação dos dados obtidos do sequenciamento completo do exoma com os do array.

Dentre os resultados selecionados (> $18 \mathrm{~kb}$ ), a taxa de sobreposição de variantes foi identificada em ambas as técnicas, sendo que cerca de 14,4 \% (74/513) das CNVs detectadas no sequenciamento do exoma foram equivalentes a aproximadamente $18,1 \%$ (56/310) das variantes detectadas no array (Gráfico 6 - A).

Destas variantes, cerca de 15,1\% (52/345) das deleções do sequenciamento do exoma correspondiam a 18,8 \% (40/213) das deleções e ROHs do array e aproximadamente $13,1 \%(22 / 168)$ das duplicações do sequenciamento do exoma equivaliam a 16,5 \% (16/97) das duplicações do array (Gráfico 6 - B).

As variantes detectadas no sequenciamento completo do exoma que apresentaram 
equivalência no array foram descritas no Anexo E, Quadro 2.

Gráfico 6 - Proporção da taxa de detecção de variantes equivalentes e não equivalentes entre as técnicas de sequenciamento completo do exoma e array
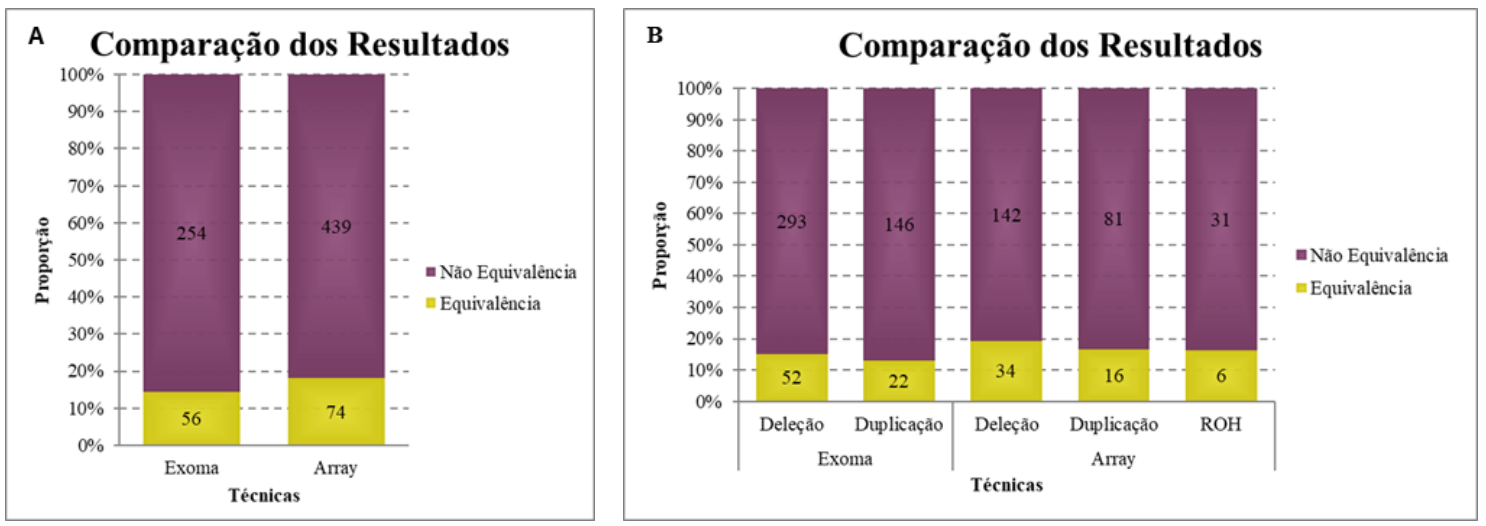

NOTA: As variantes equivalentes entre as técnicas de sequenciamento completo do exoma e array estão representadas em amarelo e as não equivalentes em roxo.

A quantidade de variantes (> $18 \mathrm{~kb}$ ), equivalentes ou não, observadas em cada amostra por meio das técnicas de sequenciamento completo do exoma e array foi descrita na tabela a seguir (Tabela 5). 
Tabela 5 - Quantidade de variantes equivalentes/totais (> $18 \mathrm{~kb}$ ) identificadas no sequenciamento completo do exoma e no array em cada amostra

\begin{tabular}{|c|c|c|c|c|c|}
\hline \multirow{2}{*}{ Amostra } & \multicolumn{2}{|c|}{ Exoma } & \multicolumn{3}{|c|}{ Array } \\
\hline & Deleção & Duplicação & Deleção & Duplicação & $\mathbf{R O H}$ \\
\hline 01 & $7 / 15$ & $0 / 5$ & $2 / 11$ & $0 / 1$ & $2 / 3$ \\
\hline 02 & $3 / 6$ & $0 / 1$ & $2 / 6$ & $0 / 4$ & $0 / 1$ \\
\hline 03 & $0 / 11$ & $3 / 6$ & $0 / 3$ & $2 / 3$ & $0 / 2$ \\
\hline 04 & $0 / 7$ & $0 / 1$ & $0 / 7$ & $0 / 2$ & $0 / 0$ \\
\hline 05 & $1 / 7$ & $1 / 8$ & $1 / 8$ & $1 / 4$ & $0 / 2$ \\
\hline 06 & $0 / 7$ & $2 / 3$ & $0 / 1$ & $2 / 4$ & $0 / 0$ \\
\hline 07 & $1 / 5$ & $0 / 9$ & $1 / 3$ & $0 / 0$ & $0 / 0$ \\
\hline 08 & $0 / 6$ & $0 / 2$ & $0 / 4$ & $0 / 3$ & $0 / 0$ \\
\hline 09 & $0 / 4$ & $1 / 7$ & $0 / 3$ & $1 / 5$ & $0 / 2$ \\
\hline 10 & $3 / 19$ & $0 / 6$ & $3 / 6$ & $0 / 1$ & $0 / 1$ \\
\hline 11 & $2 / 11$ & $1 / 8$ & $0 / 3$ & $1 / 1$ & $1 / 2$ \\
\hline 12 & $2 / 11$ & $0 / 5$ & $1 / 4$ & $0 / 3$ & $0 / 0$ \\
\hline 13 & $0 / 7$ & $2 / 7$ & $0 / 2$ & $2 / 2$ & $0 / 1$ \\
\hline 14 & $0 / 0$ & $0 / 0$ & $0 / 2$ & $0 / 3$ & $0 / 1$ \\
\hline 15 & $3 / 7$ & $0 / 7$ & $2 / 9$ & $0 / 0$ & $0 / 1$ \\
\hline 16 & $0 / 14$ & $0 / 4$ & $0 / 3$ & $0 / 3$ & $0 / 0$ \\
\hline 17 & $0 / 10$ & $0 / 3$ & $0 / 9$ & $0 / 3$ & $0 / 1$ \\
\hline 18 & $0 / 13$ & $0 / 2$ & $0 / 2$ & $0 / 4$ & $0 / 1$ \\
\hline 19 & $2 / 15$ & $0 / 5$ & $2 / 3$ & $0 / 0$ & $0 / 2$ \\
\hline 20 & $1 / 10$ & $2 / 8$ & $1 / 2$ & $2 / 3$ & $0 / 0$ \\
\hline 21 & $0 / 0$ & $0 / 1$ & $0 / 0$ & $0 / 4$ & $0 / 1$ \\
\hline 22 & $3 / 14$ & $3 / 5$ & $3 / 5$ & $1 / 3$ & $0 / 0$ \\
\hline 23 & $3 / 13$ & $0 / 10$ & $3 / 5$ & $0 / 0$ & $0 / 1$ \\
\hline 24 & $5 / 19$ & $0 / 2$ & $3 / 10$ & $0 / 2$ & $1 / 8$ \\
\hline 25 & $0 / 11$ & $0 / 4$ & $0 / 3$ & $0 / 0$ & $0 / 0$ \\
\hline 26 & $1 / 10$ & $1 / 2$ & $1 / 2$ & $1 / 6$ & $0 / 0$ \\
\hline 27 & $0 / 11$ & $0 / 2$ & $0 / 4$ & $0 / 4$ & $0 / 1$ \\
\hline 28 & $2 / 9$ & $1 / 4$ & $1 / 2$ & $1 / 3$ & $0 / 1$ \\
\hline 29 & $0 / 2$ & $0 / 5$ & $0 / 1$ & $0 / 1$ & $0 / 0$ \\
\hline 30 & $1 / 12$ & $0 / 7$ & $1 / 5$ & $0 / 4$ & $0 / 0$ \\
\hline 31 & $5 / 9$ & $0 / 3$ & $3 / 6$ & $0 / 1$ & $0 / 0$ \\
\hline 32 & $0 / 6$ & $0 / 0$ & $0 / 3$ & $0 / 3$ & $0 / 2$ \\
\hline 33 & $0 / 3$ & $5 / 8$ & $0 / 3$ & $2 / 4$ & $0 / 0$ \\
\hline 34 & $5 / 16$ & $0 / 4$ & $3 / 7$ & $0 / 2$ & $1 / 2$ \\
\hline 35 & $0 / 3$ & $0 / 4$ & $0 / 9$ & $0 / 4$ & $0 / 0$ \\
\hline 36 & $1 / 9$ & $0 / 3$ & $0 / 8$ & $0 / 2$ & $1 / 1$ \\
\hline 37 & $1 / 13$ & $0 / 5$ & $1 / 5$ & $0 / 2$ & $0 / 0$ \\
\hline 38 & $0 / 0$ & $0 / 2$ & $0 / 7$ & $0 / 3$ & $0 / 0$ \\
\hline \multirow{2}{*}{ TOTAL } & $52 / 345$ & $22 / 168$ & $34 / 176$ & $16 / 97$ & $6 / 37$ \\
\hline & \multicolumn{2}{|c|}{$74 / 513$} & \multicolumn{3}{|c|}{$56 / 310$} \\
\hline
\end{tabular}


Tendo em vista o intuito de determinar se o sequenciamento completo do exoma é um método eficaz para a identificação de CNVs patogênicas, as variantes identificadas em todas as amostras foram caracterizadas quanto a sua significância clínica em ambos os métodos (sequenciamento do exoma e array) a fim de estabelecer quais delas explicavam a ocorrência de fenótipo nos pacientes.

Dessa forma, considerando as características clínicas observadas em cada paciente e as diretrizes estabelecidas pela literatura, as variantes encontradas em cada amostra foram classificadas em benignas, patogênicas ou VUS, sendo possível concluir o diagnóstico molecular em 18 casos.

A partir da ocorrência de variantes clinicamente relevantes, foi observado que em cerca de 44,7 \% (17/38) das amostras uma CNV patogênica foi detectada em ambos os métodos, com exceção da amostra 22 que apresentou duas CNVs patogênicas em cromossomos distintos. Também foi detectada uma CNV patogênica em uma amostra $(2,6 \%)$, porém apenas pela técnica de array. Além disso, em aproximadamente $8 \%$ (3/38) dos casos foi identificada uma $\mathrm{ROH}$ apenas pelo array, a qual facilitou o direcionamento da análise para se chegar à conclusão diagnóstica. E em 44,7 \% (17/38) das amostras não foi visualizada qualquer CNV relacionada com a ocorrência de fenótipo nos pacientes (figura 10).

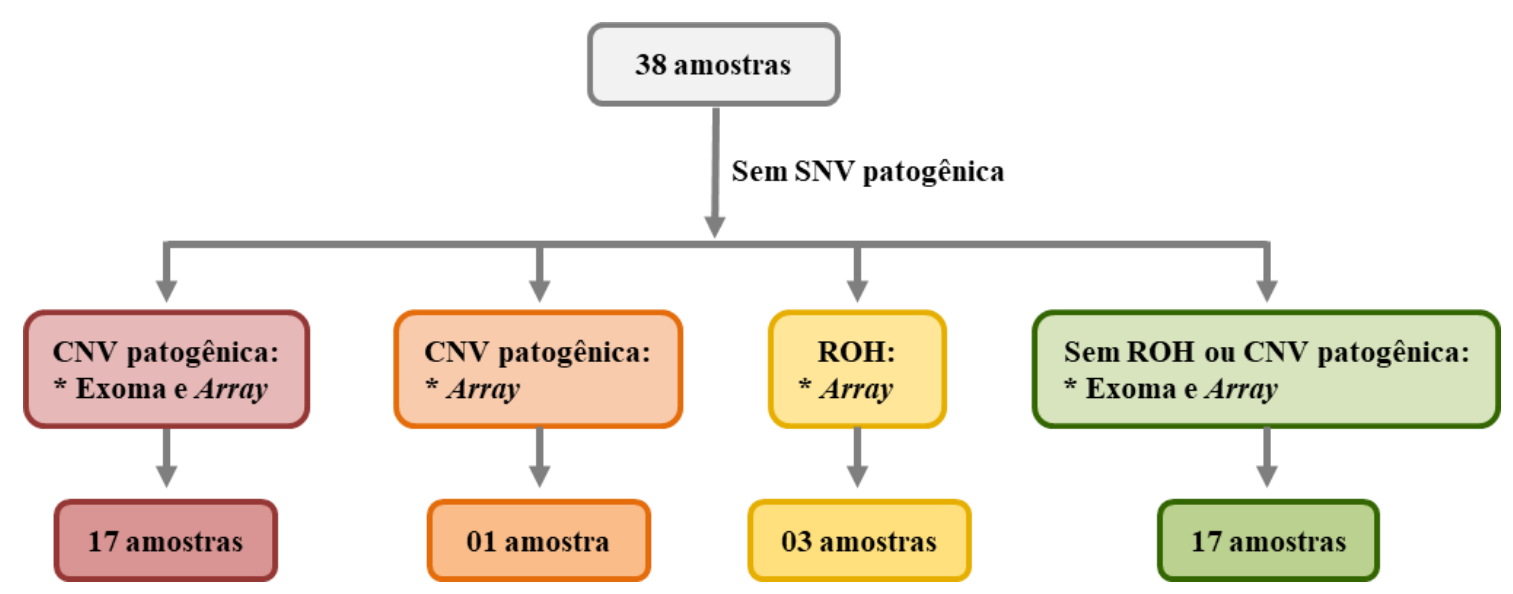

Figura 10 - Fluxograma da avaliação dos resultados encontrados pelos métodos de sequenciamento completo do exoma e de array separados por grupos conforme a elucidação do diagnóstico citogenômico

As informações reunidas de cada amostra e avaliações realizadas foram detalhadas a seguir conforme a categoria em que elas se enquadraram. 


\section{- Amostras com CNV patogênica detectada pelo sequenciamento do exoma e array:}

As amostras desse grupo apresentaram pelo menos uma CNV patogênica tanto pelo sequenciamento do exoma como pelo array. Essas deleções ou duplicações foram concordantes nas regiões cromossômicas, porém com algumas mudanças genômicas de ponto de quebra de início e término, sendo que dessas CNVs cerca de 83,3\% apresentaram elevada similaridade genômica quando comparadas entre as técnicas (Tabela 6).

Tabela 6 - CNVs patogênicas detectadas no sequenciamento completo do exoma em concordância com o array por amostra

\begin{tabular}{|c|c|c|c|c|}
\hline \multirow{2}{*}{ Amostra } & \multicolumn{3}{|c|}{ CNV patogênica } & \multirow{2}{*}{$\begin{array}{c}\text { Similaridade das } \\
\text { CNVs entre as técnicas }\end{array}$} \\
\hline & Tipo & Localização Cromossômica & Tamanho (pb) & \\
\hline 01 & $\operatorname{del}(\mathrm{x} 1)$ & $15 q 11.2-q 13.3$ & 10.275 .147 & $52,2 \%$ \\
\hline 02 & $\operatorname{del}(\mathrm{x} 1)$ & $15 q 11.1-q 13.1$ & 7.931 .520 & $51,8 \%$ \\
\hline 03 & $\operatorname{dup}(\mathrm{x} 3)$ & $16 \mathrm{p} 13.11$ & 1.166 .301 & $74,4 \%$ \\
\hline 04 & $\operatorname{dup}(\mathrm{x} 3)$ & $10 \mathrm{q} 24.31-\mathrm{q} 24.32$ & 403.289 & $* 9,9 \%$ \\
\hline 06 & $\operatorname{dup}(\mathrm{x} 3)$ & $7 q 11.23$ & 1.890 .574 & $78,4 \%$ \\
\hline 07 & $\operatorname{del}(\mathrm{x} 1)$ & $17 q 12$ & 1.767 .963 & $73,9 \%$ \\
\hline 09 & dup (x3) & $22 q 13.1-q 13.33$ & 12.610 .851 & $* 11,9 \%$ \\
\hline 12 & $\operatorname{del}(\mathrm{x} 1)$ & $22 q 11.21$ & 2.823 .431 & $84,7 \%$ \\
\hline 15 & $\operatorname{del}(\mathrm{x} 1)$ & $10 \mathrm{q} 26.2-\mathrm{q} 26.3$ & 7.821 .817 & $79,1 \%$ \\
\hline 20 & dup (x3) & $5 q 35.2-q 35.3$ & 1.036 .399 & $98,8 \%$ \\
\hline \multirow{3}{*}{22} & $\operatorname{del}(\mathrm{x} 1)$ & $7 q 11.23$ & 1.451 .593 & $98,0 \%$ \\
\hline & $\operatorname{dup}(x 4)$ & $15 q 11.1-q 13.2$ & 10.586 .279 & \multirow{2}{*}{$47,3 \%$} \\
\hline & $\operatorname{dup}(\mathrm{x} 3)$ & $15 q 13.2-q 13.3$ & 1.578 .056 & \\
\hline 24 & $\operatorname{del}(\mathrm{x} 1)$ & 10q26.12-q26.3 & 12.446 .474 & $67,3 \%$ \\
\hline 26 & $\operatorname{del}(\mathrm{x} 1)$ & $8 \mathrm{p} 22-\mathrm{p} 21.1$ & 12.014 .512 & $91,5 \%$ \\
\hline 28 & $\operatorname{del}(\mathrm{x} 1)$ & $19 q 13.33-q 13.41$ & 3.352 .377 & $99,2 \%$ \\
\hline 31 & $\operatorname{del}(\mathrm{x} 1)$ & $15 q 11.2-q 13.1$ & 5.892 .030 & $89,7 \%$ \\
\hline 33 & $\operatorname{dup}(\mathrm{x} 2)$ & $\mathrm{Xp} 22.33-\mathrm{p} 21.3$ & 26.560 .781 & $* 29,8 \%$ \\
\hline 34 & $\operatorname{del}(\mathrm{x} 1)$ & $6 p 23-p 22.3$ & 4.670 .587 & $71,6 \%$ \\
\hline
\end{tabular}

NOTA: del - deleção; dup - duplicação; x1 - uma cópia genômica; $\mathrm{x} 2$ - duas cópias genômicas; x3 - três cópias genômicas; $x 4$ - quatro cópias genômicas; $\mathrm{p}$ - braço curto do cromossomo; q braço longo do cromossomo; pb - pares de base; * - baixa porcentagem de similaridade das CNVs detectadas no sequenciamento do exoma em relação às detectadas no array.

Além disso, algumas CNVs detectadas pelo exoma apresentaram-se fragmentadas devido às características genômicas da região ou por limitação técnica, já que esta ferramenta foi desenvolvida para a detecção de SNV ou InDels e não CNV grande.

Assim todas as 17 amostras apresentaram concordância na elucidação do diagnóstico 
citogenômico, sendo que a descrição de cada caso foi detalhada no Anexo F.

\section{- Amostra com CNV patogênica detectada apenas pelo array:}

Das amostras estudadas, apenas uma (amostra 17) apresentou uma CNV patogênica detectada apenas pelo método de array.

Assim o diagnóstico citogenômico foi estabelecido a partir de uma deleção de $2 \mathrm{Mb}$ de tamanho no cromossomo 1q21.1, iniciando em 143.343 .508 pb e terminando em 145.395.440 pb. Considerando que a paciente apresentava atraso do desenvolvimento neuropsicomotor, deficiência intelectual, epilepsia e dismorfismos faciais, esta variante foi relacionada com a síndrome da deleção 1q21.1.

\section{- Amostras com ROH detectada apenas pelo array:}

Em alguns casos não foi possível estabelecer o diagnóstico utilizando a técnica do sequenciamento do exoma (Tabela 7), sendo que essa falha ocorreu devido à limitação do software de análise, o ExomeDepth ${ }^{\circledR}$, que não identifica ROHs.

Tabela 7 - ROHs detectadas apenas no array por amostra

\begin{tabular}{|c|c|c|c|}
\hline \multirow{2}{*}{ Amostra } & \multicolumn{3}{|c|}{ Variante patogênica } \\
\hline & Tipo & Localização Cromossômica & Tamanho (pb) \\
\hline 11 & $\mathrm{ROH}$ & $2 p 25.3-q 37.3$ & 243.034 .523 \\
\hline 13 & $\mathrm{ROH}$ & $14 q 11.2-q 21.1$ & 19.155 .693 \\
\hline 36 & $\mathrm{ROH}$ & $6 \mathrm{p} 25.3-\mathrm{q} 27$ & 170.871 .506 \\
\hline
\end{tabular}

NOTA: ROH - região de homozigosidade; $\mathrm{p}$ - braço curto do cromossomo; $\mathrm{q}$ - braço longo do cromossomo; $\mathrm{pb}$ - pares de base.

Nessas amostras, com um longo trecho de ROH, o array apenas indicou uma característica genômica, a qual poderia estar associada à alteração causativa do fenótipo, como por exemplo, a UPD, o imprinting genômico, ou a possibilidade ocorrência de doenças recessivas relacionadas com uma SNV.

Assim, para estes casos, foi necessário continuar a investigação citogenômica para a conclusão diagnóstica (descrição das amostras no Anexo G). 


\section{- Amostras sem CNV patogênica detectada pelo sequenciamento do exoma ou array:}

Em 17 amostras não foi possível relacionar as CNVs genômicas detectadas pelo sequenciamento do exoma ou pelo array com o fenótipo do paciente.

Para esses casos, os resultados de SNVs do exoma foram interpretados e classificados novamente, já que este é um procedimento incorporado à rotina dos laboratórios de genômica, uma vez que constantemente novas informações são inseridas nos bancos de dados, como a caracterização ou o estabelecimento de função a genes novos. Assim é aconselhável, para os casos sem diagnóstico citogenômico conclusivo, que conforme ocorram atualizações nos diversos bancos de dados as variantes genômicas sejam reclassificadas.

Dessa forma os 17 casos sem um diagnóstico conclusivo foram reavaliados, sendo que em cinco deles $(29,4 \%)$, que sofreram atualizações na classificação das SNVs, foi possível obter um diagnóstico final (Tabela 8).

Tabela 8 - Amostras sem CNV patogênica e com SNV detectada após reclassificação dos resultados do sequenciamento completo do exoma

\begin{tabular}{|c|c|c|}
\hline \multirow{2}{*}{ Amostra } & \multicolumn{2}{|c|}{ Variante patogênica } \\
\hline & Gene & Localização Cromossômica \\
\hline 05 & $A D N P$ & $20 q 13.13(49.518 .564 \mathrm{G}>\mathrm{GT})$ \\
\hline 08 & \multicolumn{2}{|c|}{ Diagnóstico inconclusivo } \\
\hline 10 & \multicolumn{2}{|c|}{ Diagnóstico inconclusivo } \\
\hline 14 & \multicolumn{2}{|c|}{ Diagnóstico inconclusivo } \\
\hline 16 & \multicolumn{2}{|c|}{ Diagnóstico inconclusivo } \\
\hline 18 & \multicolumn{2}{|c|}{ Diagnóstico inconclusivo } \\
\hline 19 & HNRNPH2 & $\mathrm{Xq22.1}(100.667 .592 \mathrm{C}>\mathrm{T})$ \\
\hline 21 & \multicolumn{2}{|c|}{ Diagnóstico inconclusivo } \\
\hline 23 & \multicolumn{2}{|c|}{ Diagnóstico inconclusivo } \\
\hline 25 & \multicolumn{2}{|c|}{ Diagnóstico inconclusivo } \\
\hline 27 & \multicolumn{2}{|c|}{ Diagnóstico inconclusivo } \\
\hline 29 & \multicolumn{2}{|c|}{ Diagnóstico inconclusivo } \\
\hline 30 & \multicolumn{2}{|c|}{ Diagnóstico inconclusivo } \\
\hline 32 & $K M T 2 A$ & $11 \mathrm{q} 23.3(118.374 .249 \mathrm{GC}>\mathrm{G})$ \\
\hline 35 & $M E C P 2$ & $\mathrm{Xq} 28(153.296 .363 \mathrm{C}>\mathrm{T})$ \\
\hline 37 & \multicolumn{2}{|c|}{ Diagnóstico inconclusivo } \\
\hline 38 & $E B F 3$ & 10q26.3 (131.757.261 T>C) \\
\hline
\end{tabular}

NOTA: $q$ - braço longo do cromossomo. 
DISCUSSÃO 


\section{DISCUSSÃO}

Uma estratégia eficiente para o diagnóstico molecular seria a utilização do sequenciamento do exoma para a detecção de variantes nos éxons no nível de pares de bases concomitante com a identificação de CNVs (De Ligt et al., 2013; Gambin et al., 2017), já que esta abordagem permitiria a avaliação do genoma dos pacientes com um melhor custo-benefício e tempo de execução, sendo, dessa forma, uma alternativa potencial para o diagnóstico das variantes genômicas patogênicas (Hehir-Kwa et al., 2015; Nam et al, 2016).

Na primeira etapa das análises deste estudo, foi avaliada a proporção de detecção de CNVs, na qual foi nítida a discrepância na taxa de identificação das variantes entre as técnicas, sendo que o sequenciamento completo do exoma obteve uma taxa muito superior à taxa do array, detectando 70,4\% das deleções e 66,1 \% das duplicações.

Porém a proporção entre a identificação de CNVs foi semelhante quando foram comparadas as duas técnicas, ou seja, a proporção de detecção do array foi de 67,5\% para deleções e 32,5 \% para duplicações e do exoma foi de 71,7 \% para deleções e 28,3 $\%$ para duplicações.

Esta inconsistência em relação à taxa de detecção entre as técnicas pode ter sido causada devido à diferença de capacidade de detecção dos métodos, ou seja, o exoma pode detectar variantes no nível de pares de bases, enquanto que o array apresenta limitação para pesquisa de CNVs muito pequenas, com a média da resolução mínima desta metodologia para detecção de variantes, utilizando o BeadChip CytoSNP-850K ${ }^{\circledR}$, de cerca de 18 kb (De Ligt et al., 2013; Hehir-Kwa et al., 2015).

Assim foram detectadas $59 \mathrm{CNVs}$, entre deleções e/ou duplicações menores que 18 $\mathrm{kb}$, pela técnica de array devido à elevada concentração de sondas nas regiões pesquisadas, sendo que essas variantes pequenas geralmente estão associadas às CNVs benignas.

A quantidade de CNVs pequenas $(<18 \mathrm{~kb})$ identificadas no exoma foi de 232 variantes, sendo que esse valor corresponde a $31 \%$ de todas as CNVs identificadas nesta técnica, muito superior à taxa identificada no array devido à limitação técnica.

Apesar das variantes pequenas serem geralmente classificadas como benignas, com 
o aprimoramento das análises dos dados de sequenciamentos de nova geração, a taxa de identificação dessas variantes pequenas associadas a doenças específicas aumentou consideravelmente (Tan et al., 2014; Hehir-Kwa et al., 2015; Harel e Lupski, 2018).

Diversos trabalhos da literatura relataram que a detecção de CNVs pequenas pelo exoma seria confiável utilizando softwares específicos e a confirmação dos achados poderia ser realizada por meio de um segundo software. Porém os algoritmos de detecção dessas variantes ainda têm baixa especificidade e sensibilidade na identificação de CNVs pequenas (1 a 4 éxons), e necessitam de um profissional especializado em bioinformática para o manuseio (Zhao et al., 2013; Samarakoon et al., 2014; Tan et al., 2014; Hong et al., 2016; Nam et al., 2016; Gambin et al., 2017).

Além disso, sabe-se que as variantes grandes são as mais confiáveis, pois abrangem diversos éxons, sendo possível comprovar sua presença por meio da técnica do array (Nam et al., 2016).

Sendo assim, devido à incerteza do exoma e à limitação do array em identificar deleções e duplicações pequenas, em uma segunda etapa da análise, foram comparadas apenas as variantes maiores que $18 \mathrm{~kb}$ identificadas por ambas as técnicas.

Dessa forma a taxa de resultados equivalentes (mesma região e/ou pontos de quebra próximos) foi de $14,4 \%$ para o exoma em relação ao array, sendo que essa proporção foi semelhante tanto para a identificação de deleções como para duplicações.

No estudo comparativo realizado por Plagnol e colaboradores (2012), utilizando 12 amostras do projeto 1000 genomas, o ExomeDepth ${ }^{\circledR}$ apresentou uma taxa de detecção de CNVs conhecidas maior do que as ferramentas exomeCopy ${ }^{\circledR}$ e ExomeCNVs ${ }^{\circledR}(75,2 \%$, $52,8 \%$ e $41,2 \%$ respectivamente), indicando uma maior sensibilidade dessa ferramenta principalmente quando a variabilidade entre as amostras era maior.

Embora Guo e colaboradores (2013) tenham reportado uma taxa de $62 \%$ de identificação de CNVs por meio do ExomeDepth ${ }^{\circledR}$ quando comparado ao array, outros estudos relatam um menor desempenho dessa ferramenta, com taxas de 18,2 \% (Tan et al., 2014) e 15,8 \% (De Ligt et al., 2013).

Apesar da taxa de identificação de CNVs verdadeiras pelo ExomeDepth ${ }^{\circledR}$ não ser a melhor dentre vários softwares (Guo et al., 2013; Tan et al., 2014), já que uma das suas limitações é identificar de forma correta variantes pequenas ( $<1 \mathrm{~kb})$ (Zhao et al., 2013), De Ligt e colaboradores (2013) apontam o ExomeDepth como umas das ferramentas com o melhor desempenho para detectar variantes clinicamente relevantes. 
Os dados do presente estudo apresentaram taxas equivalentes às relatadas por De Ligt e colaboradores (2013) e Tan e colaboradores (2014), porém vale ressaltar que foram avaliadas todas as variantes encontradas e não apenas as CNVs clinicamente relevantes.

Como a maioria das $\mathrm{CNVs}$ patogênicas detectadas pela triagem de rotina são variantes grandes e frequentemente contém diversos genes relacionados (De Ligt et al., 2013), foram selecionadas para a avaliação final apenas as CNVs consideradas patogênicas, ou seja, relacionadas com o fenótipo dos pacientes, podendo determinar se esta ferramenta apresentava desempenho satisfatório para o diagnóstico citogenômico de pacientes com ADNPM e/ou MMC.

Considerando toda a casuística inclusa neste estudo, o ExomeDepth ${ }^{\circledR}$ identificou uma taxa geral de 44,7 \% (17/38) de pacientes com CNVs patogênicas verdadeiras, porém quando foram selecionadas apenas as $\mathrm{CNVs}$ avaliadas como clinicamente relevantes detectadas pelo array, essa taxa aumentou para 94,7 \% (18/19).

Outro aspecto importante foi que essas CNVs patogênicas apresentaram 83,3 \% (15/18) de elevada similaridade (mais de $47 \%$ de sobreposição) quando comparadas aos dados obtidos (informações dos pontos de quebra, localização e tamanho) pelo array.

No estudo realizado por De Ligt e colaboradores (2013) foram obtidas taxas de detecção de CNVs patogênicas, previamente detectadas pelo array, por meio de quatro softwares diferentes. Assim o ExomeDepth ${ }^{\circledR}$ identificou corretamente 83,3 \% (10/12) de deleções e duplicações em diversos cromossomos e regiões genômicas, com um limite de corte de $30 \%$ de sobreposição para o sucesso da detecção entre as técnicas.

Apesar da taxa de detecção de CNVs patogênicas verdadeiras ter sido elevada, não foi possível comprovar se todas as outras CNVs identificadas pelo sequenciamento do exoma eram de fato reais.

A abordagem para identificação das CNVs por meio do sequenciamento do exoma é dependente da profundidade de leitura das regiões e das amostras utilizadas para normalização (pode gerar variantes falso-positivas), sendo que ainda apresenta falhas e precisa ser mais bem avaliada (De Ligt et al., 2013; Guo et al., 2013; Zhao et al., 2013; Tan et al., 2014; Hehir-Kwa et al., 2015; Gambin et al., 2017).

Quando são analisadas apenas as regiões exônicas é importante considerar que os éxons não estão posicionados uniformemente no genoma, dessa forma o exoma fica limitado a sequenciar posições específicas, em oposição às sondas do array que podem ser desenhadas para hibridarem uniformemente em todo o genoma (De Ligt et al., 2013; 
Guo et al., 2013; Tan et al., 2014; Kadalayil et al., 2015).

Assim, quando se avalia uma CNV grande, ou seja, maior que 18 kb, são necessárias informações de vários éxons, caso contrário as informações detectadas sobre deleções e duplicações envolvendo uma longa região intrônica não seriam confiáveis (Guo et al., 2013; Zhao et al., 2013; Tan et al., 2014).

Em relação às variantes pequenas, ou menor que $18 \mathrm{~kb}$, as ferramentas desenvolvidas utilizando a leitura de profundidade das regiões alvo precisam de no mínimo três éxons adjacentes alterados para considerar uma deleção ou uma duplicação (Hehir-Kwa et al., 2015).

A eficiência na captura das sequências alvo pelo exoma também é uma questão importante a ser considerada no momento da avaliação das CNVs, pois ela pode variar consideravelmente entre as regiões e gerar resultados falso-positivos ou falso-negativos (Bamshad et al., 2011; Guo et al., 2013; Zhao et al., 2013; Nam et al., 2016).

O processo de PCR, realizado no exoma na etapa de clusterização, é conhecido por gerar a maior concentração de erro, na qual regiões com baixa taxa de amplificação por PCR resultam em menos leituras, distorcendo a avaliação das variantes verdadeiras (Zhao et al., 2013; Kadalayil et al., 2015; Hong et al., 2016; Nam et al., 2016).

Além disso, regiões com concentração elevada de GC também podem dificultar a leitura, sendo necessária uma normalização adicional para corrigir esses ruídos (De Ligt et al., 2013; Guo et al., 2013; Zhao et al., 2013; Hehir-Kwa et al., 2015; Hong et al., 2016; Nam et al., 2016; Gambin et al., 2017).

Outra limitação da análise das CNVs por meio do exoma é o alinhamento quando se tem a presença de regiões repetitivas ou a caracterização do ponto de quebra caso este se localize nos íntrons (exoma compreende apenas $1 \%$ do genoma) (De Ligt et al., 2013; Zhao et al., 2013; Tan et al., 2014).

Assim o verdadeiro ponto de quebra pode ser em qualquer lugar no espaço entre o éxon terminal identificado e o éxon adjacente na região considerada normal (De Ligt et al., 2013; Kadalayil et al., 2015; Bergant et al., 2018).

Para a maioria das CNVs patogênicas deste estudo a definição dos pontos de quebra inicial ou final foi possível por meio da técnica de array, mesmo com os espaçamentos entre as sondas, pois estes apresentaram, em relação ao exoma, a localização anterior ou posterior para o início ou fim da variante, respectivamente.

Além disso, seis pontos de quebra foram aparentemente mais bem caracterizados 
pelo exoma, porém essa informação não é necessariamente precisa, já que, para quatro pontos de quebra, o intervalo diferenciado entre as técnicas apresentou sondas de array, que não estavam alteradas. Uma maneira de determinar melhor esses pontos de quebra seria sequenciar essas regiões (éxons e íntrons) para definir exatamente as bases alteradas do início e fim das CNVs.

Dessa forma identificar uma CNV verdadeira é desafiador, sendo que a etapa de normalização das amostras para eliminar os ruídos e os vieses causados pela metodologia é crucial para garantir um resultado verdadeiro (Hehir-Kwa et al., 2015; Hong et al., 2016; Nam et al., 2016; Gambin et al., 2017).

A partir dessas limitações, novos softwares estão surgindo e sendo aprimorados para que a avaliação das CNVs por meio do exoma se torne adequada (Tan et al., 2014).

O sequenciamento por meio da plataforma PacBio ${ }^{\circledR}$ (Pacific Biosciences ${ }^{\circledR}$ ), que já está sendo utilizado, elimina diversos problemas do sequenciamento, como os erros de alinhamento, principalmente em regiões repetitivas, e a necessidade de uma cobertura elevada de todo o genoma. Esta plataforma realiza leituras longas e mais precisas das regiões, utilizando uma única molécula, porém o custo para esse sequenciamento é muito elevado e ainda inviável para ser utilizado comercialmente na rotina diagnóstica (Carneiro et al., 2012; Zhao et al., 2013; Chaisson et al., 2015).

Embora, até o momento, tenham ocorrido progressos nas ferramentas para detecção das CNVs pelo exoma, nenhum dos métodos pode detectar de forma abrangente todos os tipos de CNVs (Zhao et al., 2013; Tan et al., 2014; Hwang et al., 2015).

Já as sondas de array são distribuídas por todo o genoma (éxons e íntrons), sendo projetadas para regiões conhecidas e menos problemáticas (por exemplo, para regiões não repetitivas), além de possuírem um tamanho de 50-mers e terem alta especificidade. Os dados obtidos pelo escaneamento do array também passam por um processo de normalização entre as amostras e correção de ruídos (Guo et al., 2013).

Dessa forma a literatura considera o array a técnica mais confiável para a detecção de CNVs e ROHs, já que foi desenvolvida exclusivamente para esta finalidade (De Ligt et al., 2013; Guo et al., 2013; Kadalayil et al., 2015).

Porém o array também apresenta limitações, principalmente em relação à resolução e cobertura das sondas no genoma, ou seja, a quantidade e o espaçamento das sondas influenciam diretamente a taxa de detecção de variantes menores e a exatidão na caracterização do ponto de quebra de todas as CNVs (Zhao et al., 2013; Samarakoon et 
al., 2014; Hwang et al., 2015; Nam et al., 2016).

Assim testes adicionais e aprimoramento dos softwares são necessários para obter resultados gerais mais confiáveis, sendo que sempre que uma CNV for identificada pelo exoma um segundo método desenvolvido especialmente para essa finalidade pode ser aplicado para a confirmação do resultado (Tan et al., 2014; Hehir-Kwa et al., 2015; Kadalayil et al., 2015; Nam et al., 2016).

Nesta pesquisa também foi identificado que $8 \%$ das amostras apresentaram uma ROH visualizada apenas pelo array. Esse dado não elucidou o diagnóstico citogenômico, porém facilitou a investigação para a conclusão da causa do fenótipo nos pacientes, ressaltando a necessidade da utilização do array até o momento e do aprimoramento dos softwares de análise de dados de sequenciamento para a identificação de algumas características genômicas que podem conduzir ao diagnóstico.

Assim os padrões de homozigosidade têm se mostrados úteis na identificação de SNVs patogênicas associadas com doenças de herança recessiva, e as regiões com UPD para a avaliação de imprinting genômico (Alkuraya, 2010; Kearney et al., 2011; Bergant et al., 2018; Harel e Lupski, 2018; Lu et al., 2018).

Outro dado importante obtido neste trabalho foi que para alguns pacientes não foi possível concluir o diagnóstico citogenômico avaliando as CNVs. Além disso, dados da literatura relataram que 70 a $75 \%$ dos exomas são negativos para a pesquisa de variantes dependendo do fenótipo e da forma de análise (Eldomery et al., 2017; Al-Nabhani et al., 2019).

Assim há grande complexidade em estabelecer uma classificação para as variantes identificadas, sendo que os dados de sequenciamento com resultados negativos (sem variantes patogênicas) devem ser reavaliados dentro de 1 a 3 anos devido às atualizações dos bancos de dados e descrições gênicas. Também é importante reunir todas as informações clínicas do paciente para uma relação genótipo-fenótipo mais adequada, sendo que o fenótipo pode agregar novas informações clínicas com o passar do tempo (Bamshad et al., 2011; Wright et al., 2018; Al-Nabhani et al., 2019).

Em um estudo realizado por Wright e colaboradores (2018), a reanálise de dados de sequenciamento em 1133 famílias de pacientes com alterações no neurodesenvolvimento e/ou malformações congênitas possibilitou aumentar a taxa diagnóstica em 13 \%. Já AlNabhani e colaboradores (2019), reanalisaram 50 amostras com resultados negativos para a detecção de variantes e relataram uma taxa de $12 \%$ e $26 \%$ na identificação de variantes 
patogênicas e de variantes provavelmente patogênicas, respectivamente.

Dependendo das estratégias para a avaliação e classificação das variantes a porcentagem na identificação de patogenicidade pode chegar a $48 \%$ (Shamseldin et al., 2017).

Dessa forma as 17 amostras sem conclusão diagnóstica foram reanalisadas pela equipe de bioinformatas da Mendelics e foi possível estabelecer o diagnóstico em 29,4 \% desses pacientes, já que houve atualização dos bancos de dados permitindo classificar as variantes de ponto encontradas como patogênicas.

Para as amostras em que não foi possível estabelecer um diagnóstico citogenômico, futuras avaliações serão necessárias conforme haja atualizações genômicas e novas descrições gênicas. Além disso, é importante ressaltar que as variantes podem ocorrer em outras regiões que não foram avaliadas e serem a causa da ocorrência de fenótipo (Conrad et al., 2010; Bergant et al., 2018; Wright et al., 2018).

Estudos relataram que SNVs localizadas em regiões promotoras e UTR (do inglês, Untranslated Region - região não traduzida) podem regular a expressão gênica e íntrons podem ter significância funcional, codificando proteínas específicas. Assim seria necessária a avaliação do genoma destes pacientes por meio do sequenciamento completo do genoma, porém este ainda é um método dispendioso e com a análise muito complexa, já que é difícil estabelecer uma classificação confiável para todas as variantes encontradas (Guo et al., 2012; Bergant et al., 2018; Harel e Lupski, 2018).

\subsection{Considerações finais:}

Este trabalho associado a dados da literatura sugerem que é válido identificar CNVs utilizando o sequenciamento do exoma, porém, devido às taxas elevadas de resultados falso-positivos e baixa especificidade quando comparados à técnica de array, cuidados extras na descrição dessas variantes devem ser levados em consideração, como por exemplo, confirmando os resultados por uma outra técnica (Guo et al., 2013; Kadalayil et al., 2015).

$\mathrm{Na}$ avaliação realizada nesta pesquisa por meio do sequenciamento completo do exoma utilizando o software ExomeDepth ${ }^{\circledR}$ foi possível confirmar a detecção de 18 das 19 CNVs patogênicas identificadas pelo array utilizando o software BlueFuse ${ }^{\circledR}$, porém 
também foi relatada uma quantidade grande de variantes menores que não puderam ser confirmadas como verdadeiras por limitações técnicas (671 variantes falso-positivas e 313 variantes falso-negativas). Assim o sequenciamento do exoma ainda não pode ser utilizado para substituir o array na identificação de CNVs.

Alguns autores relatam o sequenciamento completo do genoma como metodologia mais adequada para a detecção de SNVs e InDels concomitante à pesquisa de CNVs, pois avalia o genoma completo de forma contínua podendo identificar qualquer tamanho de variante. Entretanto esta técnica apresenta, além do custo elevado, uma complexidade grande para a análise e interpretação das variantes identificadas, principalmente em regiões que não compreendem os éxons (Guo et al., 2013; Tam et al., 2014; Harel e Lupski, 2018).

Dessa forma o sequenciamento do exoma demostra ser futuramente, após o aprimoramento dos softwares de análise e dos bancos de dados, uma excelente estratégia para detecção de doenças genômicas na rotina diagnóstica (Shamseldin et al., 2017). Já que a possibilidade de utilizar um único teste para identificar diferentes tipos de variantes irá reduzir os custos e melhorar significativamente o rendimento do diagnóstico citogenômico, além de ampliar o entendimento dos mecanismos das doenças e gerar estratégias de prevenção mais relevantes (Bamshad et al., 2011; Hehir-Kwa et al., 2015). 


\section{CONCLUSÕES}

Este estudo permitiu:

- Investigar o genoma de pacientes com ADNPM e/ou MMC por meio das técnicas de sequenciamento completo do exoma e array, utilizando os softwares ExomeDepth ${ }^{\circledR} \mathrm{e}$ BlueFuse $^{\circledR}$, respectivamente;

- Avaliar a capacidade do sequenciamento completo do exoma para a identificação de deleções e duplicações no genoma desses pacientes, utilizando o software de análise ExomeDepth;

- Comparar os métodos de sequenciamento completo do exoma e array para a detecção de CNVs patogênicas. 


\author{
ANEXO A \\ Termo de Consentimento Livre e Esclarecido
}

\title{
HOSPITAL DAS CLÍNICAS DA FACULDADE DE MEDICINA DA UNIVERSIDADE DE SÃO PAULO-HCFMUSP
}

TERMO DE CONSENTIMENTO LIVRE E ESCLARECIDO

DADOS DE IDENTIFICAÇÄO DO SUJEITO DA PESQUISA OU RESPONSÁVEL LEGAL

$$
\text { 1. NOME: }
$$

DADOS SOBRE A PESQUISA

TÍTULO|DO PROTOCOLO DE PESQUISA:

"Avaliação da variação do número de cópias (CNV) genômicas em portadores de malformações congênitas e atraso do desenvolvimento neuropsicomotor pelas técnicas de bead array e o sequeciamento do exoma."

1.

PESQUISADORA: Profa. Dra. Leslie Domenici Kulikowski

CARGO/FUNÇĀO: Pesquisadora e responsável pelo Laboratório de Citogenômica (LIM 03) Departamento de Patologia INSCRIÇÄO CONSELHO REGIONAL No: CRB 56833

UNIDADE DO HCFMUSP: Laboratório de Citogenômica do LIM 03 - Departamento de Patologia

2. AVALIAÇÄO DO RISCO DA PESQUISA:

$\begin{array}{lll}\text { RISCO MÍNIMO } & X & \text { RISCO MÉDIO } \\ \text { RISCO BAIXO } & \square & \text { RISCO MAIOR }\end{array}$

3. DURAÇÃO DA PESQUISA: 48 meses 


\section{HOSPITAL DAS CLINICAS DA FACULDADE DE MEDICINA DA UNIVERSIDADE DE SÃO PAULO-HCFMUSP}

1 - Desenho do estudo e objetivo(s): Estamos convidando você e sua família, no caso, seu filho ou filha para participar deste projeto de pesquisa que pode ser importante para conhecer as causas da doença do seu filho ou filha, que possui múltiplas malformaçōes congênitas e atraso do desenvolvimento neuropsicomotor.

Em algumas doenças genéticas, como a do seu filho ou filha, o diagnóstico só é possível com exames mais complexos, os quais procuram pequenas alterações de ganho ou perda de material genético para explicar a doença do paciente. Assim, ao participar deste projeto, que utiliza uma nova técnica de exame, sua família terá uma chance de saber a causa de sua doença, além de prevenir possíveis casos nos irmãos e outros familiares.

2 - Descrição dos procedimentos que serão realizados, com seus propósitos e identificação dos que forem experimentais e não rotineiros: Será realizada uma entrevista com os pais e/ou familiares responsáveis para a coleta dos dados do paciente e da família, também será feito exames físicos para verificar a saúde do paciente, e será coletada uma amostra de sangue periférico por uma punção venosa ("tirar sangue") para analisar possiveis alterações do material genético, no caso de todas as regiōes que podem estar relacionadas com a doença do paciente (DNA).

3 - Relação dos procedimentos rotineiros e como são realizados: A coleta de $5 \mathrm{~mL}$ de sangue periférico será realizada por punção venosa do antebraço do paciente ("tirar um pouco de sangue"), sendo suficiente para os exames relacionados a essa pesquisa. No caso de algum dos exames apresentarem um resultado alterado será solicitado aos pais que retonem para a explicação do resultado e para, caso necessário, uma investigação adicional com novos exames para a criança e para os pais, possibilitando o aconselhamento genético.

4 - Descrição dos desconfortos e riscos esperados nos procedimentos dos itens 2 e 3:

Pode haver um pequeno desconforto com a picada da agulha, sendo que o local poderá ficar um pouco dolorido, e as vezes o local pode ficar ("roxo"), mas desaparecerá em poucos dias sem a necessidade de medicamentos. O risco desta coleta de sangue é mínimo.

5 - Benefícios para o participante: Todos os exames realizados beneficiaram o paciente porque podem dar um diagnóstico clínico definitivo. Além disso, o estudo pode identificar possiveis causas genéticas para a doença de outros pacientes.

6 - Relação de procedimentos alternativos que possam ser vantajosos, pelos quais o paciente pode optar: Não existem outros exames alternativos disponiveis no SUS para a pesquisa das pequenas alterações no material genético relacionados aos problemas do seu filho ou filha.

7 - Garantia de acesso: Em qualquer etapa do estudo, vocè terá acesso aos profissionais responsáveis pela pesquisa para esclarecimento de eventuais dúvidas. A principal pesquisadora é a Profa. Dra. Leslie Domenici Kulikowski, que pode ser encontrada no Laboratório de Citogenômica, endereço Av. Dr. Enéas Carvalho de Aguiar, 155 - Prédio dos Ambulatórios, $2^{\circ}$ andar, Bloco 12 - telefone: (11) 2661-9506. Qualquer consideração ou dúvida sobre a ética da pesquisa, entre em contato com o Comitê de Ética em 
Pesquisa (CEP) - Rua Ovídio Pires de Campos, 225 - 50 andar - telefone: (11) 3069-6442 ramais 16, 17 , 18 ou 20, FAX: 3069-6442 ramal 26. E-mail: cappesq@hcnet.usp.br.

8 - É garantida a liberdade da retirada de consentimento a qualquer momento e deixar de participar do estudo sem qualquer prejuizo à continuidade do tratamento do paciente na Instituição.

9 - Direito de confidencialidade: As informações obtidas serão analisadas em conjunto com outros pacientes, não sendo divulgada a identificação de nenhum paciente.

10 - É garantido o direito de ser mantido atualizado sobre os resultados parciais das pesquisas, quando em estudos abertos, ou de resultados que sejam do conhecimento dos pesquisadores.

11 - Despesas e compensações: Não há despesas pessoais para o participante em qualquer fase do estudo, incluindo exames e consultas. Também não há compensação financeira relacionada à sua participação.

12 - A pesquisadora (Dra. Leslie Domenici Kulikowski) se compromete a utilizar os dados e o material coletado somente para esta pesquisa.

13- Acredito ter sido suficientemente informado a respeito das informações que li ou que foram lidas para mim, descrevendo o estudo "Avaliação da variação do número de cópias (CNV) genômicas em portadores de malformações congènitas e atraso do desenvolvimento neuropsicomotor pelas técnicas de bead array e o sequeciamento do exoma.

Eu discuti com a Profa. Dra. Leslie Domenici Kulikowski sobre a minha decisão em participar nesse estudo. Ficaram claros para mim quais são os propósitos do estudo, os procedimentos a serem realizados, seus desconfortos e riscos, as garantias de confidencialidade e de esclarecimentos permanentes.

Ficou claro também que minha participação é isenta de despesas e que tenho garantia do acesso ao tratamento hospitalar quando necessário. Concordo voluntariamente em ceder as amostras para estudos futuros e concordo em participar deste estudo sabendo que poderei retirar o meu consentimento a qualquer momento, antes ou durante o mesmo, sem penalidades ou prejuízo ou perda de qualquer beneficio que eu possa ter adquirido, ou no meu atendimento neste Serviço. 
(Somente para o responsável do projeto)

Declaro que obtive de forma apropriada e voluntária o Consentimento Livre e Esclarecido deste paciente ou representante legal para a participação neste estudo.

Assinatura do responsável pelo estudo 


\begin{abstract}
ANEXO B
Aprovação do Comitê de Ética e Pesquisa da Faculdade de Medicina da

Universidade de São Paulo (n. ${ }^{\circ}$ 235/15)

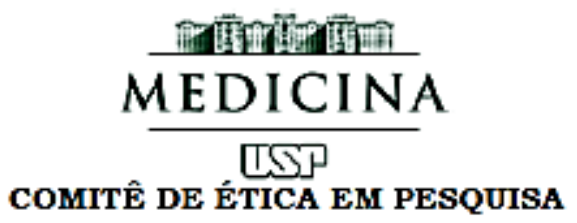

\section{APROVAÇÃO}

o Comitê de Ética em Pesquisa da Faculdade de Medicina da Universidade de São Paulo, em sessão de 10/06/2015, APROVOU o Protocolo de Pesquisa $\mathrm{n}^{0} \mathbf{2 3 5} / \mathbf{1 5}$ intitulado: "AVALLAÇÃo DA VARIAÇÃo DO NÚMIRO DE CÓPLAS (CNV) GENÔMICAS EM PORTADORES DE MALFORMAÇÕES CONGÊNTTAS E ATRASO DO DESENVOLVIMENTO NEUROPSICOMOTOR PELAS TÉCNICAS DE BEAD ARRAY E O SEQUECIAMENTO DO EXOMA." apresentado pelo Departamento de PATOLOGIA
\end{abstract}

Cabe ao pesquisador elaborar e apresentar ao CEPFMUSP, os relatórios parciais e final sobre a pesquisa (Resolução do Conselho Nacional de Saúde $n^{\circ}$ 466/12, inciso IX.2, letra "c").

Pesquisador (a) Responsável: Leslie Domenici Kulikowski Pesquisador (a) Executante: Evelin Aline Zanardo

CEP-FMUSP, 10 de Junho de 2015.

$$
\text { Pliemens. }
$$

Prof. Dr. Roger Chammas Coordenador Comitê de Ética em Pesquisa 


\section{ANEXO C}

Tabela 2 - Controles de qualidade do teste de sequenciamento completo do exoma

\begin{tabular}{|c|c|c|c|}
\hline Amostra & $\begin{array}{l}\% \text { de bases alvo com } \\
\text { pelo menos } 10 \text { leituras }\end{array}$ & $\begin{array}{l}\text { Número médio de vezes } \\
\text { que cada base foi lida }\end{array}$ & $\begin{array}{c}\text { Número de } \\
\text { sequências geradas }\end{array}$ \\
\hline 01 & $98,4 \%$ & 107 & 78.549 .751 \\
\hline 02 & $95,9 \%$ & 120 & 137.158 .162 \\
\hline 03 & $95,3 \%$ & 107 & 99.318 .464 \\
\hline 04 & $89,6 \%$ & 92 & 65.355 .247 \\
\hline 05 & $97,6 \%$ & 136 & 107.188 .792 \\
\hline 06 & $96,9 \%$ & 71 & 51.599 .593 \\
\hline 07 & $98,4 \%$ & 172 & 121.326 .905 \\
\hline 08 & $97,4 \%$ & 86 & 61.978 .688 \\
\hline 09 & $97,4 \%$ & 103 & 74.499 .758 \\
\hline 10 & $96,5 \%$ & 121 & 110.045 .899 \\
\hline 11 & $97,4 \%$ & 128 & 210.606 .364 \\
\hline 12 & $97,4 \%$ & 106 & 161.904 .660 \\
\hline 13 & $96,8 \%$ & 105 & 169.303 .494 \\
\hline 14 & $91,0 \%$ & 120 & 152.461 .064 \\
\hline 15 & $98,0 \%$ & 239 & 230.607 .049 \\
\hline 16 & $98,5 \%$ & 203 & 323.151 .740 \\
\hline 17 & $96,4 \%$ & 104 & 154.389 .316 \\
\hline 18 & $96,1 \%$ & 99 & 142.970 .112 \\
\hline 19 & $96,8 \%$ & 140 & 200.175 .482 \\
\hline 20 & $96,9 \%$ & 111 & 169.802 .972 \\
\hline 21 & $82,2 \%$ & 129 & 160.900 .028 \\
\hline 22 & $97,5 \%$ & 134 & 206.190 .958 \\
\hline 23 & $97,8 \%$ & 124 & 196.328 .200 \\
\hline 24 & $96,7 \%$ & 136 & 165.146 .667 \\
\hline 25 & $97,4 \%$ & 154 & 183.279.141 \\
\hline 26 & $94,6 \%$ & 153 & 148.801 .148 \\
\hline 27 & $97,8 \%$ & 157 & 183.359 .562 \\
\hline 28 & $96,8 \%$ & 130 & 163.564 .054 \\
\hline 29 & $97,9 \%$ & 165 & 195.024 .051 \\
\hline 30 & $97,3 \%$ & 110 & 181.814 .192 \\
\hline 31 & $97,2 \%$ & 128 & 195.560 .114 \\
\hline 32 & $96,8 \%$ & 115 & 163.431 .122 \\
\hline 33 & $98,2 \%$ & 113 & 196.903 .734 \\
\hline 34 & $95,8 \%$ & 101 & 167.078 .008 \\
\hline 35 & $94,2 \%$ & 83 & 151.376 .724 \\
\hline 36 & $95,6 \%$ & 90 & 142.620 .620 \\
\hline 37 & $96,5 \%$ & 114 & 170.057 .930 \\
\hline 38 & $98,0 \%$ & 128 & 92.800 .282 \\
\hline
\end{tabular}

NOTA: \% de bases alvo com pelo menos 10 leituras - Valor mínimo aceitável para este parâmetro em um bom experimento é > 95 \%; Número médio de vezes que cada base foi lidaMédia da cobertura do sequenciamento em cada base (x), sendo que o valor de corte é 90x. 


\section{ANEXO D}

Tabela 3 - Controles de qualidade do teste de array pelo software BlueFuse ${ }^{\circledR}$

\begin{tabular}{|c|c|c|c|}
\hline Amostra & Gênero & Median Log $R$ Deviation & Median Call Rate \\
\hline 01 & Masculino & 0,22 & 1,00 \\
\hline 02 & Masculino & 0,19 & 1,00 \\
\hline 03 & Feminino & 0,18 & 1,00 \\
\hline 04 & Masculino & 0,21 & 1,00 \\
\hline 05 & Feminino & 0,20 & 1,00 \\
\hline 06 & Masculino & 0,18 & 1,00 \\
\hline 07 & Masculino & 0,19 & 1,00 \\
\hline 08 & Feminino & 0,18 & 1,00 \\
\hline 09 & Feminino & 0,19 & 1,00 \\
\hline 10 & Masculino & 0,19 & 1,00 \\
\hline 11 & Feminino & 0,19 & 1,00 \\
\hline 12 & Masculino & 0,18 & 1,00 \\
\hline 13 & Feminino & 0,18 & 1,00 \\
\hline 14 & Masculino & 0,20 & 1,00 \\
\hline 15 & Feminino & 0,20 & 1,00 \\
\hline 16 & Masculino & 0,19 & 1,00 \\
\hline 17 & Feminino & 0,21 & 1,00 \\
\hline 18 & Masculino & 0,18 & 1,00 \\
\hline 19 & Feminino & 0,18 & 1,00 \\
\hline 20 & Feminino & 0,19 & 1,00 \\
\hline 21 & Masculino & 0,18 & 1,00 \\
\hline 22 & Masculino & 0,16 & 1,00 \\
\hline 23 & Masculino & 0,19 & 1,00 \\
\hline 24 & Feminino & 0,20 & 1,00 \\
\hline 25 & Feminino & 0,19 & 1,00 \\
\hline 26 & Masculino & 0,19 & 1,00 \\
\hline 27 & Masculino & 0,16 & 1,00 \\
\hline 28 & Masculino & 0,19 & 1,00 \\
\hline 29 & Masculino & 0,18 & 1,00 \\
\hline 30 & Masculino & 0,16 & 1,00 \\
\hline 31 & Feminino & 0,16 & 1,00 \\
\hline 32 & Feminino & 0,17 & 1,00 \\
\hline 33 & Masculino & 0,17 & 1,00 \\
\hline 34 & Masculino & 0,18 & 1,00 \\
\hline 35 & Feminino & 0,16 & 1,00 \\
\hline 36 & Masculino & 0,20 & 1,00 \\
\hline 37 & Masculino & 0,16 & 1,00 \\
\hline 38 & Masculino & 0,20 & 1,00 \\
\hline
\end{tabular}

NOTA: Median Log R Deviation - Medida que estima o ruído das sondas nos dados Log R Ratio (gráficos de CNVs), sendo que o valor esperado em um bom experimento de array é < 0,2; Median Call Rate - Medida que estima o desempenho do genótipo representado, assim o valor esperado em um bom experimento de array varia entre 0,98 e 1,00. 


\section{ANEXO E}

Quadro 2 - Variantes (> $18 \mathrm{~kb}$ ) detectadas no sequenciamento completo do exoma, que apresentaram equivalência no array (continuação)

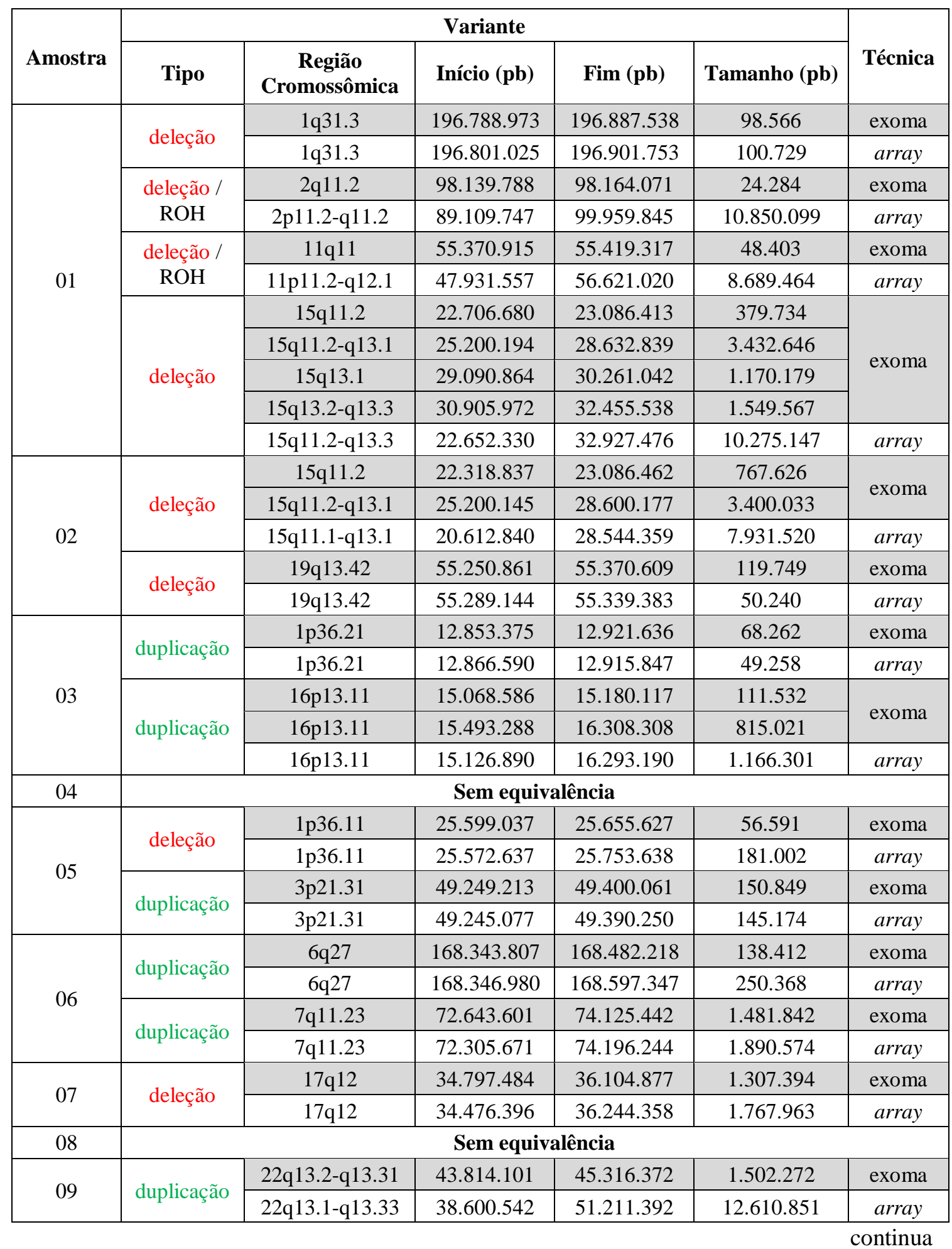


Quadro 2 - Variantes (> $18 \mathrm{~kb}$ ) detectadas no sequenciamento completo do exoma, que apresentaram equivalência no array (continuação)

\begin{tabular}{|c|c|c|c|c|c|c|}
\hline \multirow[b]{2}{*}{ Amostra } & \multicolumn{5}{|c|}{ Variante } & \multirow[b]{2}{*}{ Técnica } \\
\hline & Tipo & $\begin{array}{c}\text { Região } \\
\text { Cromossômica }\end{array}$ & Início (pb) & Fim (pb) & Tamanho (pb) & \\
\hline \multirow{6}{*}{10} & \multirow{2}{*}{ deleção } & $1 \mathrm{q} 42.12$ & 225.195 .114 & 225.506 .379 & 311.266 & exoma \\
\hline & & $1 \mathrm{q} 42.12$ & 225.191 .852 & 225.508 .712 & 316.861 & array \\
\hline & \multirow{2}{*}{ deleção } & $15 \mathrm{q} 13.2$ & 30.896 .328 & 30.927 .835 & 31.508 & exoma \\
\hline & & $15 \mathrm{q} 13.2$ & 30.657 .952 & 31.089 .526 & 431.575 & array \\
\hline & \multirow{2}{*}{ deleção } & $19 q 13.41$ & 52.852 .424 & 52.909 .898 & 57.475 & exoma \\
\hline & & $19 q 13.41$ & 52.815 .890 & 52.925 .784 & 109.895 & array \\
\hline \multirow{5}{*}{11} & \multirow{3}{*}{$\begin{array}{c}\text { deleção / } \\
\text { ROH }\end{array}$} & $2 q 11.2$ & 98.127 .600 & 98.162 .324 & 34.725 & \multirow{2}{*}{ exoma } \\
\hline & & $2 \mathrm{q} 21.1$ & 131.381 .636 & 131.415 .450 & 33.815 & \\
\hline & & $2 \mathrm{p} 25.3-\mathrm{q} 37.3$ & 14.238 & 243.048 .760 & 243.034 .523 & array \\
\hline & \multirow{2}{*}{ duplicação } & $10 \mathrm{q} 26.3$ & 135.267 .501 & 135.439 .108 & 171.608 & exoma \\
\hline & & $10 \mathrm{q} 26.3$ & 135.256 .762 & 135.378 .802 & 122.041 & array \\
\hline \multirow{3}{*}{12} & \multirow{3}{*}{ deleção } & $22 q 11.21$ & 18.726 .981 & 20.378 .972 & 1.651 .992 & \multirow{2}{*}{ exoma } \\
\hline & & $22 q 11.21$ & 20.723 .718 & 21.563 .035 & 839.318 & \\
\hline & & $22 q 11.21$ & 18.640 .300 & 21.463 .730 & 2.823 .431 & array \\
\hline \multirow{4}{*}{13} & \multirow{2}{*}{ duplicação } & $12 \mathrm{p} 13.31$ & 8.015 .964 & 8.090 .979 & 75.016 & exoma \\
\hline & & $12 \mathrm{p} 13.31$ & 8.003 .758 & 8.114 .429 & 110.672 & array \\
\hline & \multirow{2}{*}{ duplicação } & $19 \mathrm{q} 13.2-\mathrm{q} 13.31$ & 43.358 .012 & 43.530 .542 & 172.531 & exoma \\
\hline & & $19 \mathrm{q} 13.2-\mathrm{q} 13.31$ & 43.322 .065 & 43.519 .442 & 197.378 & array \\
\hline 14 & \multicolumn{6}{|c|}{ Sem equivalência } \\
\hline \multirow{5}{*}{15} & \multirow{2}{*}{ deleção } & $2 q 13$ & 110.849 .178 & 110.962 .547 & 113.370 & exoma \\
\hline & & $2 q 13$ & 110.477 .792 & 111.400 .934 & 923.143 & array \\
\hline & \multirow{3}{*}{ deleção } & $10 \mathrm{q} 26.2$ & 127.668 .398 & 129.923 .933 & 2.255 .536 & \multirow{2}{*}{ exoma } \\
\hline & & $10 \mathrm{q} 26.3$ & 131.506 .157 & 135.440 .246 & 3.934 .089 & \\
\hline & & $10 \mathrm{q} 26.2-\mathrm{q} 26.3$ & 127.656 .067 & 135.477 .883 & 7.821 .817 & array \\
\hline 16 & \multicolumn{6}{|c|}{ Sem equivalência } \\
\hline 17 & \multicolumn{6}{|c|}{ Sem equivalência } \\
\hline 18 & \multicolumn{6}{|c|}{ Sem equivalência } \\
\hline \multirow{4}{*}{19} & delec ̃̃ & $1 \mathrm{p} 36.21$ & 12.853 .375 & 12.953 .374 & 100.000 & exoma \\
\hline & deleçao & $1 \mathrm{p} 36.21$ & 12.852 .872 & 12.915 .847 & 62.976 & array \\
\hline & & $1 \mathrm{q} 23.3$ & 161.487 .763 & 161.565 .521 & 77.759 & exoma \\
\hline & deleção & $1 \mathrm{q} 23.3$ & 161.482 .520 & 161.646 .379 & 163.860 & array \\
\hline & & $5 q 35.2-q 35.3$ & 175.906 .174 & 176.932 .113 & 1.025 .940 & exoma \\
\hline & duplicação & $5 q 35.2-q 35.3$ & 175.893 .576 & 176.929 .974 & 1.036 .399 & array \\
\hline 20 & & $10 \mathrm{q} 26.3$ & 135.267 .485 & 135.381 .843 & 114.359 & exoma \\
\hline 20 & duplicaçao & $10 \mathrm{q} 26.3$ & 135.256 .762 & 135.358 .664 & 101.903 & array \\
\hline & delec ̃̃ & $14 \mathrm{q} 11.2$ & 20.215 .585 & 20.404 .763 & 189.179 & exoma \\
\hline & deleçao & $14 \mathrm{q} 11.2$ & 19.327 .823 & 20.347 .564 & 1.019 .742 & array \\
\hline 21 & & & Sem equiv & lência & & \\
\hline
\end{tabular}


Quadro 2 - Variantes (> $18 \mathrm{~kb}$ ) detectadas no sequenciamento completo do exoma, que apresentaram equivalência no array (continuação)

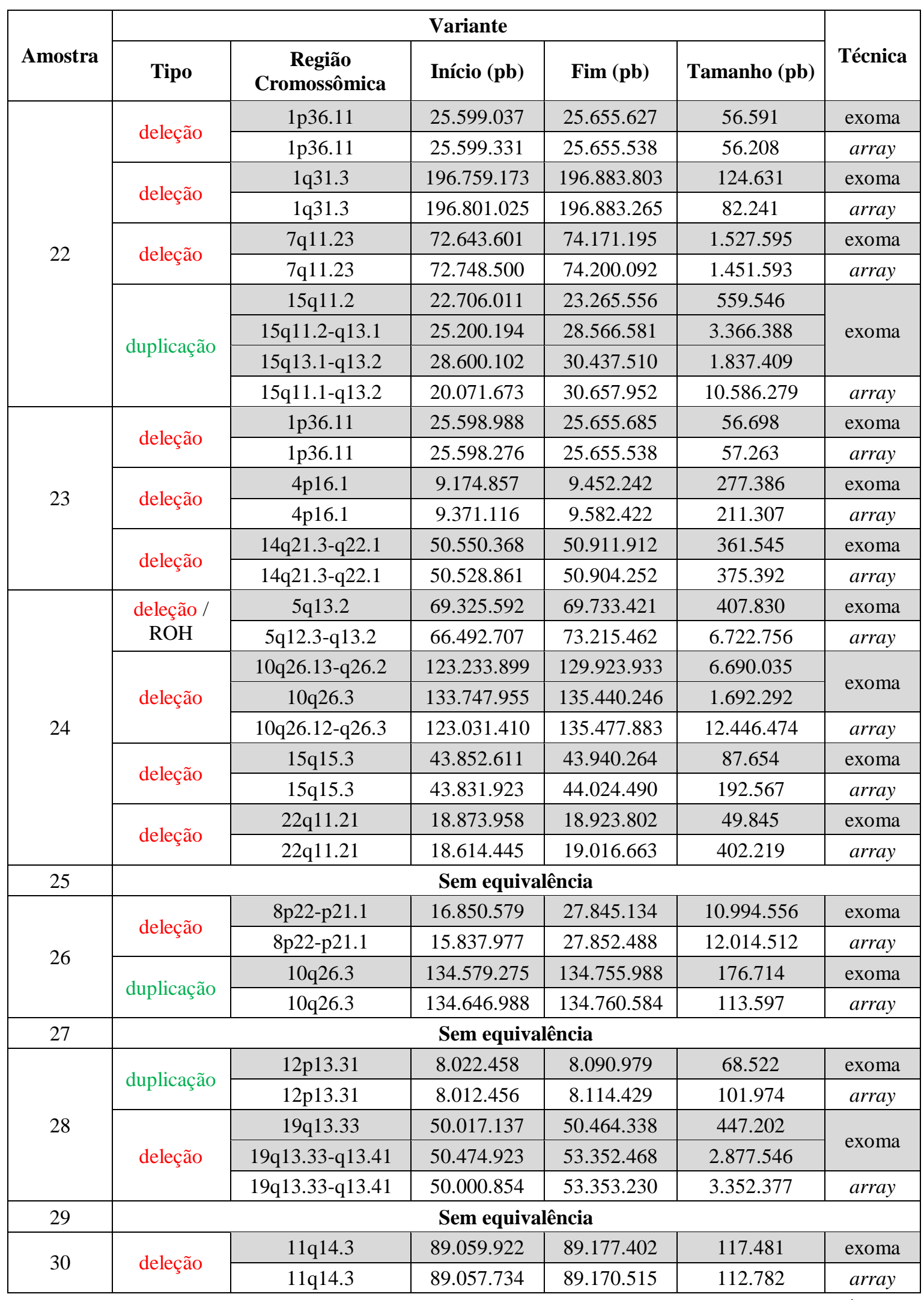

continua 
Quadro 2 - Variantes (> $18 \mathrm{~kb}$ ) detectadas no sequenciamento completo do exoma, que apresentaram equivalência no array (conclusão)

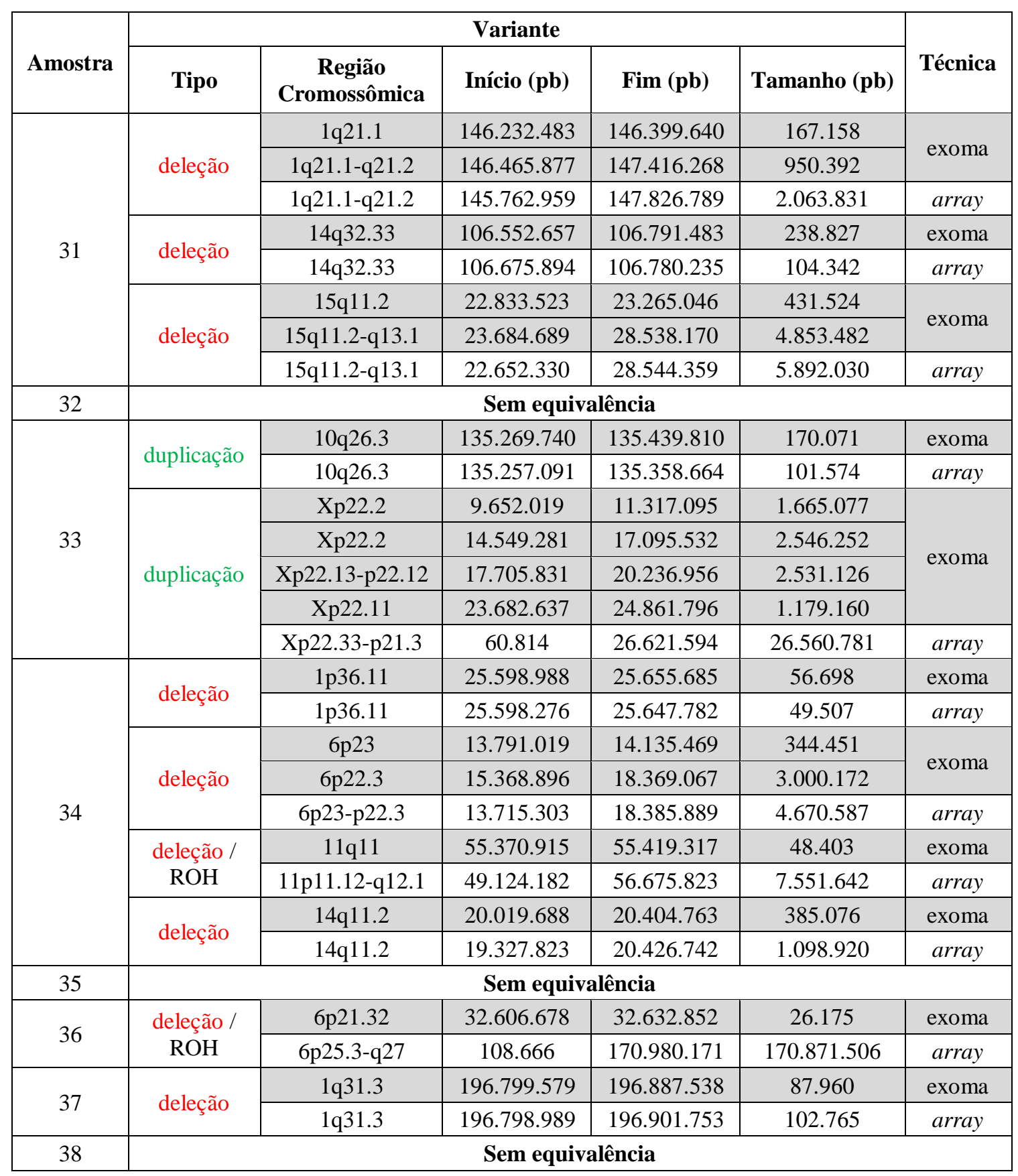




\begin{abstract}
ANEXO F
Descrição, por amostra, das CNVs patogênicas detectadas pelo sequenciamento completo do exoma e pelo array
\end{abstract}

\title{
* Amostra 01:
}

$\mathrm{Na}$ avaliação da amostra 01, pelo sequenciamento do exoma, foram encontradas quatro deleções envolvendo o braço longo do cromossomo 15:

- 15q11.2 (22.706.680 pb - 23.086.413 pb): 380 kb de tamanho.

- 15q11.2-q13.1 (25.200.194 pb - 28.632.839 pb): 3,4 Mb de tamanho.

- 15q13.1 (29.090.864 pb - 30.261.042 pb): 1,2 Mb de tamanho.

- 15q13.2-q13.3 (30.905.972 pb - 32.455.538 pb): 1,5 Mb de tamanho.

Essas deleções estavam separadas por intervalos genômicos de cerca de $2 \mathrm{Mb}$ (38 genes), $458 \mathrm{~kb}$ (23 genes) e $645 \mathrm{~kb}$ (26 genes), respectivamente. Assim o sequenciamento do exoma deveria ter considerado uma deleção única nesta região, sem falhas.

Já na técnica de array foi visualizada uma deleção de cerca de $10 \mathrm{Mb}$ envolvendo o cromossomo 15q11.2-q13.3. Esta deleção iniciou em 22.652.330 pb e terminou em 32.927.476 pb, assim foi possível notar que o array foi mais preciso na identificação de uma deleção única.

Além disso, o ponto de quebra (PQ) genômico inicial determinado pelo array começou antes e o PQ final terminou depois dos pontos identificados pelo exoma, sendo que o conteúdo genômico entre os PQs iniciais do array e exoma apresentou ausência de genes, justificando, assim, a melhor caracterização pelo array. Porém o conteúdo genômico entre os PQs finais apresentou 16 genes e deveria ter sido mais bem identificado pelo sequenciamento do exoma, ficando mais próximo do PQ reconhecido pelo array.

Em relação ao diagnóstico, este foi conclusivo, já que o paciente apresentou ADNPM, encefalopatia epiléptica, além de desvios fenotípicos, compatível com a síndrome de Angelman (OMIM \#105830).

Adicionalmente, foi realizado um estudo complementar do padrão de metilação da região crítica de Prader-Willi/Angelman, que mostrou padrão típico da síndrome de 
Angelman, indicando que a deleção tem origem materna.

\section{* Amostra 02:}

No estudo da amostra 02 , pelo sequenciamento do exoma, foram observadas duas deleções envolvendo o braço longo do cromossomo 15:

- 15q11.2 (22.318.837 pb - 23.086.462 pb): 768 kb de tamanho.

- 15q11.2-q13.1 (25.200.145 pb - 28.600.177 pb): 3,4 Mb de tamanho.

Essas deleções estavam separadas por um intervalo genômico de cerca de $2,1 \mathrm{Mb}$ (38 genes), sendo que o exoma deveria ter considerado uma deleção única nesta região.

Na técnica de array foi observada uma deleção no cromossomo 15q11.1-q13.1 ( 8 Mb de tamanho), que iniciou em 20.612.840 pb e terminou em 28.544.359 pb, ou seja, o array foi mais preciso na identificação de uma deleção única.

Em relação ao PQ inicial, foi observada uma diferença de 1,7 Mb entre o detectado pelo array e o detectado pelo exoma, sendo que o sequenciamento do exoma deveria ter identificado um início anterior para esta deleção. A respeito do PQ final, tanto o detectado pelo array quanto pelo exoma estavam muito próximos (diferença de $56 \mathrm{~kb}$ ), sendo que o PQ do array teve uma localização anterior devido à ausência de sondas presentes posteriormente até ao PQ do exoma (próxima sonda localizada em 28.924.405), ou seja, o PQ final foi redefinido pelo sequenciamento do exoma.

O diagnóstico, então, foi conclusivo e relacionado com a síndrome de Prader-Willi (OMIM \#176270), sendo que o paciente apresentou atraso no desenvolvimento neuromotor, hipotonia global com reflexos presentes e déficit de sucção.

Adicionalmente, foi realizado um estudo complementar do padrão de metilação da região crítica de Prader-Willi/Angelman, que mostrou padrão típico da síndrome de Prader-Willi, indicando que a deleção tem origem paterna.

\section{* Amostra 03:}

Nesta amostra foram visualizadas, pelo sequenciamento do exoma, duas duplicações envolvendo o cromossomo 16 :

- 16p13.11 (15.068.586 pb - 15.180.117 pb): 111 kb de tamanho. 
- 16p13.11 (15.493.288 pb - 15.308.308 pb): 815 kb de tamanho.

As duplicações apresentaram-se separadas por 313 kb e 6 genes, assim o exoma poderia ter apontado como uma variante única.

O array identificou uma duplicação no cromossomo 16p13.11 (15.126.890 pb 16.293.190 pb), porém com um tamanho de $\sim 1,2 \mathrm{Mb}$, bem maior que a soma das duas duplicações observadas no exoma.

Porém o PQ inicial do exoma foi ligeiramente anterior ao do array, que poderia ter iniciado em 15.092.778 pb por conter uma sonda nessa região. Mas, mesmo assim, o exoma redefiniu o PQ inicial da duplicação.

Em relação ao diagnóstico, este foi conclusivo, sendo que a paciente apresentou características fenotípicas relacionadas com a duplicação 16p13.11, dentre elas ADNPM, epilepsia e alguns dismorfismos.

\section{* Amostra 04:}

$\mathrm{Na}$ avaliação da amostra 04, pelo sequenciamento do exoma, foi encontrada uma duplicação envolvendo o cromossomo 10q24.32, que foi excluída inicialmente da análise por apresentar um score abaixo do limiar estipulado, porém na análise final esse dado foi considerado, pois explicava o quadro clínico do paciente. Essa variante apresentou PQ iniciando em 103.298.050 pb e terminando em 103.384.567 pb.

Pela técnica de array também foi observada uma duplicação nesta região, que iniciou em 102.934.720 pb e terminou em 103.338.008 pb, englobando $403 \mathrm{~kb}$ do cromossomo 10q24.31-q24.32.

Assim o PQ genômico inicial determinado pelo array começou antes da localização identificada pelo exoma, e o PQ final determinado exoma terminou depois da localização vista pelo array, sendo que entre essas posições existiam diversas sondas de array que não estavam duplicadas.

Com esta avaliação foi possível concluir que a duplicação estava relacionada com a clínica de ectrodactilia observada no paciente, explicando a ocorrência do quadro clínico alterado. Assim o diagnóstico foi relacionado com a ectrodactia 3 (OMIM \#246560), que apresenta herança autossômica dominante. 


\section{* Amostra 06:}

Nesta amostra foi observada, pelo sequenciamento do exoma, uma duplicação de aproximadamente 1,5 Mb envolvendo o cromossomo 7q11.23. Esta duplicação iniciou em 72.643.601 pb e terminou em 74.125.442 pb.

O array identificou a mesma duplicação, porém com um tamanho maior: - 7q11.23 (72.305.671 pb - 74.196.244 pb): 1,9 Mb de tamanho.

Analisando os resultados obtidos por ambas as técnicas foi concluído que provavelmente o exoma deveria ter identificado melhor os PQs inicial e final, já que são regiões ricas em genes.

Em relação ao diagnóstico, este foi conclusivo, já que o paciente apresentou deficiência intelectual leve, dificuldade de aprendizado e hipoplasia cerebelar, compatível com a síndrome da duplicação da região de Williams-Beuren (OMIM \#609757).

\section{* Amostra 07:}

A amostra 07 apresentou uma deleção no cromossomo 17q12 visualizada tanto no sequenciamento do exoma como no array, sendo que esta variante estava localizada no exoma em 34.797.484 pb até 36.104.877 pb ( 1,3 Mb), um pouco menor que a do array que estava localizada em 34.476.396 pb até 36.244.358 pb ( 1,8 Mb).

Assim os PQs foram mais bem determinados pela técnica de array, já que entre os PQs iniciais e finais visto pelo exoma e pelo array havia alguns genes com várias regiões exônicas.

Mesmo com essas pequenas alterações dos PQs foi possível definir um diagnóstico citogenômico para o paciente, que tinha déficit cognitivo, baixa estatura, diabetes precoce não insulinodependente, redução de dimensões pancreáticas, nefropatia e anemia refratária. Essas características clínicas permitiram a classificação da variante como patogênica, sendo atribuída a síndrome da deleção 17q12 (OMIM \#614527). 


\section{* Amostra 09:}

$\mathrm{Na}$ avaliação da amostra 09, pelo sequenciamento do exoma, foi encontrada uma duplicação de 1,5 Mb envolvendo o cromossomo 22q13.2-q13.31. Essa variante apresentou PQ iniciando em 43.814.101 pb e terminando em 45.316.372 pb.

Pela técnica de array foi observada uma duplicação bem maior envolvendo a região 22q13.1-q13.33, sendo que ela teve início em 38.600.542 pb e término em 51.211.392 pb, englobando 12,6 Mb da parte distal braço longo do cromossomo 22.

Assim o array redefiniu os PQs para mais de $5 \mathrm{Mb}$ além do indicado pelo sequenciamento do exoma.

Para este caso, o diagnóstico citogenômico da síndrome da duplicação 22q13 (OMIM \#615538) foi estabelecido, considerando que a paciente apresentou ADNPM, hipotonia, déficit pôndero-estatural e desvios fenotípicos.

\section{* Amostra 12:}

$\mathrm{Na}$ avaliação da amostra 12, por meio da técnica de exoma, foram encontradas duas deleções envolvendo o braço longo do cromossomo 22:

- 22q11.21 (18.726.981 pb - 20.378.972 pb): 1,6 Mb de tamanho.

- 22q11.21 (20.723.718 pb - 21.563.035 pb): 0,8 Mb de tamanho.

Essas deleções estavam separadas por um intervalo genômico de cerca de $345 \mathrm{~kb}$ (14 genes), sendo que neste intervalo não havia sondas de array para a avaliação.

$\mathrm{Na}$ técnica de array foi visualizada uma deleção única de cerca de 2,8 $\mathrm{Mb}$ envolvendo a mesma região cromossômica. Esta deleção iniciou em 18.640.300 pb e terminou em $21.463 .730 \mathrm{pb}$.

Os PQs genômicos inicial e final determinados pelo array começou e terminou antes dos PQs vistos pelo exoma. Assim o exoma deveria ter identificado um início anterior para a variante, porém com esta técnica foi possível delinear melhor o PQ final da deleção.

Em relação ao diagnóstico foi atribuído a síndrome da deleção 22q11.2 (OMIM \#611867), sendo que o paciente apresentou ADNPM, epilepsia, heterotopia subependimária, atraso de linguagem e dismorfismos faciais. 


\section{* Amostra 15:}

No estudo da amostra 15, pelo sequenciamento do exoma, foram observadas duas deleções envolvendo o braço longo do cromossomo 10:

- 10q26.2 (127.668.398 pb - 129.923.933 pb): 2,3 Mb de tamanho.

- 10q26.3 (131.506.157 pb - 135.440.246 pb): 3,9 Mb de tamanho.

Essas deleções estavam separadas por um intervalo genômico de cerca de 1,6 Mb com apenas 3 genes, porém o exoma deveria ter considerado estas variantes como uma deleção única.

Na técnica de array foi observada uma deleção no cromossomo 10q26.2-q26.3 ( 7,8 Mb de tamanho), que iniciou em 127.656.067 pb e terminou em 135.477.883 pb, ou seja, o array foi mais preciso na identificação de uma deleção única, sendo que na região de falha do exoma havia 605 sondas de array.

Em relação ao PQ inicial foi observada uma diferença de $12 \mathrm{~kb}$ entre o detectado na técnica de array e o detectado no exoma, e no PQ final o tamanho dessa diferença foi de quase $38 \mathrm{~kb}$. Vale ressaltar que entre os pontos detectados por ambas as técnicas não havia genes ou havia apenas um íntron, sendo assim o array definiu os PQs com uma maior precisão.

O diagnóstico, então, foi conclusivo e relacionado com a síndrome da deleção 10q26 (OMIM \#609625), sendo que a paciente apresentou ADNPM e transtorno do déficit de atenção e hiperatividade.

\section{* Amostra 20:}

Nesta amostra foi observada, pelo sequenciamento do exoma, uma duplicação de cerca de $1 \mathrm{Mb}$ envolvendo o cromossomo 5q35.2-q35.3. Esta duplicação iniciou em 175.906.174 pb e terminou em $176.932 .113 \mathrm{pb}$.

O array identificou a mesma duplicação: - 5q35.2-q35.3 (175.893.576 pb - 176.929.974 pb): 1 Mb de tamanho.

Analisando os resultados obtidos por ambas as técnicas, foi concluído que o array delineou melhor o PQ inicial, já que era uma região intrônica, e assim sem cobertura pelo exoma. Já o PQ final provavelmente foi mais bem delimitado pelo exoma já que a região 
é rica em éxons, mas vale ressaltar que havia mais duas sondas de array até a localização dada pelo exoma e estas não estavam alteradas.

Para este caso, o diagnóstico foi relacionado com a duplicação 5q35.2-q35.3 e a paciente tinha como características fenotípicas baixa estatura, pescoço curto e pterigium coli.

\section{* Amostra 22:}

O paciente 22 foi o único da casuística que apresentou duas variantes patogênicas concomitantes, sendo que ele manifestou alterações clínicas que se sobrepuseram dificultando a suspeita diagnóstica.

$\mathrm{Na}$ análise da primeira variante, pelo sequenciamento do exoma foi encontrada uma deleção de 1,5 Mb envolvendo o cromossomo 7q11.23. Essa variante apresentou PQ iniciando em 72.643.601 pb e terminando em 74.171.195 pb.

Por meio da técnica de array foi observada a mesma deleção envolvendo a região 7q11.23, porém com o tamanho um pouco menor. Essa deleção teve início em 72.748.500 pb e término em 74.200.092 pb (1,45 Mb de tamanho).

Avaliando os resultados de ambas as técnicas foi deduzido que o exoma estreitou melhor o PQ inicial, considerando que a região apresentava vários éxons, porém havia cinco sondas de array que deveriam estar alteradas para que os PQs das técnicas correspondessem. Em relação ao PQ final, o array delineou melhor a localização, sendo que o exoma deveria ter identificado uma localização final posterior.

A segunda variante visualizada no genoma deste paciente foram três duplicações no cromossomo $15 \mathrm{q}$, visualizadas por meio da técnica do sequenciamento do exoma:

- 15q11.2 (22.706.011 pb - 23.265.556 pb): 560 kb de tamanho.

- 15q11.2-q13.1 (25.200.194 pb - 28.566.581 pb): 3,4 Mb de tamanho.

- 15q13.1-q13.2 (28.600.102 pb - 30.437.510 pb): 1,8 Mb de tamanho.

Essas duplicações estavam separadas por intervalos genômicos de aproximadamente $1,9 \mathrm{Mb}$ (28 genes) e $33 \mathrm{~kb}$ (4 genes), respectivamente. Assim o sequenciamento do exoma deveria ter considerado uma duplicação única nesta região, sem falhas.

$\mathrm{Na}$ técnica de array foram visualizadas duas duplicações, uma de 10,6 Mb de tamanho e correspondente à duplicação encontrada pelo exoma, porém com quatro cópias genômicas, e outra com 1,6 Mb de tamanho e com três cópias genômicas: 
- 15q11.1-q13.2 (20.071.673 pb - 30.657.952 pb): 10,6 Mb de tamanho.

- 15q13.2-q13.3 (30.936.285 pb - 32.514.341 pb): 1,6 Mb de tamanho.

Essas duas duplicações só estavam separadas devido ao número de cópias diferentes entre elas, sendo que não foi observada nenhuma sonda de array que separasse os PQs. Assim foi possível notar que o array identificou, além da variação no número de cópias diferente no exoma (três cópias no exoma referiu-se a quatro cópias no array), uma variante de tamanho muito superior à observada pelo sequenciamento do exoma.

Este paciente apresentou como características principais atraso global de desenvolvimento, hipotonia, agenesia parcial de corpo caloso e dismorfismos faciais, sendo que o diagnóstico molecular foi considerado a síndrome de Williams-Beuren (OMIM \#194050) concomitante com a síndrome da duplicação 15q11-q13 (OMIM \#608636).

\section{* Amostra 24:}

$\mathrm{Na}$ avaliação da amostra 24, por meio da técnica de exoma, foram encontradas duas deleções envolvendo o braço longo do cromossomo 10:

- 10q26.13-q26.2 (123.233.899 pb - 129.923.933 pb): 6,7 Mb de tamanho.

- 10q26.3 (133.747.955 pb - 135.440.246 pb): 1,7 Mb de tamanho.

Essas variantes estavam separadas por um intervalo genômico de aproximadamente 3,8 Mb (17 genes), dessa forma o exoma deveria ter considerado como uma deleção única.

Na técnica de array foi visualizada uma deleção única de cerca de $12,4 \mathrm{Mb}$, com início em 123.031.410 pb e término em 135.477 .883 pb.

Os PQs genômicos inicial e final foram mais bem identificados por meio da técnica de array, pois eram regiões intrônicas ou sem genes.

Em relação ao diagnóstico foi atribuída a síndrome da deleção 10q26 (OMIM \#609625), sendo que a paciente apresentou ADNPM, microcefalia, déficit pônderoestatural e alteração de nervo óptico.

\section{* Amostra 26:}

Nesta amostra foi observada, pelo sequenciamento do exoma, uma deleção de quase 
$11 \mathrm{Mb}$ envolvendo o cromossomo 8p22-p21.1. Esta variante iniciou em $16.850 .579 \mathrm{pb}$ e terminou em $27.845 .134 \mathrm{pb}$.

Já o array identificou a deleção na mesma região, porém com PQs diferentes: 15.837.977 pb - 27.852.488 pb ( 12 Mb).

Analisando os resultados obtidos por ambas as técnicas, foi concluído que o array delineou melhor o PQ inicial e final, considerando que até o início e o fim da localização determinada por esta técnica havia genes com regiões exônicas.

Para este caso o diagnóstico foi da deleção intersticial 8p e o paciente tinha como características fenotípicas atraso de crescimento intrauterino, artrogripose distal, cardiopatia, restrição a abertura bucal, criptorquidia e hipospádia.

\section{* Amostra 28:}

Nesta amostra foram visualizadas, pelo sequenciamento do exoma, duas deleções envolvendo o cromossomo 19:

- 19q13.33 (50.017.137 pb - 50.464.338 pb): 447 kb de tamanho.

- 19q13.33-q13.41 (50.474.923 pb - 53.352.468 pb): 2,9 Mb de tamanho.

As duplicações apresentaram-se separadas por 10,6 kb e 2 genes, assim o exoma poderia ter apontado como uma variante única.

O array identificou uma deleção no cromossomo 19q13.33-q13.41 (50.000.854 pb - 53.353.230 pb), porém com um tamanho de $\sim 3,3 \mathrm{Mb}$, maior que a soma das duas deleções observadas no exoma.

O PQ inicial do exoma foi ligeiramente posterior ao do array, dessa forma o array identificou mais precisamente o PQ inicial. Além disso, o PQ final, localizado pelo array, estava presente em uma região intrônica, impossibilitando a sua correta identificação pelo exoma.

Em relação ao diagnóstico, este foi conclusivo e relacionado com a deleção do cromossomo 19q13, que são raras e não há na literatura, até o momento, um fenótipo característico bem delineado, sendo associado com alterações do neurodesenvolvimento.

O paciente foi encaminhado com suspeita da síndrome Cat eye, sendo que não foi encontrada nenhuma evidência de variante nessa região. 


\section{* Amostra 31:}

No caso 31 foram visualizadas, pelo sequenciamento do exoma, duas deleções: - 15q11.2 (22.833.523 pb - 23.265.046 pb): 431 kb de tamanho. - 15q11.2-q13.1 (23.684.689 pb - 28.538.170 pb): 4,9 Mb de tamanho.

Já pelo array foi identificada uma deleção única: - 15q11.2-q13.1 (22.652.330 pb - 28.544.359 pb): 5,9 Mb de tamanho.

Analisando estes resultados, na região entre as duas deleções detectadas no exoma havia cerca de 15 genes e cobertura de 6 sondas de array, portanto o exoma provavelmente falhou ao detectar duas variantes distintas e não uma.

Além disso, o exoma deveria ter tido um PQ inicial anterior e correspondente ao detectado pelo array, visto que a região é rica em genes. Já na região entre os PQ final de ambas as técnicas só estava presente um íntron, e, dessa forma, o array representou melhor o término dessa deleção.

Assim o diagnóstico molecular foi estabelecido como a síndrome de Angelman (OMIM \#105830), considerando as características clínicas da paciente: dificuldade para ganho de peso e refluxo gastroesofágico, e o estudo de metilação realizado para a elucidação da origem da deleção.

\section{* Amostra 33:}

No estudo da amostra 33, pelo sequenciamento do exoma, foram observadas quatro duplicações envolvendo o braço curto do cromossomo X:

- Xp22.2 (9.652.019 pb - 11.317.095 pb): 1,7 Mb de tamanho.

- Xp22.2 (14.549.281 pb - 17.095.532 pb): 2,5 Mb de tamanho.

- Xp22.13-p22.12 (17.705.831 pb - 20.236.956 pb): 2,5 Mb de tamanho.

- Xp22.11 (23.682.637 pb - 24.861.796 pb):1,2 Mb de tamanho.

Essas duplicações estavam separadas por intervalos genômicos de aproximadamente 3,2 Mb (31 genes), $610 \mathrm{~kb}$ (7 genes) e 3,4 Mb (19 genes), respectivamente. Assim o sequenciamento do exoma deveria ter considerado essas variantes como uma única, sem falhas.

Já na técnica de array foi visualizada uma duplicação de cerca de 26,6 Mb 
envolvendo a porção terminal do cromossomo Xp22.33-p21.3. Esta duplicação iniciou em 60.814 pb e terminou em 26.621 .594 pb, assim foi possível notar que o array foi mais preciso na identificação de uma única duplicação. Vale ressaltar que nas áreas de falha do exoma (regiões normais entre as duplicações) a cobertura pelas sondas de array era elevada $(668,142$ e 892 sondas, respectivamente).

Em relação ao PQ inicial foi observada uma diferença de 9,6 Mb entre o detectado na técnica de array e o detectado no exoma. Grande parte dessa região compreende a extensão pseudo-autossômica do cromossomo Xp, assim umas das limitações do exoma foi a identificação dessas áreas.

O PQ final também foi mais bem delimitado por meio do array, visto que entre o PQ do exoma e do array havia um tamanho genômico correspondente a 1,8 Mb, além de várias regiões exônicas e cobertura de 191 sondas de array.

O diagnóstico, então, foi conclusivo e relacionado com a duplicação Xp22-p21, sendo que o paciente apresentou ADNPM, déficit de crescimento, cardiopatia, criptorquidia e dismorfismos.

\section{* Amostra 34:}

No estudo do caso 34, pelo sequenciamento do exoma, foram observadas duas deleções envolvendo o braço curto do cromossomo 6:

- 6p23 (13.791.019 pb - 14.135.469 pb): 344 kb de tamanho.

- 6p22.3 (15.368.896 pb - 18.369.067 pb): 3 Mb de tamanho.

Essas deleções estavam separadas por um intervalo genômico normal de cerca de 1,2 $\mathrm{Mb}$, que deveria estar alterado.

$\mathrm{Na}$ avaliação por meio da técnica de array foi identificada uma deleção intersticial de aproximadamente 4,7 Mb no cromossomo 6p23-p22.3, que teve início em 13.715.303 pb e término em $18.385 .889 \mathrm{pb}$, assim o array foi mais preciso na identificação de uma única deleção.

Os PQs inicial e final foram definidos mais precisamente pelo array devido às características genômicas de ausência de éxons na região.

Deleções intersticiais no cromossomo 6p são raras e já foram descritas em indivíduos com graus variáveis de comprometimento clínico, mas sem um fenótipo clínico 
característico. Dessa forma este diagnóstico foi relacionado com a deleção do cromossomo 6p23-p22, sendo que o paciente apresentou ADNPM e dismorfismos faciais. 


\section{ANEXO G \\ Descrição, por amostra, das ROHs detectadas apenas pelo array}

\section{* Amostra 11:}

$\mathrm{Na}$ amostra 11, pela técnica de array, foi observada uma ROH que envolvia o cromossomo 2 inteiro:

- 2p25.3-q37.3 (14.238 pb - 243.048.760 pb): 243 Mb de tamanho.

$\mathrm{Na}$ técnica de sequenciamento do exoma não foi possível visualizar essa $\mathrm{ROH}$, pois o ExomeDepth ${ }^{\circledR}$ não identifica essa característica genômica de homozigosidade. Porém na análise preliminar foi possível visualizar que todas as variantes de ponto presentes nas regiões sequenciadas do cromossomo 2 estavam em homozigose, e assim suspeitar que os cromossomos 2 eram iguais.

Então foi concluído que, nesta paciente, ocorreu uma isodissomia uniparental no cromossomo 2 (dois cromossomos 2 idênticos provenientes de mesmo genitor), sendo que provavelmente variantes em homozigose estejam causando o fenótipo relacionado com atraso do desenvolvimento, seguido por deterioração motora, ataxia e espasticidade.

Vale ressaltar que o cromossomo 2 possui cerca de 1400 genes, sendo que até o momento muitos destes genes não possuem função conhecida e não há evidências de imprinting genômico nesse cromossomo.

\section{* Amostra 13:}

A amostra 13 apresentou uma $\mathrm{ROH}$ de aproximadamente $19 \mathrm{Mb}$ envolvendo o cromossomo 14q11.2-q21.1 (19.327.823 pb - 38.483.515 pb) visualizada apenas por meio da técnica de array.

Na ausência de consanguinidade foi sugerida a possibilidade de UPD, sendo que não foram identificadas SNVs ou InDels patogênicas em homozigose em genes que tenham função conhecida.

Adicionalmente, o cromossomo 14 apresenta uma região sujeita a imprinting 
genômico, localizada em 14q32, que é associada às síndromes de Temple (quando o material genético desta região é exclusivamente materno) e de Kagami-Ogata (quando o material genético desta região é exclusivamente paterno). Assim a ROH pode sinalizar a existência de uma UPD, com uma região isodissômica que se estendeu por $19 \mathrm{Mb}$, sendo o restante do braço longo do cromossomo 14 (69 Mb) supostamente heterodissômico.

Esta paciente apresentava como características clínicas ADNPM, aumento da translucência nucal, alterações esqueléticas, incluindo tórax em sino e artrogripose, alteração hepática e renal, além de dismorfismos, sendo provavelmente relacionada com a síndrome Kagami-Ogata.

Porém foi sugerido o estudo de metilação para a identificação exata da síndrome, combinada com a análise de marcadores microssatélites para a investigação da origem parental do cromossomo 14.

\section{* Amostra 36:}

No paciente 36 foi visualizada uma $\mathrm{ROH}$ por meio da técnica de array, que estava presente no cromossomo 6p25.3-q27. Esta característica genômica iniciou em 108.666 $\mathrm{pb}$ e terminou em $170.980 .171 \mathrm{pb}$, apresentando um tamanho de aproximadamente 171 $\mathrm{Mb}$.

O paciente apresentou como fenótipo clínico ADNPM, hipotonia, dismorfismos, criptorquidismo e cabelos acinzentados, sendo que a partir dessas observações e com a incorporação de novas informações atualizadas sobre genes foi concluído que a SNV Chr6:105.224.952G>T, localizada no gene HACE1 era patogênica.

Assim, com a $\mathrm{ROH}$, foi possível suspeitar que havia nessa região alguma variante de ponto recessiva relacionada com o fenótipo do paciente. 


\section{REFERÊNCIAS}

Alkan C, Coe BP, Eichler EE. Genome structural variation discovery and genotyping. Nat Rev Genet. 2011;12:363-76.

Alkuraya FS. Homozygosity mapping: one more tool in the clinical geneticist`s toolbox. Genet Med. 2010;12:236-9.

Al-Nabhani M, Al-Rashdi S, AL-Murshedi F, Al-Kindi A, Al-Thihli K, Al-Saegh A, AlFutaisi A, Al-Mamari W, Zadjali F, Al-Maawali A. Reanalysis of exome sequencing data of intellectual disability samples: yields and Benefits. Clin Genet. 2018;94:495-501.

Bamshad MJ, Ng SB, Bigham AW, Tabor HK, Emond MJ, Nickerson DA, Shendure J. Exome sequencing as a tool for Mendelian disease gene discovery. Nat Rev Genet. 2011;12:745-55.

Bergant G, Maver A, Lovrecic L, Čuturilo G, Hodzic A, Peterlin B. Comprehensive use of extended exome analysis improves diagnostic yield in rare disease: a retrospective survey in 1,059 cases. Genet Med. 2018;20:303-12.

Bruno DL, Ganesamoorthy D, Schoumans J, Bankier A, Coman D, Delatycki M, Gardner RJ, Hunter M, James PA, Kannu P, McGillivray G, Pachter N, Peters H, Rieubland C, Savarirayan R, Scheffer IE, Sheffield L, Tan T, White SM, Yeung A, Bowman Z, Ngo C, Choy KW, Cacheux V, Wong L, Amor DJ, Slater HR. Detection of cryptic pathogenic copy number variations and constitutional loss of heterozygosity using high resolution SNP microarray analysis in 117 patients referred for cytogenetic analysis and impact on clinical practice. J Med Genet. 2009;46:123-31.

Carneiro MO, Russ C, Ross MG, Gabriel SB, Nusbaum C, DePristo MA. Pacific biosciences sequencing technology for genotyping and variation discovery in human data. BMC Genomics. 2012;13:375. 
Chaisson MJ, Huddleston J, Dennis MY, Sudmant PH, Malig M, Hormozdiari F, Antonacci F, Surti U, Sandstrom R, Boitano M, Landolin JM, Stamatoyannopoulos JA, Hunkapiller MW, Korlach J, Eichler EE. Resolving the complexity of the human genome using single-molecule sequencing. Nature. 2015;517:608-11.

Connolly JJ, Glessner JT, Almoguera B, Crosslin DR, Jarvik GP, Sleiman PM, Hakonarson H. Copy number variation analysis in the context of electronic medical records and large-scale genomics consortium efforts. Front Genet. 2014;5:51.

Conrad DF, Pinto D, Redon R, Feuk L, Gokcumen O, Zhang Y, Aerts J, Andrews TD, Barnes C, Campbell P, Fitzgerald T, Hu M, Ihm CH, Kristiansson K, Macarthur DG, Macdonald JR, Onyiah I, Pang AW, Robson S, Stirrups K, Valsesia A, Walter K, Wei J, Wellcome Trust Case Control Consortium, Tyler-Smith C, Carter NP, Lee C, Scherer SW, Hurles ME. Origins and functional impact of copy number variations in the human genome. Nature. 2010;464:704-12.

De Ligt J, Boone PM, Pfundt R, Vissers LE, Richmond T, Geoghegan J, O’Moore K, de Leeuw N, Shaw C, Brunner HG, Lupski JR, Veltman JA, Hehir-Kwa JY. Detection of clinically relevant copy number variants with whole-exome sequencing. Hum Mutat. 2013;34:1439-48.

Edelmann L, Hirschhorn K. Clinical utility of array CGH for the detection of chromosomal imbalances associated with mental retardation and multiple congenital anomalies. Ann N Y Acad Sci. 2009;1151:157-66.

Eldomery MK, Coban-Akdemir Z, Harel T, Rosenfeld JA, Gambin T, Stray-Pedersen A, Küry S, Mercier S, Lessel D, Denecke J, Wiszniewski W, Penney S, Liu P, Bi W, Lalani SR, Schaaf CP, Wangler MF, Bacino CA, Lewis RA, Potocki L, Graham BH, Belmont JW, Scaglia F, Orange JS, Jhangiani SN, Chiang T, Doddapaneni H, Hu J, Muzny DM, Xia F, Beaudet AL, Boerwinkle E, Eng CM, Plon SE, Sutton VR, Gibbs RA, Posey JE, Yang Y, Lupski JR. Lessons learned from additional research analyses of unsolved clinical exome cases. Genome Med. 2017;9:26. 
Emanuel BS, Saitta SC. From microscopes to microarrays: dissecting recurrent chromosomal rearrangements. Nat Rev Gent. 2007;8:869-83.

Fan YS, Ouyang X, Peng J, Sacharow S, Tekin M, Barbouth D, Bodamer O, Yusupov R, Navarrete C, Heller AH, Pena SDJ. Frequent detection of parental consanguinity in children with developmental disorders by a combined CGH and SNP microarray. Mol Cytogenet. 2013;6:38.

Galasso C, Lo-Castro A, El-Malhany N, Curatolo P. "Idiopathic" mental retardation and new chromosomal abnormalities. Ital J Pediatr. 2010;36:17.

Gambin T, Akdemir ZC, Yuan B, Gu S, Chiang T, Carvalho CMB, Shaw C, Jhangiani S, Boone PM, Eldomery MK, Karaca E, Bayram Y, Stray-Pedersen A, Muzny D, Charng WL, Bahrambeigi V, Belmont JW, Boerwinkle E, Beaudet AL, Gibbs RA, Lupski JR. Homozygous and hemizygous CNV detection from exome sequencing data in a Mendelian disease cohort. Nucleic Acids Res. 2017;45:1633-48.

Gijsbers AC, Lew JY, Bosch CA, Schuurs-Hoeijmakers JH, van Haeringen A, den Hollander NS, Kant SG, Bijlsma EK, Breuning MH, Bakker E, Ruivenkamp CA. A new diagnostic workflow for patients with mental retardation and/or multiple congenital abnormalities: test array first. Eur J Hum Genet. 2009;17:1394-402.

Guo Y, Long J, He J, Li CI, Cai Q, Shu XO, Zheng W, Li C. Exome sequencing generates high quality data in non-target regions. BMC Genomics. 2012;13:194.

Guo Y, Sheng Q, Samuels DC, Lehmann B, Bauer JA, Pietenpol J, Shyr Y. Comparative study of exome copy number variation estimation tools using array comparative genomic hybridization as control. Biomed Res Int. 2013;2013:915636.

Hanemaaijer NM, Sikkema-Raddatz B, van der Vries G, Dijkhuizen T, Hordijk R, van Essen AJ, Veenstra-Knol HE, Kerstjens-Frederikse WS, Herkert JC, Gerkes EH, Leegte LK, Kok K, Sinke RJ, van Ravenswaaij-Arts CM. Practical guidelines for interpreting copy number gains detected by high-resolution array in routine diagnostics. Eur J Hum 
Genet. 2012;20:161-5.

Harel T, Lupski JR. Genomic disorders 20 years on-mechanisms for clinical manifestations. Clin Genet. 2018;93:439-49.

Hehir-Kwa JY, Pfundt R, Veltman JA. Exome sequencing and whole genome sequencing for the detection of copy number variation. Expert Rev Mol Diagn. 2015;15:1023-32.

Hong CS, Singh LN, Mullikin JC, Biesecker LG. Assessing the reproducibility of exome copy number variations predictions. Genome Med. 2016;8:82.

Hwang MY, Moon S, Heo L, Kim YJ, Oh JH, Kim YJ, Kim YK, Lee J, Han BG, Kim BJ. Combinatorial approach to estimate copy number genotype using whole-exome sequencing data. Genomics. 2015;105:145-9.

Kadalayil L, Rafiq S, Rose-Zerilli MJ, Pengelly RJ, Parker H, Oscier D, Strefford JC, Tapper WJ, Gibson J, Ennis S, Collins A. Exome sequence read depth methods for identifying copy number changes. Brief Bioinform. 2015;16:380-92.

Kearney HM, Kearney JB, Conlin LK. Diagnostic implications of excessive homozygosity detected by SNP-based microarrays: consanguinity, uniparental disomy, and recessive single-gene mutations. Clin Lab Med. 2011;31:595-613.

Koolen DA, Pfundt R, de Leeuw N, Hehir-Kwa JY, Nillesen WM, Neefs I, Scheltinga I, Sistermans E, Smeets D, Brunner HG, van Kessel AG, Veltman JA, de Vries BB. Genomic microarrays in mental retardation: a practical workflow for diagnostic applications. Hum Mutat. 2009;30:283-92.

Kulikowski LD. Citogenômica aplicada à prática médica. São Paulo: Atheneu; 2013.

LaFramboise T. Single nucleotide polymorphism arrays: a decade of biological, computational and technological advances. Nucleic Acids Res. 2009;37:4181-93. 
Lu YH, Wang BH, Xia W, Mo XB, Wu LF, Zhu XW, He P, Xie FF, Lu X, Deng FY, Lei SF. The distribution and functional relevance analysis of runs of homozygosity (ROHs) in Chinese Han female population. Mol Genet Genomics. 2018;293:197-206.

Manning M, Hudgins L. Array-based technology and recommendations for utilization in medical genetics practice for detection of chromosomal abnormalities. Genet Med. 2010;12:742-5.

Marenne G, Rodríguez-Santiago B, Closas MG, Pérez-Jurado L, Rothman N, Rico D, Pita G, Pisano DG, Kogevinas M, Silverman DT, Valencia A, Real FX, Chanock SJ, Génin E, Malats N. Assessment of copy number variation using the Illumina Infinium 1M SNP-array: a comparison of methodological approaches in the Spanish Bladder Cancer/EPICURO study. Hum Mutat. 2011;32:240-8.

Miller CA, Hampton O, Coarfa C, Milosavljevic A. ReadDepth: a parallel R package for detecting copy number alterations from short sequencing reads. PLoS One. 2011;6:e16327.

Miller DT, Adam MP, Aradhya S, Biesecker LG, Brothman AR, Carter NP, Church DM, Crolla JA, Eichler EE, Epstein CJ, Faucett WA, Feuk L, Friedman JM, Hamosh A, Jackson L, Kaminsky EB, Kok K, Krantz ID, Kuhn RM, Lee C, Ostell JM, Rosenberg C, Scherer SW, Spinner NB, Stavropoulos DJ, Tepperberg JH, Thorland EC, Vermeesch JR, Waggoner DJ, Watson MS, Martin CL, Ledbetter DH. Consensus statement: chromosomal microarray is a first-tier clinical diagnostic test for individuals with developmental disabilities or congenital anomalies. Am J Hum Genet. 2010;86:749-64.

Nam JY, Kim NK, Kim SC, Joung JG, Xi R, Lee S, Park PJ, Park WY. Evaluation of somatic copy number estimation tools for whole-exome sequencing data. Brief Bioinform. 2016;17:185-92.

Plagnol V, Curtis J, Epstein M, Mok KY, Stebbings E, Grigoriadou S, Wood NW, Hambleton S, Burns SO, Thrasher AJ, Kumararatne D, Doffinger R, Nejentsev S. A robust model for read count data in exome sequencing experiments and implications for 
copy number variant calling. Bioinformatics. 2012;28:2747-54.

Redon R, Ishikawa S, Fitch KR, Feuk L, Perry GH, Andrews TD, Fiegler H, Shapero MH, Carson AR, Chen W, Cho EK, Dallaire S, Freeman JL, González JR, Gratacòs M, Huang J, Kalaitzopoulos D, Komura D, MacDonald JR, Marshall CR, Mei R, Montgomery L, Nishimura K, Okamura K, Shen F, Somerville MJ, Tchinda J, Valsesia A, Woodwark C, Yang F, Zhang J, Zerjal T, Zhang J, Armengol L, Conrad DF, Estivill X, Tyler-Smith C, Carter NP, Aburatani H, Lee C, Jones KW, Scherer SW, Hurles ME. Global variation in copy number in the human genome. Nature. 2006;444:444-54.

Salman M, Jhanwar SC, Ostrer H. Will the new cytogenetics replace the old cytogenetics? Clin Genet. 2004;66:265-75.

Samarakoon PS, Sorte HS, Kristiansen BE, Skodje T, Sheng Y, Tjønnfjord GE, Stadheim B, Stray-Pedersen A, Rødningen OK, Lyle R. Identification of copy number variants from exome sequence data. BMC Genomics. 2014;15:661.

Shamseldin HE, Maddirevula S, Faqeih E, Ibrahim N, Hashem M, Shaheen R, Alkuraya FS. Increasing the sensitivity of clinical exome sequencing through improved filtration strategy. Genet Med. 2017;19:593-8.

Siggberg L, Ala-Mello S, Linnankivi T, Avela K, Scheinin I, Kristiansson K, Lahermo P, Hietala M, Metsähonkala L, Kuusinen E, Laaksonen M, Saarela J, Khuutila S. Highresolution SNP array analysis of patients with developmental disorder and normal array CGH results. BMC Med Genet. 2012;13:84.

Tan R, Wang Y, Kleinstein SE, Liu Y, Zhu X, Guo H, Jiang Q, Allen AS, Zhu M. An evaluation of copy number variation detection tools from whole-exome sequencing data. Hum Mutat. 2014;35:899-907.

Vasconcelos B, Albano LMJ, Bertola DR, Sbruzzi I, Honjo RS, Moreira M, Brasil AS, Castro C, Koiffmann C, Kim CA. Anormalidades cromossômicas nos pacientes atendidos em serviço de genética. Pediatria (São Paulo). 2007;29:26-32. 
Vermeesch JR, Brady PD, Sanlaville D, Kok K, Hastings RJ. Genome-wide arrays: quality criteria and platforms to be used in routine diagnostics. Hum Mutat. 2012;33:90615.

Vissers LE, de Vries BB, Veltman JA. Genomic microarrays in mental retardation: from copy number variation to gene, from research to diagnosis. J Med Genet. 2010;47:28997.

Wright CF, McRae JF, Clayton S, Gallone G, Aitken S, FitzGerald TW, Jones P, Prigmore E, Rajan D, Lord J, Sifrim A, Kelsell R, Parker MJ, Barrett JC, Hurles ME, FitzPatrick DR, Firth HV, DDD Study. Making new genetic diagnoses with old data: iterative reanalysis and reporting from genome-wide data in 1,133 families with developmental disorders. Genet Med. 2018;20:1216-23.

Zanardo ÉA, Dutra RL, Piazzon FB, Dias AT, Novo-Filho GM, Nascimento AM, Montenegro MM, Damasceno JG, Madia FAR, da Costa TVMM, Melaragno MI, Kim CA, Kulikowski LD. Cytogenomic assessment of the diagnosis of 93 patients with developmental delay and multiple congenital abnormalities: the Brazilian experience. Clinics (Sao Paulo). 2017;72:526-37.

Zhao M, Wang Q, Wang Q, Jia P, Zhao Z. Computational tools for copy number variation $(\mathrm{CNV})$ detection using next-generation sequencing data: features and perspectives. $B M C$ Bioinformatics. 2013;14:S1. 
APÊNDICES 


\title{
APÊNDICE A
}

\section{Artigo submetido para publicação}

\section{the Journal of Molecular Diagnostics}

\section{Manuscript Details}

\section{Manuscript number}

Title
JMDI_2019_210

Application of WES in cytogenomic routine for CNVs detection in patients with developmental delay and/or multiple congenital malformations

\begin{abstract}
Overcoming the challenges for the unambiguous detection of copy number variations is essential to broaden our understanding of the role of genomic variants in the clinical phenotype, in that sense, with the improvement of software and databases the whole exome sequencing can quickly become an excellent strategy in the diagnosis routine of patients with developmental delay and/or multiple congenital malformations. However, even after a detailed analysis of pathogenic single nucleotide variants and indels in known disease genes, using whole exome sequencing, some patients with suspected syndromic conditions are left without a conclusive diagnostic. These negative results could be due to different factors including non-genetic etiologies, lack of knowledge about the genes that cause different disease phenotypes, or in some cases a deletion or duplication of genomic information not routinely detectable by whole exome sequencing variant calling. And while the copy number variants detection is possible using whole exome sequencing data, such analysis presents significant challenges.
\end{abstract}

Keywords

Corresponding Author

Order of Authors copy number variants detection; whole exome sequencing; array; cytogenomic routine diagnostic.

\section{Évelin Zanardo}

Évelin Zanardo, Fabiola Monteiro, Samar Chehimi, Yanca Oliveira, Alexandre Dias, Larissa Athayde Costa, Luiza Ramos, Gil Novo-Filho, Marilia Montenegro, Amom Nascimento, João Kitajima, Fernando Kok, Leslie Kulikowski

\section{INTRODUCTION}

Uncovering of copy number variations (CNVs) and single nucleotide variants (SNVs) is essential for cytogenomic diagnostic. Nevertheless, the CNVs detection using only whole exome sequencing (WES) data still represent an extensive and laborious and does not always present decisive results (01).

In routine, chromosomal microarray (CMA) is the first-tier clinical test for CNVs detection, as well as uniparental disomy and regions of homozygosity $(\mathrm{ROH})$ in patients with developmental delay (DD) and multiple congenital malformations (MCM) (01, 02, 03, 04).

On the other hand, WES analysis allows SNVs and InDels (insertions and deletions of one or some nucleotides) detection, even on identification of variants without prior knowledge on the affected gene, diagnosing patients with a suspected phenotype of 
Mendelian (single-gene) genetic disorder, since $85 \%$ of the variants described as causing disease are located in the exons $(05,06,07)$.

Some authors argue that patients with genomic abnormalities suspicion and genetic heterogeneity should be evaluated initially by WES since this technique could allow a better cost-benefit and execution time than other cytogenomic techniques $(08,09,10)$.

The literature describes a rate of $22 \%$ to $60 \%$ success in molecular diagnosis conclusion using WES $(09,10,11,12)$. Thus the use of WES has increased significantly since the laboratories began to offer it into diagnostic routine. So, the WES has achieved much highlight and has become an attractive technique for diagnostic routine requested by clinicians, especially in the cases with challenging phenotypic features $(12,13,14)$.

Recently the screening of CNVs from WES data using specific software has been applied in research since this would make it possible to identify different types of pathogenic variants in a single method and it has been reported as a potential alternative for detection of genomic abnormalities $(08,12)$.

Since it is already possible to search CNVs in WES results, this rate of variants detection may increase and so many laboratories are integrating this analysis. Thus, it could replace the array and deploy the WES as the first-tier genomic test, reducing the time to obtain a final diagnosis (15).

There is no doubt that the WES is a powerful technique that has the potential to impact and improve patient diagnosis, but care is needed mainly because it is unclear whether WES is the most appropriate method to be used as the first-tier test to achieve a diagnosis of patients with suspected rare disease $(14,15,16)$.

Therefore, we evaluated whether in the cases with previous negative result for pathogenic SNVs and InDels detection by WES there were CNVs that explained the phenotype in these patients and whether the choice of WES as the first-tier test was the most appropriate for diagnosis.

\section{MATERIALS AND METHODS}

This study was performed at Laboratório de Citogenômica in collaboration with Mendelics Análise Genômica. The patients were evaluated by clinicians from different specialties. 
This study involved 38 patients with DD and/or MCM and previous negative result for SNV and InDels detection. The WES data were analyzed for CNVs search and the results found were confirmed by array technique.

Genomic DNA was isolated from $3 \mathrm{~mL}$ of peripheral blood from patients using a commercially available DNA isolation kit (QIAamp DNA Blood Mini Kits, Qiagen, Hilden, Germany) according to the manufacturer's instructions. The quality and quantity of the DNA samples were determined using a Qubit 2.0 Fluorometer (Invitrogen, Carlsbad, California, USA), and the integrity of the DNA was ascertained via agarose gel electrophoresis analysis.

All of the genomic DNAs were processed by Nextera Rapid Capture Exomes (Illumina, San Diego, California, USA) following the manufacturer's instructions.

The method started with the library prep to convert input genomic DNA into adapter-tagged libraries. The tagmentation of DNA step shattered and tagged the DNA without the need for mechanical shearing. Next, libraries were denatured into singlestranded DNA and biotin-labeled probes specific to the exons region were used for the Rapid Capture hybridization. The pool was enriched for the desired regions by adding streptavidin beads that bind to the biotinylated probes.

After, the biotinylated DNA fragments bound to the streptavidin beads were magnetically pulled down from the solution. The enriched DNA fragments were then eluted from the beads and hybridized for a second Rapid Capture.

Recovery of the hybridized fragments by biotin-streptavidin-based pulldown was followed by amplification and massively parallel sequencing of the enriched. Sequencing was performed on Illumina HiSeq 2500 (San Diego, California, USA) and the candidate causal variants were mapped and called. WES was performed with a minimum median coverage of $80 \mathrm{X}$.

CNVs were analyzed by ExomeDepth v1.0.7 software. The initial BAM files were realigned and the base quality scores were recalibrated. After marking the duplicates, the final set of alignment data (BAM files) required for computational CNV prediction were generated.

Array technique were employed on Illumina platform (San Diego, California, USA) using CytoSNP-850K, with 843,888 markers and an average probe spacing of $1.8 \mathrm{~kb}$ across the whole genome. 
In all samples, amplification, hybridization, staining and washing were performed according to the manufacturers' protocols, and the data were extracted by iScan scanner (Illumina, San Diego, California, USA).

The raw data were analyzed using BlueFuse Multi v4.3 software, thus the signal intensities were identified, normalized, compared with a reference dataset based on prerun reference samples, and then the $\log 2$ ratios were calculated.

The criteria used to determine a CNV included the involvement of at least ten consecutive probes sets in a region and $\log 2$ ratio cut-offs of -0.41 and +0.32 for loss and gain, respectively. The software produced graphical representations of CNVs breakpoints and regions of homozygosity (ROHs) for each sample. Moreover, the bead arrays supply the $\mathrm{B}$ allele frequency (BAF), which represents the proportion of $\mathrm{B}$ alleles in the genotype. A region without evidence of CNVs should show a $\log 2$ ratio near zero and three $\mathrm{BAF}$ clusters of $0,0.5$, and 1 , corresponding to the $\mathrm{AA}, \mathrm{AB}$, and $\mathrm{BB}$ genotypes, respectively.

All samples were evaluated and were found to be in accordance with the quality standards.

The results were analyzed according to the American College of Medical Genetics standards and guidelines, and were compared with the following databanks of CNVs and classified as benign, pathogenic or VUS (variants of uncertain clinical significance): the Database of Genomic Variants (DGV - http://projects.tcag.ca/variation/), the Database of Chromosomal Imbalance and Phenotype in Humans Using Ensembl Resources (DECIPHER - http://decipher.sanger.ac.uk/), the National Center for Biotechnology Information (NCBI - http://www.ncbi.nlm.nih.gov/), the Online Mendelian Inheritance in Man (OMIM - https://www.omim.org/), the Ensembl Genome Browser (http://www.ensembl.org/index.html) and the UCSC Genome Bioinformatics database (http://genome.ucsc.edu). The genomic positions are reported according their mapping on the GRCh37/hg19 genome build.

\section{ETHICS}

The Research Ethics Committee of the Faculdade de Medicina da Universidade de São Paulo approved this study (n. ${ }^{\circ} 235 / 15$ ), and written informed consent for publication was obtained from the parents of the patients. 


\section{RESULTS}

Across all 38 samples, the ExomeDepth identified 745 CNVs (534 deletions and 211 duplications) and the BlueFuse found $332 \mathrm{CNVs}$ (224 deletions and 108 duplications) and 37 ROHs.

Among these results, it was verified that approximately 50\% (556/1114) of the alterations were smaller than $50 \mathrm{~kb}$, of which about $74 \%(411 / 556)$ were detected by ExomeDepth.

So, we classified the CNVs and selected only the pathogenic deletions and duplications to measure the consistency with array and identify the true and relevant results for diagnosis.

Thus, we identified $44.7 \%$ (17/38) of the patients presented pathogenic CNVs detected by both techniques including deletions and duplications in different chromosomal regions. The samples presented in this set showed concordance in genomic region for elucidation of the diagnosis, but some changes of the breakpoints (start and end) were identified. These regions showed $83.3 \%$ of the high genomic similarity when compared between the techniques. Moreover, some CNVs identified by ExomeDepth were fragmented due to genomic characteristics of the region or by technical limitation, since WES was initially developed for detection of SNV (table 01).

We also detected only one patient that showed pathogenic CNV detected by BlueFuse and missed by ExomeDepth. This patient present one deletion on chromosome 1q21.1 with approximately $2 \mathrm{Mb}$ of size and related with 1q21.1 deletion syndrome (\#612474).

Additionally, only array technique revealed cases with ROH $(8 \%-03 / 38)$ that contributed to correct diagnostic elucidation. These cases showed uniparental disomy, genomic imprinting or possibility occurrence of recessive diseases related with a SNV (table 02).

We did not find pathogenic CNVs in the other 17 samples (44.7\%), wherein the SNV found by WES and classified in benign or VUS will be reanalyzed because new information is constantly being inserted into the databases, such as the characterization or establishment of new genes. 


\section{DISCUSSION}

Although WES is an excellent technique for SNVs and InDels detection, it will not always lead to the diagnosis of the patients with developmental delay and multiple congenital malformations. The reasons for unsolved diagnosis after WES test are incomplete coverage of the genome (e.g. variants present in intronic or repetitive regions) or even abnormalities that are not detectable by WES (CNVs, chromosome rearrangements or epigenomic abnormalities) $(11,15)$.

Since it is possible to analyze CNVs in WES data, the integration of this detection to SNVs and InDels identification would improve the diagnostic efficiency and then promote a more attractive cost-benefit of WES $(08,12)$.

However, the rates reported in the literature of the efficiency in CNVs detection varied widely among the tools and the studies, making the interpretation and evaluation of the performance of this analysis very difficult $(06,17,18)$. So, there is not yet a consensus on the most effective tool for the evaluation of CNVs from exome data, since each algorithm has advantages and disadvantages $(18,19)$.

In the comparative study performed by Plagnol and collaborators, using 12 samples from the 1000 genome project, ExomeDepth showed a higher detection rate of know CNVs than the exomeCopy and ExomeCNVs tools (75.2\%, 52.8\% and $41.2 \%$, respectively) (17). Our analysis showed about 45\% (17/38) of the cases presented large pathogenic CNVs identified by ExomeDepth in the WES data.

Comparing our results obtained by WES with those of the array, the WES analysis missed a deletion in one patient and was not able to correctly determine the breakpoints, so the pathogenic CNVs were identified more accurately by the array. In the study conducted by De Ligt and collaborators, the rates of detection of pathogenic CNVs confirmed previous by array were $83.3 \%$ (10/12), thus the ExomeDepth identified correctly deletions and duplications in several chromosomes and detected genomic regions with an overlap cut-off limit of $30 \%$ for the success between the techniques. So, this tool was considered to have the best performance to detect clinically relevant variants (12).

For the selected patients in this research, the decision to perform WES was based upon the judgment of the clinicians (pediatrics, neurologists or geneticists) who evaluated the patients and considered the WES as the best test in these cases. But we can observe that this choice of using the WES as the first-tier test was not adequate in all cases. 
Firstly, these patients did not present pathogenic SNVs or InDels, and when they were evaluated for CNVs screening half of them achieved the conclusive diagnosis. Even though the ExomeDepth showed almost all CNVs, the array technique was still essential for correctly elucidation and accuracy of the breakpoints and the diagnosis.

In addition, it was also identified that $8 \%$ of the samples presented $\mathrm{ROH}$ showed only by array, and the identification by ExomeDepth was not possible due to technical limitations. This information did not elucidate the cytogenomic diagnosis, but facilitated the investigation to conclude the cause of the phenotype in the patients, highlighting the need to use array and the improvement of software for WES data analysis to identification of some genomic characteristics which may lead to diagnosis. Thus, the homozygosity patterns have been useful in identifying pathogenic variants associated with disease of recessive inheritance, and regions with UPD for evaluation of genomic imprinting ( 01 , 04, 20, 21).

So, considering that the detection of CNVs by WES is not yet well standardized, it would be better for these patients to have been evaluated by the array, saving time and money. But for this approach the physicians who evaluated the patients should recognize the clinical signs suggestive of chromosomal abnormalities and specific syndromes to direct the patient to the correct technique $(14,16)$.

Thus, the success rate of WES often dependents on the targeting of the clinical characteristics reported by the physician. This presents a challenge, since not all professionals have the necessary training in genetics, or the understanding of the strategy for the most appropriate tests $(11,13,14,15,16)$.

In conclusion, WES is a good alternative when there is monogenic or with no specific disorders suspicion after the careful phenotype evaluation by a trained geneticist. But a more selective use of this technique is required for a better cost-effectiveness and diagnostic conclusion in which it will benefit the patient.

\section{ACKNOWLEDGMENTS}

We thank all of the patients who participated in this study. This study was supported by grants from Coordenação de Aperfeiçoamento de Pessoal de Nível Superior (CAPES). 


\section{REFERENCES}

01. Harel T, Lupski JR. Genomic disorders 20 years on-mechanisms for clinical manifestations. Clin Genet 2018, 93:439-49.

02. Manning M, Hudgins L. Array-based technology and recommendations for utilization in medical genetics practice for detection of chromosomal abnormalities. Genet Med 2010, 12:742-5.

03. Zanardo ÉA, Dutra RL, Piazzon FB, Dias AT, Novo-Filho GM, Nascimento AM, Montenegro MM, Damasceno JG, Madia FAR, da Costa TVMM, Melaragno MI, Kim CA, Kulikowski LD. Cytogenomic assessment of the diagnosis of 93 patients with developmental delay and multiple congenital abnormalities: the Brazilian experience. Clinics (Sao Paulo) 2017, 72:526-37.

04. Kearney HM, Kearney JB, Conlin LK. Diagnostic implications of excessive homozygosity detected by SNP-based microarrays: consanguinity, uniparental disomy, and recessive single-gene mutations. Clin Lab Med 2011, 31:595-613.

05. Samarakoon PS, Sorte HS, Kristiansen BE, Skodje T, Sheng Y, Tjønnfjord GE, Stadheim B, Stray-Pedersen A, Rødningen OK, Lyle R. Identification of copy number variants from exome sequence data. BMC Genomics 2014, 15:661.

06. Kadalayil L, Rafiq S, Rose-Zerilli MJ, Pengelly RJ, Parker H, Oscier D, Strefford JC, Tapper WJ, Gibson J, Ennis S, Collins A. Exome sequence read depth methods for identifying copy number changes. Brief Bioinform 2015, 16:380-92.

07. Han JY, Jang W, Park J, Kim M, Kim Y, Lee IG. Diagnostic approach with genetic tests for global developmental delay and/or intellectual disability: Single tertiary center experience 2019, 83:115-23.

08. Hehir-Kwa JY, Pfundt R, Veltman JA. Exome sequencing and whole genome sequencing for the detection of copy number variation. Expert Rev Mol Diagn 2015, 15:1023-32.

09. Gambin T, Akdemir ZC, Yuan B, Gu S, Chiang T, Carvalho CMB, Shaw C, Jhangiani S, Boone PM, Eldomery MK, Karaca E, Bayram Y, Stray-Pedersen A, Muzny D, Charng WL, Bahrambeigi V, Belmont JW, Boerwinkle E, Beaudet AL, Gibbs RA, Lupski JR. Homozygous and hemizygous CNV detection from exome sequencing data in a Mendelian disease cohort. Nucleic Acids Res 2017, 45:1633-48.

10. Stark Z, Tan TY, Chong B, Brett GR, Yap P, Walsh M, Yeung A, Peters H, Mordaunt D, Cowie S, Amor DJ, Savarirayan R, McGillivray G, Downie L, Ekert PG, Theda C, 
James PA, Yaplito-Lee J, Ryan MM, Leventer RJ, Creed E, Macciocca I, Bell KM, Oshlack A, Sadedin S, Georgeson P, Anderson C, Thorne N, Melbourne Genomics Health Alliance, Gaff C, White SM. A prospective evaluation of whole-exome sequencing as a first-tier molecular test in infants with suspected monogenic disorders. Genet Med 2016, 18:1090-6.

11. Sawyer SL, Hartley T, Dyment DA, Beaulieu CL, Schwartzentruber J, Smith A, Bedford HM, Bernard G, Bernier FP, Brais B, Bulman DE, Warman Chardon J, Chitayat D, Deladoëy J, Fernandez BA, Frosk P, Geraghty MT, Gerull B, Gibson W, Gow RM, Graham GE, Green JS, Heon E, Horvath G, Innes AM, Jabado N, Kim RH, Koenekoop RK, Khan A, Lehmann OJ, Mendoza-Londono R, Michaud JL, Nikkel SM, Penney LS, Polychronakos C, Richer J, Rouleau GA, Samuels ME, Siu VM, Suchowersky O, Tarnopolsky MA, Yoon G, Zahir FR, FORGE Canada Consortium, Care4Rare Canada Consortium, Majewski J, Boycott KM. Utility of whole-exome sequencing for those near the end of the diagnostic odyssey: Time to address gaps in care. Clin Genet 2016, 89:27584.

12. De Ligt J, Boone PM, Pfundt R, Vissers LE, Richmond T, Geoghegan J, O’Moore K, de Leeuw N, Shaw C, Brunner HG, Lupski JR, Veltman JA, Hehir-Kwa JY. Detection of clinically relevant copy number variants with whole-exome sequencing. Hum Mutat 2013, 34:1439-48.

13. Iglesias A, Anyane-Yeboa K, Wynn J, Wilson A, Truitt Cho M, Guzman E, Sisson R, Egan C, Chung WK. The usefulness of whole-exome sequencing in routine clinical practice. Genet Med 2014, 16:922-31.

14. Volk A, Conboy E, Wical B, Patterson M, Kirmani S. Whole-exome sequencing in the clinic: Lessons from six consecutive cases from the clinician's perspective. Mol Syndromol 2015, 6:23-31.

15. Bertier G, Hétu M, Joly Y. Unsolved challenges of clinical whole-exome sequencing: a systematic literature review of end-users' views. BMC Med Genomics 2016, 9:52.

16. Bertier G, Sénécal K, Borry P, Vears DF. Unsolved challenges in pediatric wholeexome sequencing: A literature analysis. Crit Rev Clin Lab Sci 2017, 54:134-42.

17. Plagnol V, Curtis J, Epstein M, Mok KY, Stebbings E, Grigoriadou S, Wood NW, Hambleton S, Burns SO, Thrasher AJ, Kumararatne D, Doffinger R, Nejentsev S. A robust model for read count data in exome sequencing experiments and implications for copy number variant calling. Bioinformatics 2012, 28:2747-54. 
18. Tan R, Wang Y, Kleinstein SE, Liu Y, Zhu X, Guo H, Jiang Q, Allen AS, Zhu M. An evaluation of copy number variation detection tools from whole-exome sequencing data. Hum Mutat 2014, 35:899-907.

19. Zhao M, Wang Q, Wang Q, Jia P, Zhao Z. Computational tools for copy number variation $(\mathrm{CNV})$ detection using next-generation sequencing data: features and perspectives. BMC Bioinformatics 2013, 14:S1.

20. Alkuraya FS. Homozygosity mapping: one more tool in the clinical geneticist's toolbox. Genet Med 2010, 12:236-9.

21. Bergant G, Maver A, Lovrecic L, Čuturilo G, Hodzic A, Peterlin B. Comprehensive use of extended exome analysis improves diagnostic yield in rare disease: a retrospective survey in 1,059 cases. Genet Med 2018, 20:303-12. 
Table 1: Patients with pathogenic CNVs detected by both techniques

\begin{tabular}{|c|c|c|c|c|}
\hline \multirow{2}{*}{ Sample } & \multicolumn{3}{|c|}{ Pathogenic CNV } & \multirow{2}{*}{ Diagnostic Conclusion / OMIM } \\
\hline & Type & Chromosomal Position & Size (pb) & \\
\hline 01 & $\operatorname{del}(\mathrm{x} 1)$ & $15 q 11.2-q 13.3$ & $10,275,147$ & Angelman syndrome / \#105830 \\
\hline $\mathbf{0 2}$ & $\operatorname{del}(\mathrm{x} 1)$ & $15 \mathrm{q} 11.1-\mathrm{q} 13.1$ & $7,931,520$ & Prader-Willi syndrome / \#176270 \\
\hline $\mathbf{0 3}$ & $\operatorname{dup}(\mathrm{x} 3)$ & $16 \mathrm{p} 13.11$ & $1,166,301$ & 16p13.11 duplication \\
\hline 04 & $\operatorname{dup}(x 3)$ & $10 \mathrm{q} 24.31-\mathrm{q} 24.32$ & 403,289 & $\begin{array}{l}\text { Split-hand/foot malformation } 3 \text { / } \\
\qquad \# 246560\end{array}$ \\
\hline 06 & $\operatorname{dup}(\mathrm{x} 3)$ & $7 \mathrm{q} 11.23$ & $1,890,574$ & $\begin{array}{c}\text { Williams-Beuren region } \\
\text { duplication syndrome / \#609757 }\end{array}$ \\
\hline 07 & $\operatorname{del}(\mathrm{x} 1)$ & $17 q 12$ & $1,767,963$ & $\begin{array}{c}\text { 17q12 deletion syndrome / } \\
\# 614527\end{array}$ \\
\hline 09 & $\operatorname{dup}(\mathrm{x} 3)$ & $22 \mathrm{q} 13.1-\mathrm{q} 13.33$ & $12,610,851$ & $\begin{array}{l}\text { 22q13 duplication syndrome / } \\
\# 615538\end{array}$ \\
\hline 12 & $\operatorname{del}(\mathrm{x} 1)$ & $22 q 11.21$ & $2,823,431$ & $\begin{array}{l}\text { 22q11.2 deletion syndrome / } \\
\# 611867\end{array}$ \\
\hline 15 & $\operatorname{del}(\mathrm{x} 1)$ & $10 \mathrm{q} 26.2-\mathrm{q} 26.3$ & $7,821,817$ & $\begin{array}{l}\text { 10q26 deletion syndrome / } \\
\# 609625\end{array}$ \\
\hline \multirow[t]{2}{*}{20} & $\operatorname{dup}(\mathrm{x} 3)$ & $5 \mathrm{q} 35.2-\mathrm{q} 35.3$ & $1,036,399$ & 5q35.2-q35.3 duplication \\
\hline & $\operatorname{del}(\mathrm{x} 1)$ & $7 \mathrm{q} 11.23$ & $1,451,593$ & $\begin{array}{l}\text { Williams-Beuren syndrome / } \\
\# 194050\end{array}$ \\
\hline \multirow[t]{2}{*}{22} & $\operatorname{dup}(\mathrm{x} 4)$ & $15 q 11.1-q 13.2$ & $10,586,279$ & 15q11-q13 duplication syndrome / \\
\hline & $\operatorname{dup}(\mathrm{x} 3)$ & $15 q 13.2-q 13.3$ & $1,578,056$ & \#608636 \\
\hline 24 & $\operatorname{del}(\mathrm{x} 1)$ & $10 \mathrm{q} 26.12-\mathrm{q} 26.3$ & $12,446,474$ & $\begin{array}{l}\text { 10q26 deletion syndrome / } \\
\# 609625\end{array}$ \\
\hline 26 & $\operatorname{del}(\mathrm{x} 1)$ & 8 p22-p21.1 & $12,014,512$ & 8p22-p21 deletion \\
\hline 28 & $\operatorname{del}(\mathrm{x} 1)$ & 19q13.33-q13.41 & $3,352,377$ & 19q13.33-q13.41 deletion \\
\hline 31 & $\operatorname{del}(\mathrm{x} 1)$ & $15 q 11.2-q 13.1$ & $5,892,030$ & Angelman syndrome / \#105830 \\
\hline 33 & $\operatorname{dup}(\mathrm{x} 2)$ & Xp22.33-p21.3 & $26,560,781$ & Xp22.33-p21.3 duplication \\
\hline 34 & $\operatorname{del}(\mathrm{x} 1)$ & $6 \mathrm{p} 23-\mathrm{p} 22.3$ & $4,670,587$ & 6 p23-p22.3 deletion \\
\hline
\end{tabular}

Table 2: Patients with ROH detected by array technique

\begin{tabular}{|c|c|c|c|c|}
\hline \multirow{2}{*}{ Sample } & \multicolumn{3}{|c|}{ Pathogenic alteration } & \multirow{2}{*}{ Diagnostic Conclusion } \\
\hline & Type & Chromosomal Position & Size (pb) & \\
\hline 11 & $\mathrm{ROH}$ & 2p25.3-q37.3 & 243.034 .523 & $\begin{array}{l}\text { Uniparental isodisomy / whole } \\
\text { chromosome } 2\end{array}$ \\
\hline 13 & $\mathrm{ROH}$ & $14 q 11.2-q 21.1$ & 19.155 .693 & $\begin{array}{l}\text { Uniparental disomy / Kagami- } \\
\text { Ogata syndrome }\end{array}$ \\
\hline 36 & $\mathrm{ROH}$ & $6 \mathrm{p} 25.3-q 27$ & 170.871 .506 & ROH with SNV on HACEI gene \\
\hline
\end{tabular}




\title{
APÊNDICE B
}

\section{Abstracts de artigos publicados durante o desenvolvimento deste doutorado, porém sem relação direta com a temática do presente estudo}

\section{Short Report}

Cytogeneticand Genome Research

\section{Mosaic Trisomy 12 Associated with Overgrowth Detected in Fibroblast Cell Lines}

\author{
Yanca Gasparini $^{\mathrm{a}}$ Marília M. Montenegro ${ }^{\mathrm{a}}$ Gil M. Novo-Filho ${ }^{\mathrm{a}}$ \\ José R.M. Ceroni ${ }^{b}$ Rachel S. Honjo ${ }^{b}$ Évelin A. Zanardo ${ }^{a}$ Alexandre T. Dias ${ }^{a}$ \\ Amom M. Nascimento ${ }^{a}$ Thaís V.M.M. Costa ${ }^{a}$ Fabrícia A. Madia ${ }^{a}$ \\ Samar N. Chehimi ${ }^{\mathrm{a}}$ Jullian G. Damasceno ${ }^{\mathrm{a}}$ Chong A. Kim ${ }^{\mathrm{b}}$ \\ Leslie D. Kulikowski ${ }^{\mathrm{a}}$

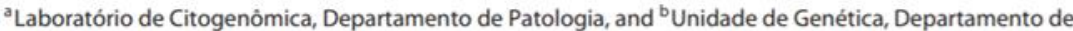 \\ Pediatria, Instituto da Criança, Hospital das Clinicas HCFMUSP, Faculdade de Medicina, Universidade de São Paulo, \\ São Paulo, Brazil
}

\section{Keywords}

Cutaneous mosaicism - Cytogenetics - Fibroblasts - FISH .

Genotype-phenotype correlation - Trisomy 12

\section{Abstract}

Mosaic trisomy 12 is a rare anomaly, and only 9 cases of live births with this condition have been reported in the literature. The clinical phenotype is variable, including neuropsychomotor developmental delay, congenital heart disease, microcephaly, cutaneous spots, facial asymmetry, prominent ears, hypotonia, retinopathy, and sensorineural hearing loss. A 2-year-old female presented with neuropsychomotor developmental delay, prominent forehead, dolichocephaly, patchy skin pigmentation, and unexpected over-growth at birth. Cytogenetic analysis of her peripheral blood showed normal results, suggesting the presence of a chromosomal alteration in other tissues. Further studies using G-banding and FISH performed on fibroblasts from both hyper- and hypopigmented regions identified a $47, \mathrm{XX},+12 / 46, \mathrm{XX}$ karyo- type. To the best of our knowledge, no patients with mosaic trisomy 12 associated with overgrowth have been reported to date. Congenital overgrowth and neonatal overgrowth have been frequently linked to Pallister-Killian syndrome (PKS; OMIM 601803). This case suggests the possibility of an association of genes present in the $12 \mathrm{p}$ region with fetal overgrowth, considering that chromosomal duplications could lead to an increase in the production of aberrant transcripts and disturbing gene dosage effects. This case highlights the importance of cytogenetic analysis in different tissues to provide relevant information to the specific genotype/phenotype correlation. 02019 S. Karger AG, Basel 


\section{SCIENTIFIC REPRTS}

OPEN A Multicentric Brazilian

Investigative Study of Copy

Number Variations in Patients

Received: 9 March 2018

Accepted: 21 August 2018 with Congenital Anomalies and Intellectual Disability

J. R. M. Ceroni ${ }^{1}$, R. L. Dutra ${ }^{2}$, R. S. Honjo ${ }^{1}$, J. C. Llerena Jr. ${ }^{3}$, A. X. Acosta ${ }^{4}$, P. F. V. Medeiros ${ }^{5}$, M. F. Galera ${ }^{6}$, E. A. Zanardo ${ }^{2}$, F. B. Piazzon ${ }^{2}$, A.T. Dias ${ }^{2}$, G. M. Novo-Filho ${ }^{2}$,

M. M. Montenegro ${ }^{2}$, F. A. R. Madia ${ }^{2}$, D. R. Bertola ${ }^{1,7}$, J. B. de Melo ${ }^{8}$, L. D. Kulikowski ${ }^{2}$ \& C. A. $\mathrm{Kim}^{1}$

Genomic imbalances are the most common cause of congenital anomalies (CA) and intellectual disability (ID). The aims of this study were to identify copy number variations (CNVs) in 416 patients with CA and ID from 5 different genetics centers within 4 different states by using the Multiplex Ligation-dependent Probe Amplification (MLPA) technique and to apply the chromosomal microarray (CMA) methodology in selected cases. The samples were analyzed by MLPA kits P064, P036, P070 and P250. Positive results were found in 97/416 (23.3\%) patients. CMA was applied in 14 selected cases. In 6/14 (42.85\%) patients, CMA detected other copy number variations not detected by the MLPA studies. Although CMA is indispensable for genotype refinement, the technique is still unfeasible in some countries as a routine analysis due to economic and technical limitations. In these cases, clinical evaluation followed by karyotyping and MLPA analysis is a helpful and affordable solution for diagnostic purposes. 


\title{
Case Report
}

\section{Gestational Tubal Choriocarcinoma Presenting as a Pregnancy of Unknown Location following Ovarian Induction}

\author{
Lawrence Hsu Lin $\odot,{ }^{1}$ Koji Fushida, ${ }^{1}$ Eliane Azeka Hase, ${ }^{1}$ Regina Schultz $\subset{ }^{2}$ \\ Laysa Manatta Tenorio, ${ }^{1}$ Fabricia Andrea Rosa Madia, ${ }^{3}$ Evelin Aline Zanardo, ${ }^{3}$ \\ Leslie Domenici Kulikowski, ${ }^{3}$ and Rossana Pulcineli Vieira Francisco $\mathbb{C}^{1}$ \\ ${ }^{1}$ University of Sao Paulo Trophoblastic Disease Center, University of Sao Paulo Medical School, Sao Paulo, SP, Brazil \\ ${ }^{2}$ Department of Pathology, University of Sao Paulo Medical School, Sao Paulo, SP, Brazil \\ ${ }^{3}$ Cytogenomic Laboratory, Department of Pathology, University of Sao Paulo Medical School, Sao Paula, SP, Brazil \\ Correspondence should be addressed to Lawrence Hsu Lin; 1.lin@hc.fm.usp.br \\ Received 7 February 2018; Accepted 26 March 2018; Published 3 May 2018 \\ Academic Editor: Erich Cosm \\ Copyright 192018 Lawrence Hsu Lin et al. This is an open access article distributed under the Creative Commons Attribution \\ License, which permits unrestricted use, distribution, and reproduction in any medium, provided the original work is properly \\ cited. \\ The management of pregnancy of unknown location (PUL) can be a challenging situation, since it can present as several different \\ conditions. Here we describe a rare case of gestational choriocarcinoma arising in the fallopian tube after ovarian induction in \\ an infertile patient. The patient received clomiphene for ovarian induction and had rising levels of human chorionic gonadotropin \\ (hCG) over nine months without sign of pregnancy. After referral to our center, the patient was diagnosed with a paraovarian tumor, \\ which revealed a gestational choriocarcinoma arising in the fallopian tube; the final diagnosis was supported by pathological and \\ cytogenomic analysis. Malignancies, such as gestational trophoblastic disease, should be in the differential diagnosis of PUL; the \\ early recognition of these conditions is key for the proper treatment and favorable outcome.
}




\title{
Deletion of $R U N X 1$ exons 1 and 2 associated with familial platelet disorder with propensity to acute myeloid leukemia
}

Marcela Cavalcante de Andrade Silva ${ }^{a, 4}$, Ana Cristina Victorino Krepischic, Leslie Domenici Kulikowski ${ }^{d}$, Evelin Aline Zanardo ${ }^{d}$, Luciana Nardinelli ${ }^{\mathrm{b}}$, Aline Medeiros Leal ${ }^{a}$, Silvia Souza Costa ${ }^{\circ}$, Nair Hideki Muto ${ }^{\circ}$, Vanderson Rocha ${ }^{a, b}$, Elvira Deolinda Rodrigues Pereira Velloso ${ }^{a, c}$

"Departamento de Hematologia, Laboratório de Citogenética, Hospital das Clinicas HCFMUSP, Faculdade de Medicina FMUSP, Universidade de Sao Paulo, Sso Paulo, SP, BR Av. Dr. Eneas de Carvalho 255, Cerqueira César 01246-000, S9̄o Paulo, SP, Brazil; 'b Dopartamonto de Homalologia, Laboralónio Biologia Tumoral, Hospilal das Clinicas HCFMUSP, Faculdado de Medicina FMUSP, Universidade de Sao Paulo, S9o Paulo, SP, BR Av. Dr. Eneas de Carvalho 255, Cerqueira César $01246-000$, Sāo Paulo, SP, Brazil; ' ${ }^{\circ}$ Department of Genetics and Evolutionary Biology, Institute of Biosciences, University of Säo Paulo, SP. Brazil Rua do Matäo, 321. Butantä, 05508-090. Säo Paulo, SP. Brazil; 'Deparlarnonlo do Patologia, Laboratonio de Citogenomica do LIM 03, Hospital das Clinicas HCFMUSP, Faculdade de Medicina FMUSP, Universidade de Sao Paulo, Sao Paulo, SP, BR. Av. Dr. Eness de Carvalho 255, Cerqueira César 01246-000, Sāo Paulo, SP, Brazil; ‘ Hospital Israclita Albort Einstoin. Av. Albort Einstcin, $627 / 701$ Morumbi 05652- 900 - Saio Paulo, SP, Brazil

\begin{abstract}
Famillal platcict disordcr with propensity to acute myclold Icukcmia (FPL/AML) assoclated wth RUNXI mutations is an autosomal dorninant disorder included in the group of the myeloid neoplasms with germ line predisposition. We describe two brothers who were dlagnosed with hematological mallgnancics (one with AML and the other with T-cell lymphoblastic lymphoma). There was a history of leukemia in the paternal family and two of their siblings presented with low platelet counts and no history of significant biccding. A microdelction cncompassing cxons 1-2 of PUNX1 (outside the cluster region of the Runt Homology domain and the transactivation domain) was detected in six farnily members using array-CGH and MLPA validation. A low platelet count was not present in all deletion camicrs and, therefore, it should not be used as an indication tor screening in suspectcd tamillics and tamily mombers.

Keywords RUNXI. Acute leukemia, Myelodysplastic syndrome, Farnilial thrombocytopenia, Gorm line myclold nooplasm, FPD/AML. O 2018 Elsevier Inc. All rights reserved.
\end{abstract}

\footnotetext{
Peceived July 14, 2017; accepted January 16, 2018

- Corresponding author.

E-mall addresses: marcelacas $\Theta$ uol.com.br.

ana.krepischie ibusp. br, lesliokulik @usp.br, nair.muto e einstein.br, elvira.velloso e fm.usp.br
} 


\section{Cytogenomic assessment of the diagnosis of 93 patients with developmental delay and multiple congenital abnormalities: The Brazilian experience}

Évelin Aline Zanardo, ${ }^{1 *}$ Roberta Lelis Dutra,' Flavia Balbo Piazzon,' Alexandre Torchio Dias,' Gil Monteiro Novo-Filho,' Amom Mendes Nascimento,' Marília Moreira Montenegro,' Jullian Gabriel Damasceno,' Fabrícia Andreia Rosa Madia,' Thaís Virgínia Moura Machado da Costa,' Maria Isabel Melaragno," Chong Ae Kim,"' Leslie Domenici Kulikowski'

'Laboratorio de Citogenomica, Departamento de Patologia, Faculdade de Medicina FMUSP, Universidade de Sao Paulo, Sao Paulo, SP, BR. "Departamento de Morfologia e Genetica, Universidade Federal de Sao Paulo, Sao Paulo, SP, BR. "'Unidade de Genetica, Departamento de Pediatria, Instituto da Crianca, Hospital das Clinicas HCFMUSP, Faculdade de Medicina, Universidade de Sao Paulo, Sao Paulo, SP, BR.

OBJECTIVE: The human genome contains several types of variations, such as copy number variations, that can generate specific clinical abnormalities. Different techniques are used to detect these changes, and obtaining an unequivocal diagnosis is important to understand the physiopathology of the diseases. The objective of this study was to assess the diagnostic capacity of multiplex ligation-dependent probe amplification and array techniques for etiologic diagnosis of syndromic patients.

METHODS: We analyzed 93 patients with developmental delay and multiple congenital abnormalities using multiplex ligation-dependent probe amplifications and arrays.

RESULTS: Multiplex ligation-dependent probe amplification using different kits revealed several changes in approximately $33.3 \%$ of patients. The use of arrays with different platforms showed an approximately $53.75 \%$ detection rate for at least one pathogenic change and a $46.25 \%$ detection rate for patients with benign changes. A concomitant assessment of the two techniques showed an approximately $97.8 \%$ rate of concordance, although the results were not the same in all cases. In contrast with the array results, the MLPA technique detected $\sim 70.6 \%$ of pathogenic changes.

CONCLUSION: The obtained results corroborated data reported in the literature, but the overall detection rate was higher than the rates previously reported, due in part to the criteria used to select patients. Although arrays are the most efficient tool for diagnosis, they are not always suitable as a first-line diagnostic approach because of their high cost for large-scale use in developing countries. Thus, clinical and laboratory interactions with skilled technicians are required to target patients for the most effective and beneficial molecular diagnosis.

KEYWORDS: Cytogenomic Techniques; MLPA; Array; Developmental Delay; Multiple Congenital Abnormalities.

Zanardo EA, Dutra RL, Piazzon FB, Dias AT, Novo-filho GM, Nascimento AM, et al. Cytogenomic assessment of the diagnosis of 93 patients with developmental delay and multiple congenital abnormalities: The Brazilian experience. Clinics. 2017;72(9):526-537

Received for publication on December 14, 2016; First review completed on February 21, 2017; Accepted for publication on May 4, 2017

*Corresponding author. E-mail: evelinzanardo@yahoo.com.br 
Cytogenetic and Genome Research

Accepted: July 11, 2016 by $M$. Schmid Published online: September 24,2016

\title{
Subtelomeric Copy Number Variations: The Importance of $\mathbf{4 p / 4 q}$ Deletions in Patients with Congenital Anomalies and Developmental Disability
}

\author{
Gil M. Novo-Filho ${ }^{a}$ Marília M. Montenegro ${ }^{a}$ Évelin A. Zanardo ${ }^{a}$ \\ Roberta L. Dutra $^{\mathrm{b}}$ Alexandre T. Dias ${ }^{\mathrm{a}}$ Flavia B. Piazzon ${ }^{\mathrm{a}}$ Taís V.M.M. Costa ${ }^{\mathrm{a}}$ \\ Amom M. Nascimento ${ }^{a, b}$ Rachel S. Honjo ${ }^{b}$ Chong A. Kim ${ }^{b}$ Leslie D. Kulikowski ${ }^{a}$ \\ aDepartment of Pathology, Cytogenomics Laboratory and 'bepartment of Pediatrics, Instituto da Criança, \\ Faculdade de Medicina da Universidade de São Paulo, São Paulo, Brazil
}

\section{Abstract}

The most prevalent structural variations in the human genome are copy number variations (CNVs), which appear predominantly in the subtelomeric regions. Variable sizes of $4 p / 4 q$ CNVs have been associated with several different psychiatric findings and developmental disability (DD). We analyzed 105 patients with congenital anomalies (CA) and developmental and/or intellectual disabilities (DD/ID) using MLPA subtelomeric specific kits (P036/P070) and 4 of them using microarrays. We found abnormal subtelomeric CNVs in 15 patients (14.3\%), including 8 patients with subtelomeric deletions at $4 \mathrm{p} / 4 \mathrm{q}(53.3 \%)$. Additional genomic changes were observed at 1p36, 2q37.3, 5p15.3, 5q35.3, 8p23.3, $13 q 11,14 q 32.3,15 q 11.2$, and $\mathrm{Xq} 28 / \mathrm{Yq} 12$. This indicates the prevalence of independent deletions at $4 p / 4 q$, involving PIGG, TRIML2, and FRG1. Furthermore, we identified 15 genes with changes in copy number that contribute to neurological development and/or function, among them CRMP1, SORCS2, SLC2SA4, and HELT. Our results highlight the association of genes with changes in copy number at $4 p$ and $4 q$ subtelomeric regions and the DD phenotype. Cytogenomic characterization of additional cases with distal deletions should help clarifying the role of subtelomeric CNVs in neurological diseases.

02016 S. Karger AG, Basel

\section{Key Words}

$4 \mathrm{p} / 4 \mathrm{q}$ deletion - Arrays - Developmental disability - MLPA .

Subtelomeric copy number variations 


\section{Post-mortem cytogenomic investigations in patients with congenital malformations}

Alexandre Torchio Dias ${ }^{\mathrm{a}, *}$, Évelin Aline Zanardo ${ }^{a}$, Roberta Lelis Dutra ${ }^{\mathrm{a}}$, Flavia Balbo Piazzon ${ }^{\mathrm{a}}$, Gil Monteiro Novo-Filho a , Marilia Moreira Montenegro a , Amom Mendes Nascimento a, Mariana Rocha ${ }^{\mathrm{a}, \mathrm{b}}$, Fabricia Andreia Rosa Madia ${ }^{\mathrm{a}}$, Thais Virgínia Moura Machado Costa ${ }^{\mathrm{a}}$, Cintia Milani ${ }^{\mathrm{a}}$, Regina Schultz ${ }^{\mathrm{c}}$, Fernanda Toledo Gonçalves ${ }^{d}$, Cintia Fridman ${ }^{d}$, Guilherme Lopes Yamamoto ${ }^{e}$, Débora Romeo Bertola ${ }^{e}$, Chong Ae Kim ${ }^{\mathrm{e}}$, Leslie Domenici Kulikowski ${ }^{\mathrm{a}, \mathrm{b}}$

a Department of Pathology, Cytogenomic Laboratary - LM 03 - HC-PMUSP, Universidade de Säo Paulo, SP, Brazil

b Human Reproduction and Generic Center, Department of Colerive Healch - Faculdade de Medidna do ABC, Santo André, SP, Brazil

- Division of Pathology - Clinical Hospital - HC -FMUSP, Universidade de Salo Paulo, SP, Brazil

a Department of Legal Medicine - HC-PMUSP. Universidade de SOo Paula, SP. Brozil

- Cenertics Unit Instituto da Crianca HC-FMUSP - Universidade de Sao Paulo, SP. Brazil

A R T I C L E I N F O

\section{Article history:}

Received 28 September 2015

and in revised form 16 June 201

Accepted 19 July 2016

Available online 20 July 2016

\section{Keywards:}

Congenital malformations

Post-mortem cytogenomic investigation

DNA copy number variations

\section{A B S T R A C T}

Congenital anomalies are the second highest cause of infant deaths, and, in most cases, diagnosis is a challenge. In this study, we characterize patterns of DNA copy number aberrations in different samples of post-mortem tissues from patients with congenital malformations. Twenty-eight patients undergoing autopsy were cytogenomically evaluated using several methods, specifically, Multiplex Ligation-dependent Probe Amplification (MLPA), microsatellite marker analysis with a MiniFiler kit, FISH, a cytogenomic array technique and bidirectional Sanger sequencing, which were performed on samples of different tissues (brain, heart, liver, skin and diaphragm) preserved in RNAlater, in formaldehyde or by paraffin-embedding. The results identified 13 patients with pathogenic copy number variations (CNVs). Of these, eight presented aneuploidies involving chromosomes $13,18,21$ $\mathrm{X}$ and $\mathrm{Y}$ (two presented inter- and intra-tissue mosaicism). In addition, other abnormalities were found, including duplication of the TYMS gene (18p11.32); deletion of the CHL1 gene (3p26.3); deletion of the HICI gene (17p13.3); and deletion of the TOM112 gene (17p11.2). One patient had a pathogenic missense mutation of g.8535C $>$ G $(c .746 C>G)$ in exon 7 of the FGFR3 gene consistent with Thanatophoric Dysplasia type 1 . Cytogenomic techniques were reliable for the analysis of autopsy material and allowed the identification of inter- and intra-tissue mosaicism and a better understanding of the pathogenesis of congenital malformations. 


\title{
Rare Genomic Rearrangement in a Boy with Williams-Beuren Syndrome Associated to XYY Syndrome and Intriguing Behavior
}

\author{
Roberta L. Dutra, ${ }^{1,2 *}$ Flavia B. Piazzon, ${ }^{2}$ Évelin A. Zanardo, ${ }^{2}$ Thais Virginia Moura Machado Costa, ${ }^{2}$ \\ Marília M. Montenegro, ${ }^{1,2}$ Gil M. Novo-Filho, ${ }^{1,2}$ Alexandre T. Dias, ${ }^{2}$ Amom M. Nascimento, ${ }^{1,2}$ \\ Chong Ae Kim, ${ }^{1}$ and Leslie D. Kulikowski ${ }^{2,3}$ \\ ${ }^{1}$ Genetics Unit, Instituto da Criança, Faculdade de Medicina da Universidade de Sào Paulo (USP), Sào Paulo, Brazil \\ ${ }^{2}$ Department of Pathology, Cytogenomics Lab - LIM03, Faculdade de Medicina da Universidade de Säo Paulo (USP), Säo Paulo, Brazil \\ ${ }^{3}$ Department of Collective Health - Human Reproduction and Genetics Center, , Faculdade de Medicina do ABC, Santo André, Sảo Paulo, \\ Brazil
}

Manuscript Received: 19 August 2014; Manuscript Accepted: 17 August 2015

Williams-Beuren syndrome (WBS) is caused by a hemizygous contiguous gene microdeletion of $1.55-1.84 \mathrm{Mb}$ at $7 q 11.23$ re gion. Approximately, 28 genes have been shown to contribute to classical phenotype of SWB with presence of dysmorphic facial features, supravalvular aortic stenosis (SVAS), intellectual dis. ability, and overfriendliness. With the use of Microarray-based comparative genomic hybridization and other molecular cytogenetic techniques, is possible define with more accuracy partial or atypical deletion and refine the genotype-phenotype correla tion. Here, we report on a rare genomic structural rearrangement in a boy with atypical deletion in $7 q 11.23$ and $\mathrm{XYY}$ syndrome with characteristic clinical signs, but not sufficient for the diagnosis of WBS. Cytogenetic analysis of G-banding showed a karyotype 47,XYY. Analysis of DNA with the technique of MLPA (Multiplex Ligation-dependent Probe Amplification) using kits a combination of kits (P064, P036, P070, and P029) identified an atypical deletion on 7q11.23. In addition, high resolution SNP Oligonucleotide Microarray Analysis (SNP-array) confirmed the alterations found by MLPA and revealed others pathogenic CNVs, in the chromosomes 7 and $\mathrm{X}$. The present report demonstrates an association not yet described in literature, between Williams-Beuren syndrome and $47, \mathrm{XYY}$. The identification of atypical deletion in 7 q11.23 concomitant to additional pathogenic CNVs in others genomic regions allows a better comprehension of dinical consequences of atypical genomic rearrangements. 02015 wiley Periodicals, tac.

Key words: atypical deletion; 7q11.23; Williams syndrome; 47, $\mathrm{XYY}$ syndrome; genomic rearrangement; behavioral phenotype

How to Cite this Article:

Dutra RL, Piazzon FB, Zanardo ÉA, Costa TVMM, Montenegro MM, Novo-Filho GM, Dias AT, Nascimento AM, Kim CA, Kulikowski I.D. 2015. Rare genomic rearrangement in a boy with WilliamsBeuren syndrome associated to XYY syndrome and intriguing behavior. Am J Med Genet Part A 167A:3197-3203. 